\title{
ANÁLISE DA MODULAÇÃO AUTONÔMICA DO CORAÇÃO EM REPOUSO E ATIVIDADE ELETROMIOGRÁFICA RELACIONADA À VARIABILIDADE DA FREQÜÊNCIA CARDÍACA DURANTE EXERCÍCIO DINÂMICO EM CICLOERGÔMETRO
}

\section{Cristiano Sales da Silva}

Dissertação apresentada ao Programa de PósGraduação Interunidades em Bioengenharia / Escola de Engenharia de São Carlos / Faculdade de Medicina de Ribeirão Preto / Instituto de Química de São Carlos, da Universidade de São Paulo para obtenção do título de Mestre em Bioengenharia.

ORIENTADORA: Prof. ${ }^{\text {a }}$ Dr. ${ }^{\text {a }}$ Ester da Silva 
Aos meus pais, Iraci e José

que sempre me deram força

e confiança para a

realização dos meus

sonhos.

À minha noiva Barbara, por

todo o apoio, paciência, carinho e tempo dispensado

no decorrer desta realização.

Aos meus irmãos Mari Célia, Márcia e Mário pelo apoio. Aos meus sobrinhos pela simples presença como fonte de inspiração 


\begin{abstract}
À Prof. ${ }^{a}$ Dr. ${ }^{\underline{a}}$ Ester da Silva minha orientadora e amiga pela dedicação, atenção e paciência dispensada para a concretização deste sonho.
\end{abstract}




\section{AGRADECIMENTOS ESPECIAIS}

Agradeço em especial aos meus amigos e companheiros de pesquisa Fernanda Regina de Moraes e Robison José Quitério pela inestimável colaboração e tempo dispensados para a conclusão deste estudo.

A Prof. ${ }^{a}$ Dr.. Aparecida M. Catai por toda a confiança, colaboração e ensinamentos nestes anos de convívio.

Ao Lucien de Oliveira pelas implementações computacionais sem as quais não seria possível o desenvolvimento deste trabalho e pela atenção, paciência e ensinamentos dispensados nos momentos que precisei.

Aos professores José Carlos Pereira e Luis Eduardo Barreto Martins pelas orientações e ensinamentos de grande valia para a conclusão deste trabalho.

Ao amigo Fábio Micolis pela ajuda na realização deste estudo.

Aos amigos de laboratório Ana Paula, Lílian, Fabrício, Albaiza, Daniel, Luciana, Pozzi, Lucas, Zé, Adriana, Fábio, Eduardo Gouvêa, Maria Antonia, Vera Marães, Tatiane Flores, Valéria, Luciana pela disposição e companherismo dispensado sempre que precisei.

Aos amigos Silvinho e Ricardo pelo apoio e ajuda inestimável de sempre.

A Cláudia, Marcos, Letícia, D. Lucia Rosa e o Sr. Romeu pelo apoio dispensado. 


\section{AGRADECIMENTOS}

Ao meu sempre professor Luis Carlos Marques Vanderlei por acreditar em mim e pela sabedoria e ensinamentos dispensados.

Aos amigos Ricardo Passos, Alessandra Tanuri, Fabiana América, Lais Coimbra, Patrícia Tavano pelo apoio de sempre.

Aos voluntários que participaram com dedicação e paciência deste estudo.

Agradeço ao meu mestre professor Júlio Hamada que me ajudou em momentos difíceis no caminho até aqui e sempre estendeu sua mão.

Aos colegas da Bioengenharia e do Lab-Ciber da USP Rodrigo, Fransérgio, Daniel, Otávio, Renato, Giovana, Patrícia, Marcos, Elaine, Irene, pelo apoio e convivência.

A secretária Janete da Bioengenharia pela ajuda e atenção.

Aos órgãos de fomentos CAPES, CNPq e FAPESP pelo suporte financeiro. 


\section{SUMÁRIO}

LISTA DE TABELAS

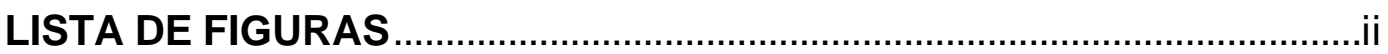

LISTA DE ABREVIATURAS E SIGLAS ....................................................iii

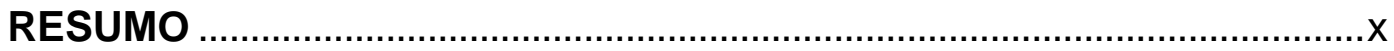

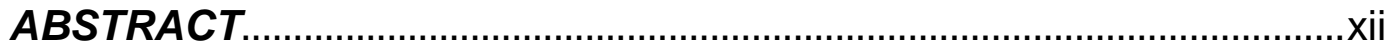

1 INTRODUÇÃO

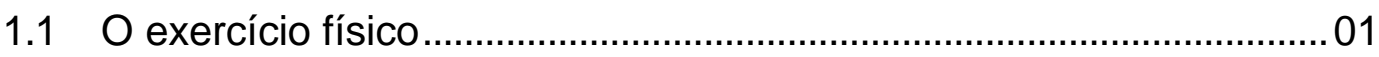

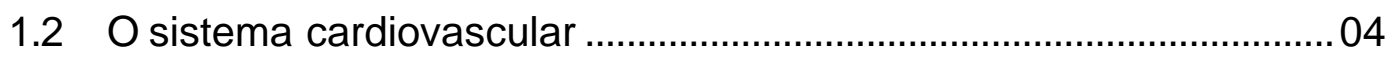

1.3 Eletromiografia de superfície .......................................................... 08

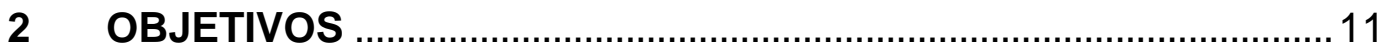

3 MATERIAIS E MÉTODOS …........................................................... 12

3.1 Voluntários estudados ......................................................................12

3.2 Local do estudo ………………………………............................. 12

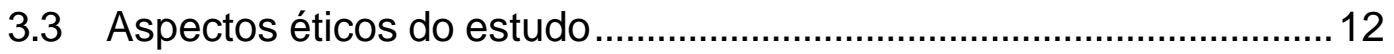

3.4 Critérios para inclusão dos voluntários no estudo ..............................13

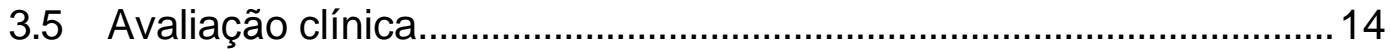

3.6 Avaliação da capacidade funcional e do sistema cardiovascular

3.7 Avaliação da modulação autonômica do coração, da variabilidade da freqüência cardíaca e da atividade eletromiográfica ...................................................................................... 17

3.7.1Protocolo II: teste de exercício físico dinâmico contínuo do tipo rampa (TEFDC-R) .................................................17

3.8 Procedimentos experimentais.........................................................18

3.8.1 Controle ambiental e preparação pré-teste ...........................................21

3.8.2 Procedimento para coleta dos dados de freqüência

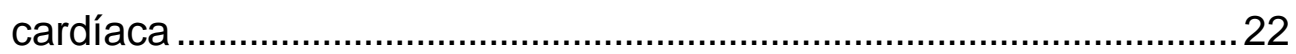

3.8.3 Eletromiografia de superfície (EMGs) …………….........................23 
3.8.3.1 Equipamento

3.8.3.2 Colocação dos eletrodos

3.8.3.3 Coleta dos sinais de eletromiografia de superfície

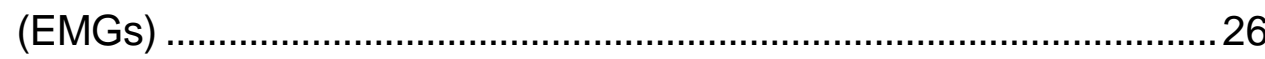

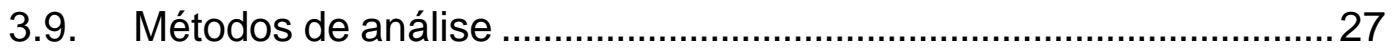

3.9.1 Análise descritiva dos dados dos voluntários ..................................27

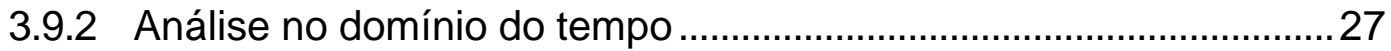

3.9.2.1 Análise dos dados da freqüência cardíaca obtidos durante a realização do TEFDC-D (protocolo I).

3.9.2.2 Análise dos dados de freqüência cardíaca obtidos durante a realização do TEFDC-R (protocolo II)

3.9.2.3 Análise da freqüência cardíaca $(\mathrm{bpm})$ e dos iR-R (ms) obtidos durante a realização do TEFDC-R (protocolo II) 28

3.9.2.4 Análise dos dados eletromiográficos de superfície obtidos durante a realização do TEFDC-R (protocolo II)

3.10 Normalização dos dados de RMSSD dos iR-R (ms) e de RMS da amplitude do sinal eletromiográfico a partir do valor mediano. 30

3.11 Metodologia estatística 31

4 RESULTADOS 33

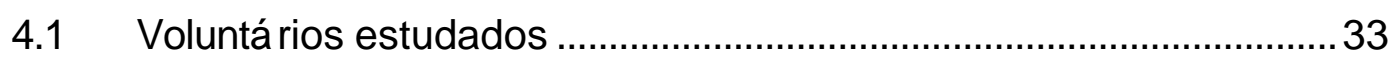

4.2 Respostas das variáveis cardiovasculares durante a realização do TEFDC-D (protocolo I) .

4.3 Análise da freqüência cardíaca e da variabilidade da freqüência cardíaca em repouso 36

4.3.1 Análise gráfica visual .......................................................................36

4.3.2 Análise no domínio do tempo …………………….............................

4.4 Análise visual gráfica da freqüência cardíaca e do sinal da EMGs durante o TEFDC-R (protocolo II). 40 
4.5 Análise da freqüência cardíaca, da variabilidade da freqüência cardíaca e do sinal de EMGs no domínio do tempo e correlações entre as variáveis estudadas e os intervalos de potências durante 0 TEFDC-R

4.6 Correlação entre freqüência cardíaca, variabilidade da freqüência cardíaca e a eletromiografia de superfície. 46

4.7 Análise dos dados de RMSSD e RMS normalizados 48

5 DISCUSSÃO 50

5.1 Comportamento da freqüência cardíaca e de sua variabilidade nas condições de repouso 51

5.2 Comportamento da freqüência cardíaca e de sua variabilidade e da atividade muscular na condição de exercício durante o TEFDC-R (protocolo II) 53

6 CONCLUSÕES 60

7 REFERÊNCIAS BIBLIOGRÁFICAS 62

8 APÊNDICES. 70 


\section{LISTA DE TABELAS}

TABELA 01 -Dados da umidade relativa do ar em porcentagem (\%) e temperatura em graus Celsius do laboratório durante a realização do protocolo II (TEFDC-R) dos voluntários estudados $(n=10)$. . .80

TABELA 02 - Idade em anos, características antropométricas (peso em quilogramas $(\mathrm{kg})$, altura em metros $(\mathrm{m})$ e índice de massa corpórea (IMC) em quilogramas por metro ao quadrado $\left.\left(\mathrm{kg} / \mathrm{m}^{2}\right)\right)$, tipo de atividade física (TAF) e horas semanais $(\mathrm{H} / \mathrm{S})$ dos voluntários estudados $(n=10)$

TABELA 03 -Dados referentes aos exames laboratoriais: colesterol total, HDL colesterol, LDL colesterol, VLDL colesterol, triglicérides, ácido úrico, creatinina, uréia e glicemia em jejum dos voluntários estudados $(n=10)$

TABELA 04 -Valores de freqüência cardíaca (FC), em batimentos por minuto (bpm), estimada para a idade, em repouso supino e a máxima (pico) atingida durante a realização do TEFDC-D. Pressão arterial sistólica (PAS) e diastólica (PAD), em milímetros de mercúrio $(\mathrm{mmHg})$, durante a condição de repouso supino e na potência pico, em Watts (W), do TEFDC-D. 


\section{LISTA DE FIGURAS}

FIGURA 01 - Representação esquemática do teste de exercício físico dinâmico contínuo em degraus com carga inicial de 4 Watts (W), durante $2 \mathrm{~min}$, e incrementos de $25 \mathrm{em} 25 \mathrm{~W}$ a cada $3 \mathrm{~min}$

FIGURA 02 - Representação esquemática do teste de exercício físico dinâmico contínuo em rampa (TEFDC-R) com carga inicial de 4 Watts (W), por 2 min, e incrementos de $20 \mathrm{~W}$ por min .18

FIGURA 03 - llustração da montagem experimental do teste de exercício físico dinâmico em degrau contínuo tipo rampa (TEFDC-R). A: bicicleta ergométrica de frenagem eletromagnética; $\mathrm{B}$ : condicionador de sinais da eletromiografia de superfície (EMGs); C: computador com o software de aquisição dos dados de EMGs; D: eletrocardiograma (ECG); E: computador com o softWare de aquisição dos dados de freqüência cardíaca; F: controlador de potências microprocessado; G: posicionamento dos eletrodos de ECG; $\mathrm{H}$ : posicionamento dos eletrodos de EMGs. 
FIGURA 04 - Ilustração da aquisição dos dados da freqüência cardíaca, batimento a batimento em tempo real, obtida a partir dos intervalos $\mathrm{R}-\mathrm{R}$ do registro de eletrocardiograma na condição de exercício

FIGURA 05 - llustração do posicionamento do eletrodo no ventre muscular do músculo vasto lateral, na distância média entre trocanter maior e côndilo lateral do fêmur, para registro do sinal eletromiográfico

FIGURA 06 - A: eletrodos de superfície de fibra de carbono, B: eletrodo bipolar diferencial ativo e C: terminais de acoplamento ao eletrodo de carbono

FIGURA 07 - Representação esquemática do janelamento de 6 em 6 segundos para a análise da VFC pelo índice RMSSD

FIGURA 08 - llustração de uma das telas do software AQDados 5 de captação dos sinais de eletromiografia de superfície (EMGs), em tempo real: em A está representado o intervalo do sinal de uma contração muscular do músculo vasto lateral do voluntário LBC na potência de 140 Watts, e em B dados do intervalo do sinal de EMGs a ser analisado no intervalo de tempo de $400 \mathrm{~ms}$ 
FIGURA 09 - Análise dos valores absolutos do índice de RMS da amplitude dos sinais eletromiográficos $\mu \mathrm{V}$ ) dos voluntários estudados $(n=10)$ quanto à distribuição dos dados. Em A estão representado os valores observados em relação aos esperados. Em B curva de Gauss e histograma do número de observações.

FIGURA 10 - Freqüência cardíaca, em batimentos por minuto (bpm), registrada em tempo real, durante os 900 $s$ nas condições de repouso supino e sentado antes da realização do TEFDC-R de um dos voluntários estudados (CJR)

FIGURA 11 - Freqüência cardíaca média, em batimentos por minuto (bpm), observada nas condições de repouso durante 15 min nas posições supina e sentada dos voluntários estudados $(n=10)$. Nível de significância $\alpha=0,05$.

FIGURA 12 - Intervalos R-R (ms) calculados em média dos 15 minutos em repouso, nas posições supina $e$ sentada, dos voluntários estudados $(n=10)$. Nível de significância $\alpha=0,05$. 
FIGURA 13 - Índice RMSSD dos iR-R (ms) obtidos das condições de repouso durante 15 minutos na posição supina e sentada dos voluntários estudados ( $n=10)$. Nível de significância $\alpha=0,05$

FIGURA 14 - Índices RMSSD da freqüência cardíaca (bpm) obtidos nas condições de repouso durante 15 minutos na posição supina e sentada dos voluntários estudados $(n=10)$. Nível de significância $\alpha=0,05$.

FIGURA 15 - A: Sinal eletromiográfico (amplitude normalizada) do voluntário FP durante o repouso inicial (1) e na condição de exercício (2). B: Freqüência cardíaca (bpm) registrada batimento a batimento, em tempo real, dos voluntários estudados $(n=10)$, obtidas durante os 60 s de repouso (1) pré-exercício. De 2 a 7 representa as fases do comportamento da freqüência cardíaca no período de exercício do TEFDC-R. Em destaque a representação da freqüência cardíaca média entre o repouso e a potência de 140 Watts (W) 
FIGURA 16 - Freqüências cardíacas (bpm) obtidas durante a realização do TEFDC-R na potência de $4 \mathrm{~W}$ e nos intervalos de potências entre 15 e $20 \mathrm{~W}, 35$ e $40 \mathrm{~W}, 55$ e $60 \mathrm{~W}, 75$ e $80 \mathrm{~W}, 95$ e $100 \mathrm{~W}, 115$ e $120 \mathrm{~W}, 135$ e $140 \mathrm{~W}$ dos voluntários estudados $(n=10)$. Nível de significância $\alpha=0,05$ 43

FIGURA 17 - Índices do RMSSD obtidos dos iR-R (ms) durante a realização do TEFDC-R na potência de $4 \mathrm{~W}$ e nos intervalos de potências entre $15 \mathrm{e}$ $20 \mathrm{~W}, 35$ e $40 \mathrm{~W}, 55$ e $60 \mathrm{~W}, 75$ e $80 \mathrm{~W}, 95$ e $100 \mathrm{~W}, 115$ e $120 \mathrm{~W}, 135$ e $140 \mathrm{~W}$ dos voluntários estudados $(n=10)$. Nível de significância $\alpha=0,05$ 44

FIGURA 18 - Índices de RMS da amplitude da EMGs, em $\mu \mathrm{V}$, durante a realização do TEFDC-R na potência de $4 \mathrm{~W}$ e nos intervalos de potências entre $17 \mathrm{e}$ $20 \mathrm{~W}, 37$ e $40 \mathrm{~W}, 57$ e $60 \mathrm{~W}, 77$ e $80 \mathrm{~W}, 97$ e $100 \mathrm{~W}, 117$ e $120 \mathrm{~W}, 137$ e $140 \mathrm{~W}$ dos voluntários estudados $(n=10)$. Nível de significância $\alpha=0,05$ .45

FIGURA 19 - Correlação entre os índices de RMSSD dos iR$\mathrm{R}$ (ms) e do RMS dos sinais eletromiográficos, em $\mu \mathrm{V}$, do músculo vasto lateral, durante 0 protocolo II dos voluntários estudados $(n=10)$. Nível de significância $\alpha=0,05$ 
FIGURA 20 - Correlação entre a freqüência cardíaca (bpm) e o índice de RMS dos sinais eletromiográficos, em $\mu \mathrm{V}$, do músculo vasto lateral, durante o protocolo II dos voluntários estudados $(n=10)$. Nível de significância $\alpha=0,05$

FIGURA 21 - Correlação entre a freqüência cardíaca (bpm) e o índice RMSSD dos iR-R (ms) durante o protocolo II dos voluntários estudados $(n=10)$. Nível de significância $\alpha=0,05$. .48

FIGURA 22 - Ajuste do conjunto de dados proporcionalizados em relação aos valores máximos medianos da série de RMSSD dos iR-R (ms) e dos RMS dos sinais de EMGs $(\mu \mathrm{V})$ obtidos nos intervalos de potências de $4 \mathrm{~W}, 15$ a $20 \mathrm{~W}, 35$ a $40 \mathrm{~W}, 55$ a $60 \mathrm{~W}, 75$ a $80 \mathrm{~W}, 95$ a $100 \mathrm{~W}, 115$ a $120 \mathrm{~W}$ e de 135 a $140 \mathrm{~W}$ do TEFDC-R, dos voluntários estudados $(n=10)$. 


\section{LISTA DE ABREVIATURAS E SIGLAS}

\begin{tabular}{|c|c|}
\hline ATP & - Adenosina de trifosfato \\
\hline bpm & - Batimentos por minuto \\
\hline $\mathrm{CO}_{2}$ & - Gás carbônico \\
\hline ECG & - Eletrocardiograma \\
\hline EMGs & - Eletromiografia de superfície \\
\hline EMGs & - Eletromiografia de superfície \\
\hline HDL & - High Density Lipoprotein \\
\hline $\mathrm{Hz}$ & - Hertz \\
\hline IMC & - Índice de Massa Corpórea \\
\hline $\mathbb{R}-\mathrm{R}(\mathrm{ms})$ & - Intervalos R-R em milisegundos \\
\hline $\mathrm{Kg}$ & - quilogramas \\
\hline LDL & - Low Density Lipoprotein \\
\hline $\mathrm{m}$ & - metro \\
\hline$m^{2}$ & - metros ao quadrado \\
\hline $\min$ & - minuto $(s)$ \\
\hline $\mathrm{mV}$ & - milivolts \\
\hline $\mathrm{n}$ & - número de voluntários \\
\hline $\mathrm{O}_{2}$ & - Oxigênio \\
\hline PAD & - Pressão arterial diastólica \\
\hline PAS & - Pressão arterial sistólica \\
\hline RMS & - Root Mean Square \\
\hline RMSSD & - Root Mean Square Successive Difer \\
\hline
\end{tabular}




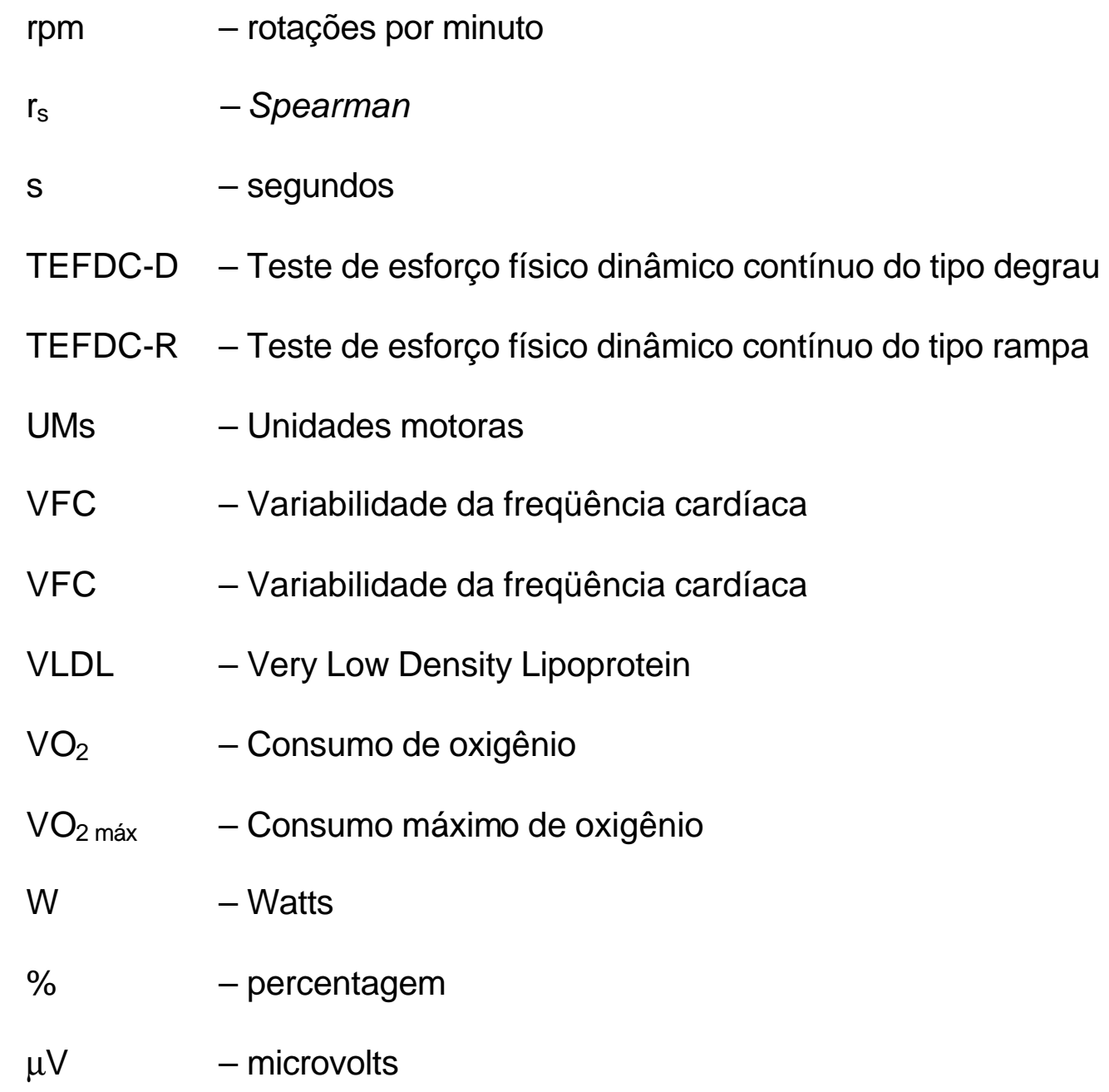




\section{RESUMO}

SILVA, C. S. Análise da modulação autonômica do coração em repouso e atividade eletromiográfica relacionada à variabilidade da freqüência cardíaca durante exercício dinâmico em cicloergômetro. São Carlos, 2002, 81p. Dissertação (Mestrado) - Escola de Engenharia de São Carlos / Faculdade de Medicina de Ribeirão Preto / Instituto de Química de São Carlos, Universidade de São Paulo.

A variabilidade da freqüência cardíaca (VFC) tem sido utilizada como um marcador fisiológico do controle autonômico do coração, enquanto a eletromiografia de superfície (EMGs) tem mostrado ser uma ferramenta útil de análise para avaliar a resposta muscular frente ao exercício físico. Assim os objetivos do presente estudo foram: avaliar o controle autonômico do coração a partir das respostas da freqüência cardíaca e de sua variabilidade nas condições de repouso, nas posições supina e sentada, e durante teste de esforço físico dinâmico contínuo do tipo rampa (TEFDC-R). Avaliar a atividade eletromiográfica durante $\circ$ TEFDC-R e ainda verificar a correlação entre a atividade eletromiográfica e a variabilidade da freqüência cardíaca durante o TEFDC-R. Metodologia: estudou-se 10 homens, ativos, saudáveis, jovens (23,7 $\pm 3,02$ anos) em repouso, nas posições supina e sentada, e durante TEFDC-R, com incrementos de 20 Watts (W) por minuto. Os dados de freqüência cardíaca e dos intervalos $R-R(\mathrm{~ms})$ foram coletados em tempo real, batimento a batimento, durante o repouso e o exercício. A EMGs integrada foi coletada do músculo vasto lateral (VL) nos 20 segundos finais de cada minuto durante o TEFDC-R. Análise dos dados: foram calculados os valores médios da freqüência cardíaca (FC) em bpm e dos intervalos RR (iR-R) em ms em repouso durante os 15 minutos e o índice temporal RMSSD dos iR-R (ms) e da FC (bpm) nessas condições. Durante o TEFDC-R, foi obtida a média da FC (bpm) e o RMSSD dos iR-R (ms) nos $20 \mathrm{~s}$ finais de cada minuto de exercício paralelamente a análise da EMGs pelo índice RMS da amplitude do sinal em microvolts. Metodologia estatística: Para a análise estatística utilizou-se os testes não paramétricos de Wilcoxon para amostras pareadas, de Friedman para medidas repetidas seguido de técnicas de 
comparações múltiplas com o teste de Dunn e análise de correlação de Spearman. Foram considerados níveis de significância de á $=0,05$. Resultados: os dados apresentam significância estatística $(p<0,05)$ nas seguintes análises: 1$)$ menor FC (bpm) e maior iR-R (ms) médios em supino em relação a sentado; 2) maior VFC em supino quando comparado a sentado; 3) FC (bpm) média e RMSSD dos iR-R (ms), durante o TEFDC-R, entre a potência de $4 \mathrm{~W}$ e os intervalos a partir de 55 e $60 \mathrm{~W}$; 4) aumento do índice RMS da EMGs entre $4 \mathrm{~W}$ e a partir do intervalo de 57 e $60 \mathrm{~W}$; 5) correlação entre RMS e RMSSD ( $r S=-0,64)$, entre FC e RMS ( $r s=0,61)$ e entre FC (bpm) e RMSSD ( $r s=-0,76)$. Conclusões: nossos dados sugerem que houve uma alteração no balanço vago-simpático com predominância vagal na posição supina quando comparada com a sentada. Mostram ainda, uma associação entre 0 incremento de potências durante 0 exercício físico com o aumento do recrutamento de fibras musculares com concomitante aumento da freqüência cardíaca e diminuição da VFC. Essa associação é atribuída tanto ao comando de controle central como dos mecanismos reflexos periféricos, ativados a partir das aferências das fibras musculares do grupo III (ergoceptores) e do grupo IV (metaboloreceptores). Sugerindo o trânsito de informações advindos do córtex motor ativando as fibras musculares e paralelamente à área cardiovascular, modulando o sistema nervoso autonômico do coração.

Palavras-chave: variabilidade da freqüência cardíaca; modulação autonômica; eletromiografia de superfície; exercício físico dinâmico. 


\section{ABSTRACT}

SILVA, C. S. Analysis of the autonomic modulation of the heart in rest and activity electromyographic related the heart rate variability during dynamic exercise in cicle ergometer. São Carlos, 2002, 81p. Dissertação (Mestrado) - Escola de Engenharia de São Carlos / Faculdade de Medicna de Ribeirão Preto / Instituto de Química de São Carlos, Universidade de São Paulo.

Heart rate variability (HRV) has been used as a physiological marker of heart autonomic control, while surface electromyography (SEMG) has shown to be a useful analysis tool for evaluating muscular response to physical exercise. Therefore, the purpose of the present research was to evaluate heart autonomic control beginning from heart rate (HR) answers and its variability (HRV) in rest conditions, in supine and seating positions, and during test of dynamic physical exercise continuous of ramp type (TDPEC-R). We also intended to evaluate electromyographic activity during TDPEC-R and analyze correlation between HRV and SEMG during test of dynamic physical exercise continuous of ramp type (TDPEC-R). Methodology: Ten men; young (23,7 $\pm 3,02$ years), healthy and with an active life style; were followed up during TDPEC-R in rest, supine and seating positions, with $20 \mathrm{~W}$ increments per minute. The HR and RR intervals (R-RI) data were recorded on a beat-to-beat basis in real time during rest and exercise. Integrated SEMG was collected from vastus lateralis muscle captured during the last 20 seconds of each minute during TDPEC-R. Analysis of the data:HR average values were calculated [in beats per minute (bpm)] and RRI, in rest condition for 15 minutes. RMSSD temporal index of R-RI and HR were calculated in both conditions. During TDPEC-R, the average HR and RMSSD of RRI was achieved in the last $20 \mathrm{~s}$ of each minute of exercise in parallel with SEMG analysis by RMS index of signal width in microvolts. Statistics Methodology: Wilcoxon nonparametric tests were used for paired samples, Friedman's for repeated measures followed by multiple comparisons techniques with Dunn test and correlation analysis of Spearman. $\alpha=0.05$ was the considered level of significance. Results: the data presented statistic significance $(p<0,05)$ in the following analyses: 1) lower $H R$ (bpm) and RRI (ms) average values in supine than in seating position; 2) higher $\mathrm{HRV}$ values in supine in comparison to seating position; 3) average HR (bpm) and 
RMSSD of R-RI (ms) values, during TDPEC-R, between potency of $4 \mathrm{~W}$ and intervals starting from 55 and $60 \mathrm{~W}$; 4) increase of RMS index of SEMG between 4 $\mathrm{W}$ and starting from interval of 57 and $60 \mathrm{~W} ; 5$ ) correlation between RMS and RMSSD ( $\mathrm{rs}=-0.64$ ), between HR and RMS ( $\mathrm{rs}=0.61)$ and between HR (bpm) and RMSSD ( $\mathrm{r}=-0.76$ ). Conclusions: our data suggest that there was an alteration in vagal- sympathetic balance with vagal predominance in supine position in comparison to seating position. The data also demonstrate association between power increment during physical exercise with increase of muscular fibers recruitment with simultaneous HR increase and HRV decrease. This association is attributed to central control command as well as to outlying reflexes mechanisms, activated from afferent muscular fibers of groups III (ergoreceptors) and IV (metaboreceptors). Which suggests information traffic from the motor cortex, activating muscular fibers, and parallel to cardiovascular area, modulating the autonomous nervous system of the heart.

Keywords: heart rate variability; autonomic modulation; surface electromyography; dynamic physical exercise. 


\section{INTRODUÇÃO}

\section{$1.1 \quad$ O exercício físico}

Durante o exercício físico ocorre uma série de ajustes hemodinâmicos e metabólicos envolvendo a participação de vários sistemas orgânicos e, dentre eles, o muscular. A atividade muscular é realizada graças a produção de energia propiciada pela quebra de adenosina trifosfato (ATP), um composto que armazena e libera energia para todos os processos celulares. A alta energia livre da hidrólise da ligação terminal do ATP é utilizada para mudanças nas conformações das moléculas de actina e miosina muscular transformando energia química em mecânica. $O$ processo aeróbio de formação do ATP é capaz de garantir um aumento progressivo deste substrato à medida que o exercício aumenta sustentando a atividade muscular necessária (WASSERMAN et al., 1999).

Para que a produção aeróbia de ATP a nível muscular ocorra é necessário à ativação de processos de transporte de oxigênio $\left(\mathrm{O}_{2}\right)$ desde as vias aéreas superiores até as mitocôndrias onde o gás carbônico $\left(\mathrm{CO}_{2}\right)$ produzido, produto final do metabolismo, é transportado e removido. Para isso é necessária uma participação efetiva de vários sistemas, dentre eles o respiratório, cardiovascular e muscular, todos sobre o controle do sistema nervoso central (ROWELL, 1986). 
Três mecanismos de controle diferentes se completam em função das necessidades metabólicas e em respostas a estímulos eferentes, sendo eles: 1) o mecanismo nervoso de comando central que tem origem no córtex motor e transmite impulsos aferentes aos neurônios localizados no bulbo (FOSS et al., 2000); 2) o mecanismo neural reflexo periférico, que se relaciona com as descargas aferentes, originários nas terminações nervosas musculares das fibras dos grupos III e IV, que possuem sensibilidade a estímulos mecânicos (ergoreceptores ou mecanorreceptores) e metabólicos (metaboloreceptores ou quimiorreceptores) locais, respectivamente (MITCHELL et al., 1983; FOSS et al., 2000); 3) o comando cardiodinâmico: responsável pela integração dos ajustes cardiovasculares e pulmonares cuja função é o suprimento adequado de sangue arterial aos músculos ativos para que se processe um adequado metabolismo local McARDLE et al., 1998).

Esses mecanismos interagem com o centro cardiovascular, localizado na formação retículo bulbar, e a transmissão dos impulsos eferentes ao coração é processada através dos componentes simpático e parassimpático do sistema nervoso autônomo (KALIA et al., 1981; McARDLE et al., 1998; FOSS et al., 2000).

Nota-se assim, que existe uma relação importante entre o mecanismo de controle cardiovascular e a atividade muscular durante a realização de um exercício físico.

Com o decorrer do exercício progressivo, o sistema oxidativo necessita da participação de um sistema alternativo de formação de ATP 
para que o esforço seja mantido, desta forma entra em ação o sistema anaeróbio para produção de energia. Tal sistema, apesar de menos eficiente, garante a continuidade do esforço até potências iguais ou superiores ao ponto de saturação do sistema de transporte de $\mathrm{O}_{2}$ denominado de consumo máximo de $\mathrm{O}_{2}\left(\mathrm{VO}_{2}\right.$ máx.) (McARDLE et al., 1998).

A partir dessas informações podemos inferir que ocorrem mudanças no metabolismo muscular com o decorrer do exercício físico progressivo as quais estão diretamente relacionadas aos níveis de potências executados.

NAGATA et al. (1981), relatam que o aumento progressivo na freqüência de descarga das unidades motoras (UMs), dos músculos em atividade, já ativadas e/ou de algumas recém recrutadas poderia ser para compensar o déficit na força desenvolvida, em conseqüência de que o suprimento de ATP para as fibras musculares oxidativas de contração lenta, pela fosforilação oxidativa, torna-se inadequado e deve ser suplementado pela reserva de energia disponível através da glicólise anaeróbia, levando a uma acidose metabólica.

\subsection{O sistema cardiovascular}

O sistema nervoso autônomo, através dos seus componentes simpático e parassimpático, desempenha um importante papel nos ajustes do sistema cardiovascular (MACIEL et al., 1986; SMITH et al., 1990; GALLO JR. et al., 1995; FREITAS, 2000; CATAI et al., 2002).

O sistema nervoso parassimpático inerva o miocárdio através dos nervos parassimpáticos ou vagos, que se distribuem principalmente para os 
nodos sinusal e átrio ventricular e, em menor escala, para os músculos atriais e ventriculares. A estimulação parassimpática faz com que o hormônio acetilcolina seja liberado nas terminações vagais, diminuindo a freqüência do ritmo do nodo sinusal e a excitabilidade das fibras juncionais atrioventriculares, tornando mais lenta a transmissão do impulso cardíaco para os ventrículos (LONGO et al., 1995; POWERS et al., 1997; MARÃES, 1999; FOSS et al., 2000).

Os nervos simpáticos, por outro lado, distribuem-se a todas as partes do coração, com predominância para o músculo ventricular. A estimulação simpática produz respostas basicamente opostas à do parassimpático: libera noradrenalina que aumenta a freqüência de descarga do nodo sinusal, aumenta a velocidade de condução e a excitabilidade em todas as partes do coração e ainda, aumenta a força de contração do músculo cardíaco (LONGO et al., 1995; MARÃES, 1999; FOSS et al., 2000).

Uma das principais características dos sistemas simpático e parassimpático é a de aumentar ou diminuir, de acordo com as necessidades orgânicas, a freqüência dos batimentos cardíacos, como resultado da estimulação ou inibição desses dois efetores regulando, assim, a modulação da freqüência cardíaca e adaptando-a a diferentes estímulos, como o exercício físico, o estresse, a respiração, as alterações metabólicas, entre outros (LONGO et al., 1995).

A variabilidade da freqüência cardíaca (VFC) pode ser caracterizada pelas variações da duração dos intervalos entre duas ondas $R$ (iR-R) do eletrocardiograma (ECG), onde a estimulação ou inibição do simpático e do 
parassimpático no coração modulam a resposta da freqüência cardíaca adaptando-a as necessidades de cada momento (MALLIANI et al., 1991).

Uma das condições onde a VFC pode ser utilizada para verificar o controle autonômico sobre o coração é a mudança postural. Quando um indivíduo muda de postura, o sistema nervoso autônomo atua sobre o coração para conduzir o mesmo aos ajustes necessários para suprir as demandas metabólicas do organismo (MARTINELLI, 1996). LINDQVIST et al. (1990), observaram que a VFC apresentou-se maior na posição supina, e que a simples transferência para a postura em pé, produzia uma diminuição da mesma.

Alguns estudos (MARÃES, 1999; RIBEIRO, 2001; SILVA et al., 2001) investigaram o comportamento da VFC durante o repouso na posição supina e sentada e encontraram uma maior VFC em supino quando comparado com a posição sentada.

Com relação ao exercício físico dinâmico, este promove mudanças na VFC. Investigações (MARÃES, 1999; RIBEIRO, 2001; SILVA et al., 2001) observaram que a VFC, analisada a partir do índice RMSSD dos iR-R em milisegundos (ms) no domínio do tempo, era maior quando os voluntários realizaram baixos níveis de esforço e que, com o incremento de potências, ocorria uma diminuição da mesma.

Sob o argumento de que são escassos os estudos que relacionam o comportamento da freqüência cardíaca e da VFC com diferentes intensidades e fases metabólicas do exercício físico dinâmico progressivo, como a intensificação do metabolismo anaeróbio e o surgimento da acidose 
metabólica, ALONSO et al. (1998) realizaram um estudo utilizando protocolo incremental em cicloergômetro, em forma de degrau, e relataram que houve uma relação linear entre a freqüência cardíaca e consumo de oxigênio $\left(\mathrm{VO}_{2}\right)$ e uma diminuição da VFC a partir dos primeiros instantes de exercício até alcançar níveis expressivos de diminuição a partir do limiar de anaerobiose tendendo a uma estabilidade após este momento.

É sabido que a freqüência cardíaca apresenta aumento linear quando um indivíduo é submetido a uma atividade física crescente, por exemplo, a um protocolo com incremento de potências em forma de rampa (MARÃES, 1999). Em potências mais elevadas, utilizando protocolo descontínuo, CATAI (1999) relata que tal incremento é atribuído à predominância da estimulação do simpático sobre o coração, que é denominado de componente lento de elevação da freqüência cardíaca (GALLO JR. et al., 1987).

A partir da análise da VFC pode-se obter informações de forma não invasiva sobre a integridade neurocardíaca e a regulação autonômica sobre o coração, permitindo assim, o reconhecimento e a caracterização de situações nas quais doenças possam afetar tal controle e, com isso auxiliar no diagnóstico e prognóstico de tais situações clínicas (AKSELROD et al., 1981; LONGO et al., 1995; STEIN et al., 1999; RIBEIRO et al., 2000).

A VFC pode ser avaliada por vários métodos divididos em análise no domínio do tempo e análise no domínio da freqüência (MALLIANI et al., 1991; STEIN et al., 1999). O mais simples é a análise no domínio do tempo a partir da medida dos $\mathrm{iR}-\mathrm{R}(\mathrm{ms})$ do eletrocardiograma. Nesse método, a freqüência cardíaca instantânea ou o intervalo entre os iR-R são analisados 
por meio de cálculos estatísticos simples. Medidas baseadas nas diferenças entre iR-R (ms) adjacentes podem ser avaliadas, por exemplo, pela raiz quadrada da média das diferenças sucessivas entre os iR-R (ms) (ANTILA, 1979; TASK FORCE, 1996; STEIN et al., 1999).

\subsection{Eletromiografia de superfície}

A contração muscular pode ser estudada com a utilização de um método não invasivo e de fácil aplicação que é a denominada eletromiografia de superfície (EMGs).

A EMGs consiste na captação de potenciais elétricos gerados pela despolarização do músculo em atividade durante a contração muscular. Tais potenciais são denominados de potenciais de ação das unidades motoras (UMs) e estão diretamente relacionados com o tipo de exercício (isométrico ou isotônico) e com o nível de atividade realizada durante esses exercícios. Os registros gráficos dos potenciais de ação das UMs são denominados de eletromiograma (BASMAJIAN et al., 1985; O'SULLIVAN et al., 1993).

A EMGs tem sido utilizada para avaliar a capacidade de resistência do músculo, a biomecânica muscular, o aprendizado motor, a capacidade de relaxamento neuromuscular, as lesões musculares, as desordens neuromusculares, a fadiga muscular, bem como avaliar o limiar de anaerobiose (NAGATA et al., 1981; MORITANI et al., 1998).

Alguns autores (BROOKS, 1991; WASSERMAN et al., 1999) relatam que o limiar de anaerobiose é correspondente ao nível de potência e de $\mathrm{VO}_{2}$ submáximos em que a falta relativa de $\mathrm{O}_{2}$, em nível mitocondrial, atingiria 
magnitude suficiente para que a produção de ácido lático excedesse sua metabolização. Além do acúmulo do ácido lático, em um determinado estágio do exercício físico dinâmico progressivo, a fisiologia intramuscular sofre mudanças tempo dependentes onde ocorre acúmulo de metabólitos, íons hidrogênio e trocas nas concentrações de íons potássio por sódio, o que também caracteriza a passagem do metabolismo aeróbio para o anaeróbio NAGATA et al., 1981; JAMMES et al., 1998). Essas mudanças podem afetar o mecanismo excitação contração, incluindo as propriedades da membrana muscular e propagação dos potenciais de ação no músculo conduzindo as manifestações eletromiográficas do que alguns autores denominam de fadiga muscular (MORITANI et al., 1998).

Estudos na literatura (NAGATA et al., 1981; MATSUMOTO et al., 1991; JAMMES et al., 1998) referem que a EMGs é um método eficiente na estimativa não invasiva do limiar de anaerobiose. Esses autores relatam que, através da análise dos sinais mioelétricos que refletem o recrutamento das UMs e a freqüência de disparo das mesmas, é evidenciável um determinado momento onde ocorre um incremento mais acentuado e não linear do recrutamento muscular, representado pela análise da amplitude do sinal, e tal fato ocorre para que haja o suprimento adequado da demanda exigida nos músculos em atividade. Este ponto de mudança no padrão de recrutamento das UMs teria uma relação com o limiar de anaerobiose.

Outros autores (SKINNER et al., 1980) relacionam a atividade das UMs com seus respectivos tipos de fibras musculares, lentas (oxidativas) ou rápidas (glicolíticas), e o limiar de anaerobiose. Os referidos autores relatam 
que ocorre um recrutamento inicial intenso das UMs oxidativas durante 0 exercício físico dinâmico progressivo e quando o nível do limiar de anaerobiose é ultrapassado, ocorre uma contribuição no aumento de disparos de UMs glicolíticas se a potência de exercício continuar aumentando.

Outros autores (MILNER-BROWN et al., 1973; TANJl et al., 1973; DE LUCA et al., 1982; DE LUCA et al., 1994) trazem que as maiores contribuições do recrutamento das UMs podem ocorrer em níveis de força muscular relativamente baixos, enquanto a contribuição no aumento da freqüência de disparos das UMs torna-se mais importante em níveis de forças maiores

Ainda, estudos mostraram que existe uma relação proporcional entre a EMGs e o incremento de potências de trabalho com uma maior ativação das fibras musculares, dos músculos em atividade, durante o exercício físico dinâmico em cicloergômetro progressivo. (MIYASHITA et al., 1981; MATEIKA et al., 1994).

Para se avaliar a resposta do sinal obtido a partir da EMGs existem diferentes métodos de análises dos sinais eletromiográficos no domínio do tempo ou da freqüência. No domínio do tempo, o índice denominado Root Mean Square (RMS), raiz quadrada da média do sinal coletado, é o mais utilizado na verificação do comportamento do sinal eletromiográfico quanto a sua amplitude e que está diretamente relacionada ao recrutamento de UMs e, conseqüentemente, ao maior ou menor grau de atividade muscular frente ao exercício físico (MATEIKA et al., 1994; ARNAUD et al., 1997). JAMMES 
et al. (1997) estudando homens jovens saudáveis, treinados e não treinados, captando e analisando as variáveis ventilatórias (VO2 e VCO2), o pH arterial, o lactato plasmático e a EMGs do músculo vasto lateral, relatam que o aumento do recrutamento das UMs está relacionado com incremento nos valores do índice RMS da EMGs.

Diante do exposto verifica-se que há poucos estudos relacionando a atividade muscular, através da EMGs, com o exercício físico dinâmico quando comparado as investigações envolvendo exercício isométrico. Já, trabalhos envolvendo as respostas cardiovasculares possuem um número considerável. 


\section{OBJETIVOS}

Avaliar o controle autonômico do coração a partir das respostas da freqüência cardíaca e de sua variabilidade nas condições de repouso, nas posições supina e sentada, e durante o exercício físico dinâmico do tipo rampa.

Avaliar a atividade eletromiográfica durante o exercício físico dinâmico do tipo rampa.

Verificar a correlação entre a freqüência cardíaca e sua variabilidade com a atividade eletromiográfica durante a realização de exercício físico dinâmico do tipo rampa. 


\section{MATERIAIS E MÉTODOS}

\subsection{Voluntários estudados}

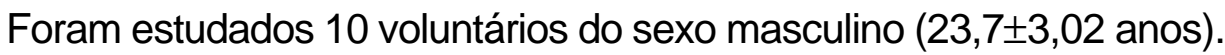

\subsection{Local do estudo}

O presente estudo foi realizado no Núcleo de Pesquisa em Exercício Físico, Laboratório de Fisioterapia Cardiovascular do Departamento de Fisioterapia da Universidade Federal de São Carlos - UFSCar.

\subsection{Aspectos éticos do estudo}

O projeto de pesquisa foi aprovado pelo Comitê de Ética e Pesquisa com Seres Humanos da Universidade Federal de São Carlos - UFSCar, parecer número 086/2000 (apêndice 1).

Todos os voluntários foram previamente esclarecidos e orientados sobre os procedimentos experimentais a que seriam submetidos no presente estudo. No caso de aceitação plena assinavam um termo de consentimento formal (apêndice 2), conforme determina a resolução 196/96 do Conselho Nacional de Saúde (CNS). 


\subsection{Critérios para inclusão dos voluntários no estudo:}

a Idade entre 19 e 29 anos;

\ Não fumantes;

- Padrão de vida ativo (atividade física aeróbia regular pelo menos 3 horas semanais);

a ECG normal em todas as derivações, em repouso e durante o teste de exercício físico máximo;

- Exames laboratoriais (urina tipo I, creatinina, uréia, hemograma completo, HDL colesterol, VLDL colesterol, LDL colesterol, colesterol total, triglicérides, ácido úrico e o de glicemia em jejum) dentro dos níveis de normalidade;

- Ausência de quaisquer problemas do sistema cardiovascular, muscular, osteoarticular, bem como de qualquer outro sistema;

- Não estivessem em uso de medicação na época dos testes experimentais.

Para tanto os voluntários foram submetidos a exames de avaliação clínica geral complementada por teste ergométrico, raio $\mathrm{X}$ e exames laboratoriais para detectar possíveis alterações (isquemia do miocárdio e/ou arritmias desenvolvidas durante o exercício) ou qualquer doença que contraindicasse a participação dos mesmos no estudo. 


\subsection{Avaliação clínica}

a) Anamnese constando de todos dados pessoais, hábitos de vida, antecedentes familiares, história pregressa e atual de possíveis doenças, entre outros (ficha de avaliação no apêndice 3).

b) Exame físico de inspeção geral e aferição da freqüência cardíaca, pressão arterial sistólica e diastólica em repouso (duas medidas), peso, altura, avaliação postural e muscular geral, ausculta cardíaca e pulmonar (ficha de avaliação no apêndice 3).

c) Exames laboratoriais complementares: de urina tipo I, creatinina, uréia, hemograma completo, HDL colesterol, VLDL colesterol, LDL colesterol, colesterol total, triglicérides, ácido úrico e o de glicemia em jejum.

d) ECG convencional de 12 derivações realizado em repouso na posição supina, e nas posições supina, sentada e em hiperventilação nas derivações $M_{5}, D_{\|}$e $V_{2}$ modificadas com os eletrodos dispostos da seguinte maneira:

- $\mathrm{MC}_{5}$ : o eletrodo negativo posicionado no ápice do manúbrio, o positivo no quinto espaço intercostal em direção à linha axilar anterior esquerda referente a V5 e o eletrodo neutro no quinto espaço intercostal direito; 
- DII: o eletrodo negativo posicionado no ápice do manúbrio esternal e o positivo no sexto espaço intercostal esquerdo na linha axilar anterior.

- $V_{2}$ : eletrodo positivo no quarto espaço intercostal a esquerda do esterno.

\subsection{Avaliação da capacidade funcional e do sistema cardiovascular}

Essa avaliação tinha por finalidade diagnosticar possíveis alterações como hipertensão arterial reativa, isquemia do miocárdio e arritmias importantes desenvolvidas durante o exercício físico.

Protocolo I (TEFDC-D): representado na figura 1, foi realizado em cicloergômetro de frenagem eletromagnética (Quinton-Corival-400) na posição sentada com flexão do joelho entre 5 e 10 graus. A potência inicial foi de 4 Watts (W) por um período de $2 \mathrm{~min}$, com o intuito de aquecimento, e posteriormente foram introduzidos incrementos de $25 \mathrm{~W}$ a cada 3 min até a exaustão física e/ou o surgimento de sinais e sintomas limitantes.

Antes e após a realização do protocolo I (TEFDC-D), foi realizado um ECG convencional de 12 derivações em repouso na posição supina. E nas derivações MC5, DII e $V_{2}$ modificadas, com os eletrodos posicionados como descrito anteriormente, foram realizadas nas posições supina e sentada. Também se procedeu à aferição da pressão arterial sistólica, diastólica e da freqüência cardíaca. Durante o protocolo I, os voluntários foram monitorizados continuamente nas derivações MC5, DII e $V_{2}$ modificadas. O registro do ECG e 
da freqüência cardíaca bem como as aferições das pressões arteriais sistólica e diastólica foram realizadas nos 15 segundos finais de cada nível de exercício.

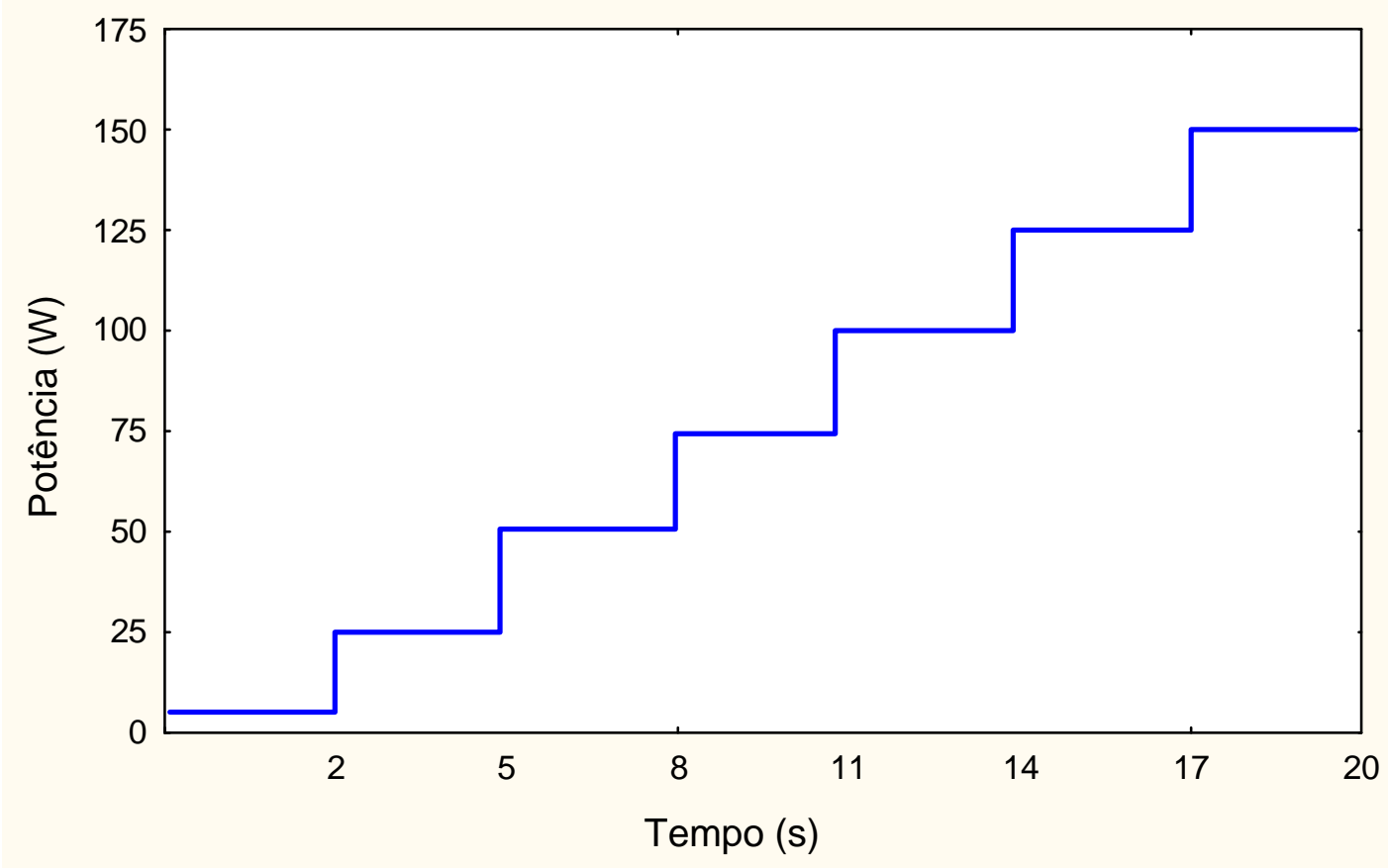

FIGURA 1 - Representação esquemática do teste de exercício físico dinâmico contínuo em degraus com carga inicial de 4 Watts (W), durante 2 min, e incrementos de 25 em $25 \mathrm{~W}$ a cada 3 min. 
3.7 Avaliação da modulação autonômica do coração, da variabilidade da freqüência cardíaca e da atividade eletromiográfica.

3.7.1 Protocolo II: teste de exercício físico dinâmico contínuo do tipo rampa (TEFDC-R)

Esse protocolo foi padronizado com o objetivo de avaliar a modulação autonômica do coração, a partir das respostas da freqüência cardíaca, e também avaliar a atividade muscular durante o exercício físico, a correlação entre os iR-R (ms) e a EMGs.

Antes do início do exercício físico os voluntários permaneciam em repouso nas posições supina e sentada durante 15 min com registro da freqüência cardíaca. Após este período os voluntários eram colocados sentados no cicloergômetro e permaneciam em repouso por um período de $1 \mathrm{~min}$. Davase início ao TEFDC-R com nível de potência de $4 \mathrm{~W}$ por 2 min e com incrementos de potências de 20 W por min (JAMMES et al., 1998; SHINOHARA et al., 1997) (figura 2) até a potência de 140 W. O incremento de potência era controlado automaticamente por um microprocessador modelo Worload Programm (Quinton-Groningen, Netherlands). 


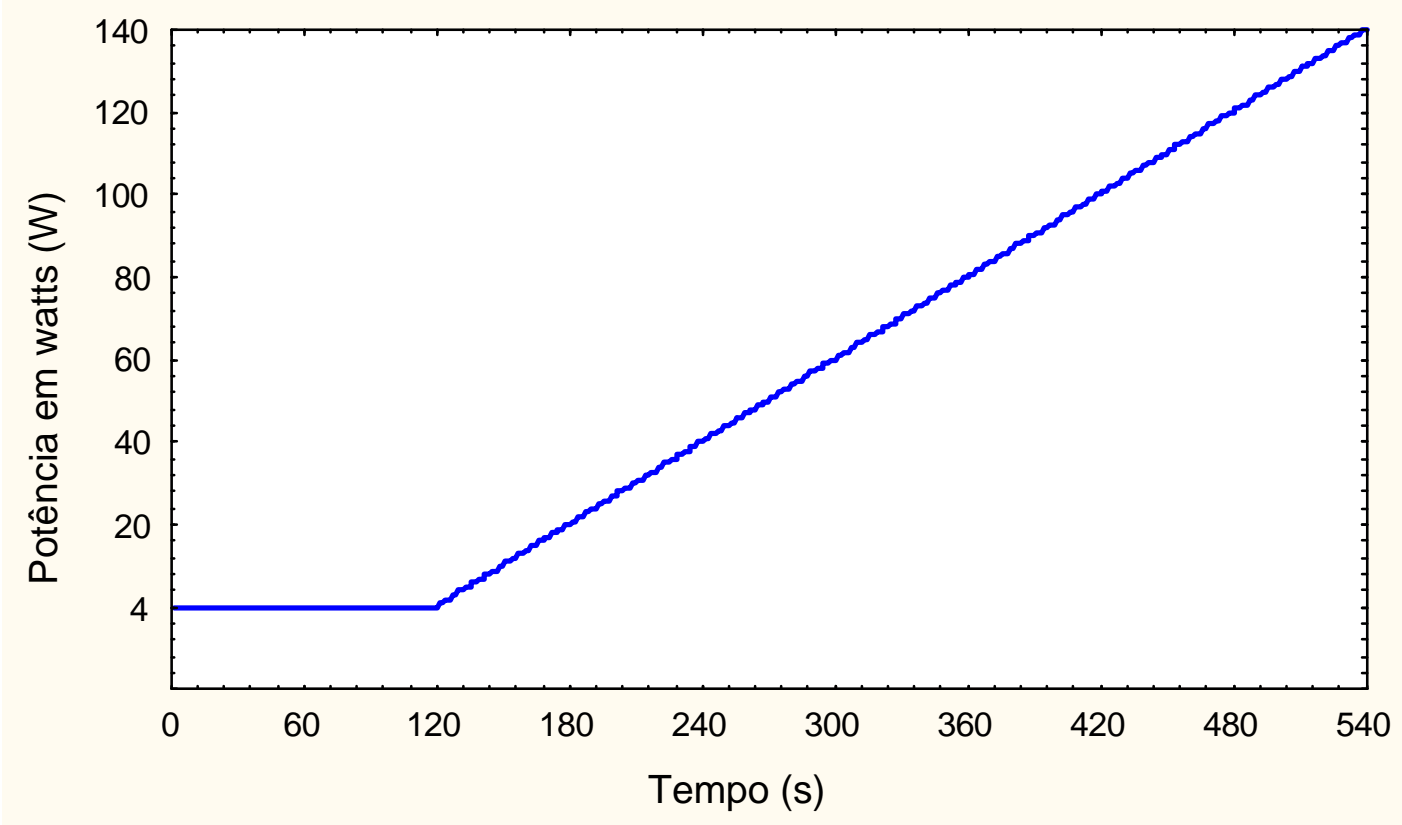

FIGURA 2 - Representação esquemática do teste de exercício físico dinâmico contínuo em rampa (TEFDC-R) com carga inicial de 4 Watts (W), por 2 min, e incrementos de $20 \mathrm{~W}$ por min.

\subsection{Procedimentos experimentais}

Os voluntários foram instruídos a seguirem algumas recomendações específicas nas 24 horas que precediam os testes: não ingerir bebidas alcoólicas e/ou estimulantes como café e chá; não praticar atividades físicas; alimentar-se sem extravagâncias; ter uma boa noite de sono; fazer uma refeição leve 2 horas antes dos testes. 
Durante a realização de ambos os protocolos, I e II, os voluntários foram instruídos a:

- Manter a freqüência de pedalada constante em 60 rotações por $\min (\mathrm{rpm})$;

- Manter a freqüência respiratória normal;

口 Não conversar;

- Não realizar contração isométrica com os membros superiores ao segurarem o guidão da bicicleta.

A figura 3 ilustra a montagem experimental do protocolo II (TEFDC-R). 


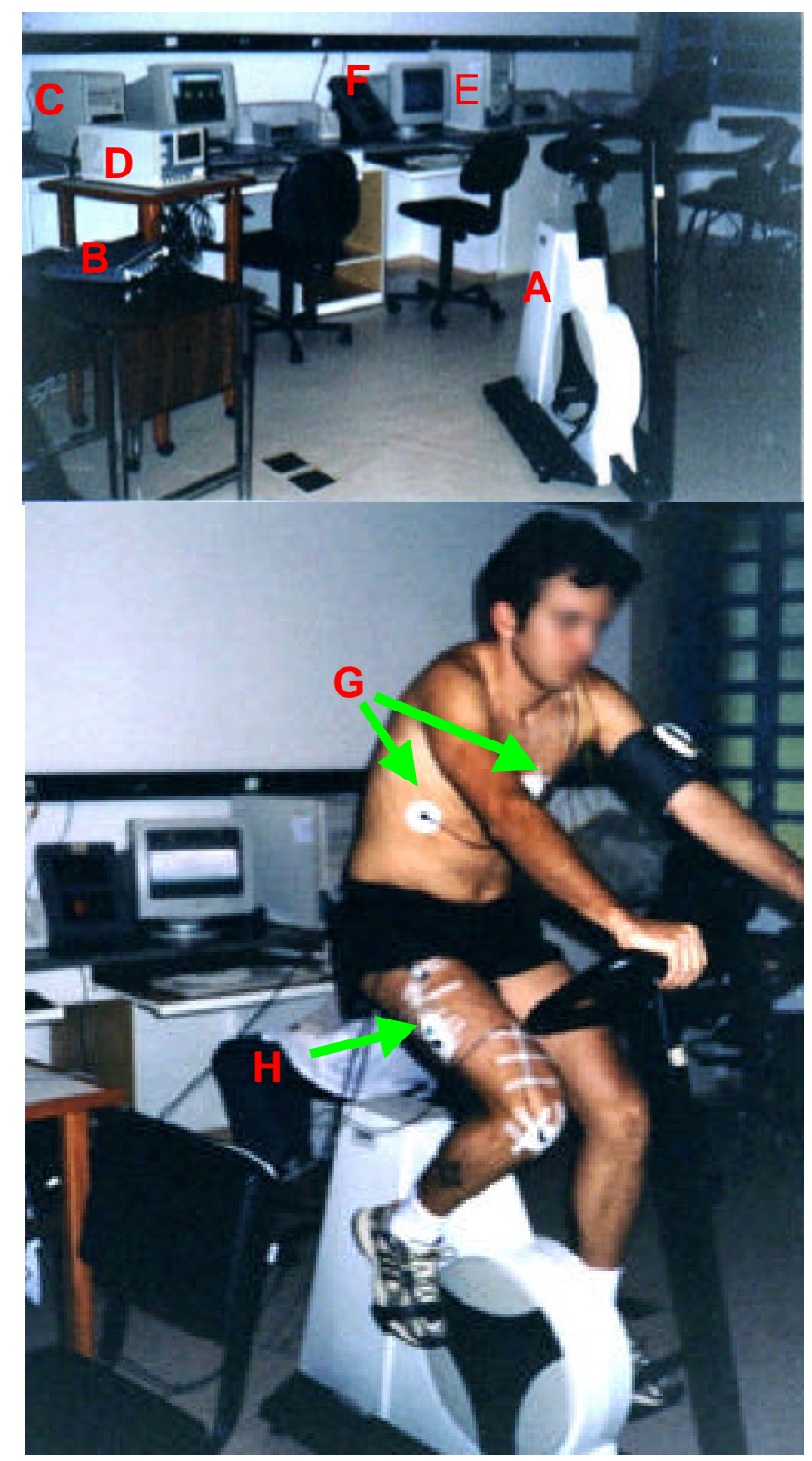

FIGURA 3 - llustração da montagem experimental do teste de exercício físico dinâmico em degrau contínuo tipo rampa (TEFDC-R). A: bicicleta ergométrica de frenagem eletromagnética; $B$ : condicionador de sinais da eletromiografia de superfície (EMGs); C: computador com o software de aquisição dos dados de EMGs; D: eletrocardiograma (ECG); E: computador com o software de aquisição dos dados de freqüência cardíaca; F: controlador de potências microprocessado; G: posicionamento dos eletrodos de ECG; H: posicionamento dos eletrodos de EMGs. 


\subsubsection{Controle ambiental e preparação pré-teste}

Para minimizar os efeitos externos sobre as respostas fisiológicas, os protocolos experimentais foram realizados nas mesmas condições em relação ao horário, temperatura e umidade relativa do ar (tabela 1, apêndice 4). Para a medição dos valores de temperatura e umidade relativa do ar foi utilizado um higrotermômetro hygrometer thermo clock (Templec ${ }^{T M}$ ). A temperatura foi controlada artificialmente por um aparelho de ar condicionado modelo Mini Split $\left(\right.$ TEMPSTAR $\left.^{\circledR}\right)$. Tais condições foram garantidas pela chegada antecipada dos pesquisadores ao laboratório assim como, a preparação dos materiais e equipamentos utilizados nas coletas experimentais.

Antes de serem iniciados os testes, os voluntários foram submetidos aos procedimentos de tricotomia e limpeza da pele com álcool e algodão, tanto no tórax quanto no membro inferior dominante, para a colocação dos eletrodos de registro do ECG e da EMGs, respectivamente. Previamente foi realizada a medição do membro inferior dominante para a localização dos pontos de colocação dos eletrodos no músculo vasto lateral para a obtenção dos sinais de EMGs.

Após tais procedimentos, os voluntários permaneciam $10 \mathrm{~min}$ repousando na posição supina antes dos testes serem iniciados, com o intuito de que as variáveis cardiovasculares, pressão arterial e freqüência cardíaca, se adaptassem às condições ambientais e estabilizassem em seus valores basais. 


\subsubsection{Procedimento para coleta dos dados de freqüência cardíaca}

Os voluntários foram monitorizados na derivação bipolar MC5, com o eletrodo negativo no ápice do manúbrio ou ao nível do $2^{\circ}$ ou $3^{\circ}$ espaço intercostal, o positivo na região do quinto espaço intercostal na linha axilar anterior esquerda referente à derivação V5 e o eletrodo neutro no $5^{\circ}$ espaço intercostal direito. Tal disposição foi escolhida para se obter uma maior diferença entre os picos das ondas $R$ e os picos das ondas $T$, dos sinais eletrocardiográficos.

Os sinais eletrocardiográficos foram captados por um monitor cardíaco de 1 canal (ECAFIX TC500) e processados por meio de um conversor analógico digital Lab. PC+ (National Instruments, CO.), que constitui uma interface entre o monitor cardíaco e o microcomputador Pentium Il. A partir do ECG, os iR-R (ms) foram registrados utilizando-se um programa de processamento de sinais (SILVA et al., 1994; OLIVEIRA et al., 1996) ilustrado na figura 4.

O registro da freqüência cardíaca, batimento a batimento, foi realizado durante 15 min em repouso nas condições supina e sentada em uma cadeira, com os pés apoiados no chão, e durante 1 min em repouso antes, 3 min após o TEFDC-R e durante todo o período de exercício. 


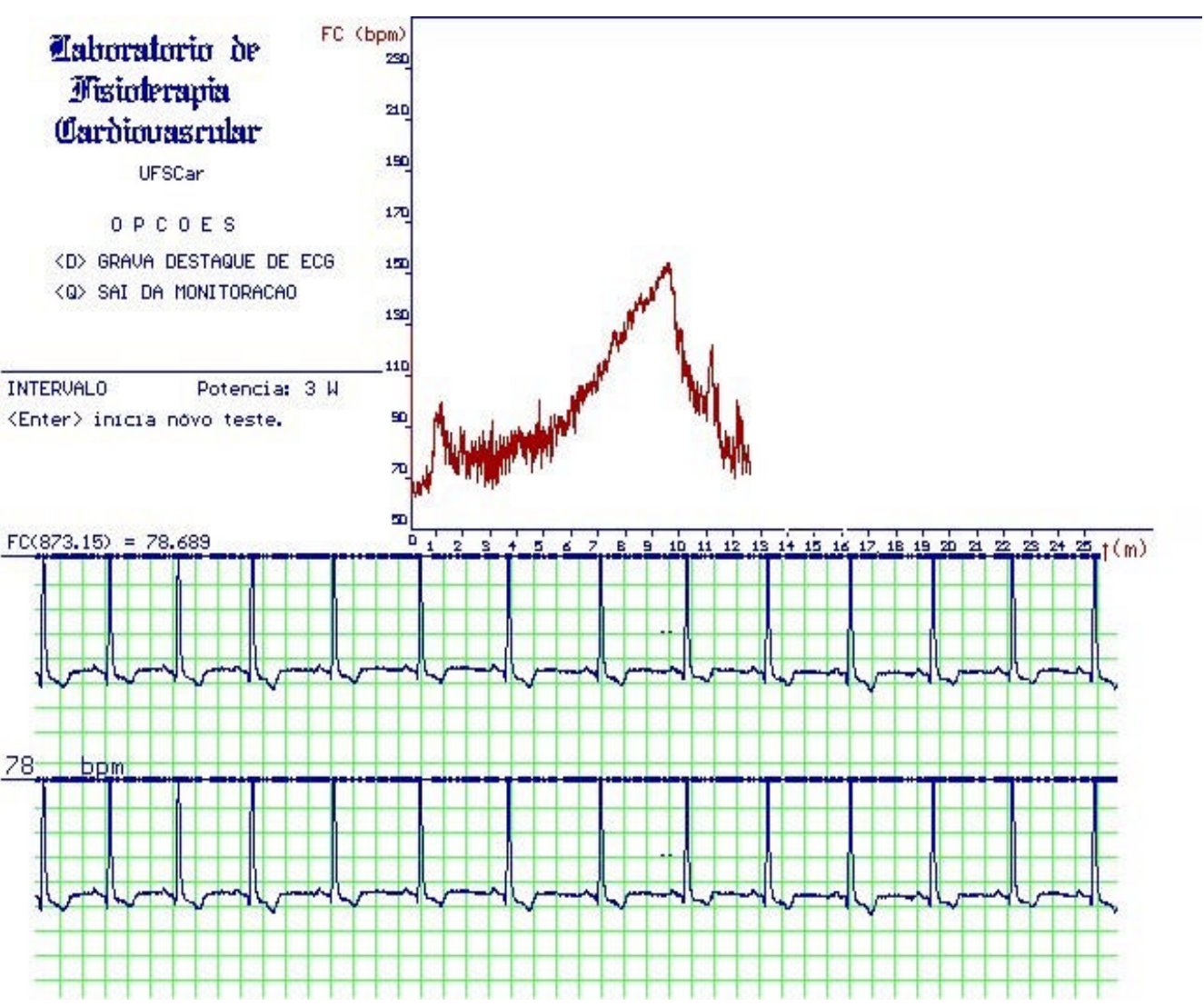

FIGURA 4 - llustração da aquisição dos dados da freqüência cardíaca, batimento a batimento em tempo real, obtida a partir dos intervalos RR do registro de eletrocardiograma na condição de exercício.

\subsubsection{Eletromiografia de superfície (EMGs)}

\subsubsection{Equipamento}

Para a aquisição do sinal da EMGs foi utilizado um eletromiógrafo computadorizado de 16 canais (Lynx Tecnologia Eletrônica Ltda.) e um programa de aquisição de sinais (AqDados5). O equipamento é composto de um módulo condicionador de sinais de 16 entradas analógicas simples (MCS 1000V2), uma placa conversora analógico-digital (CAD 12/32) de 12 bits de 
resolução com amplificador, interfaceados a um microcomputador $P C$-Celeron 300. Os sinais da EMGs foram processados por um filtro digital passa banda com freqüências de cortes de $20 \mathrm{~Hz}$ e $500 \mathrm{~Hz}$ para as altas freqüências. A freqüência de amostragem, do conversor analógico-digital foi $1000 \mathrm{~Hz}$, com faixa de tensão de entrada do sinal no canal analógico de $-10 a+10$ milivolts $(\mathrm{mV})$.

Calibração: a calibração do eletrodo foi com o ganho de 1000, sendo 20 vezes no eletrodo e 50 vezes na placa, obtendo-se assim um ponto de referência de calibração a ser posteriormente utilizado (de acordo com o manual do fabricante).

\subsubsection{Colocação dos eletrodos}

Posteriormente à realização da tricotomia, abrasão e limpeza da pele com álcool, os eletrodos foram posicionados com uma distância de $2 \mathrm{~cm}$ intereletrodo, de centro a centro, e fixados com fita adesiva (Micropore) no ventre do músculo vasto lateral longitudinalmente em relação às suas fibras conforme técnica descrita por BASMAJIAN et al. (1985), que refere ser o posicionamento mais adequado para representar a atividade elétrica das fibras musculares. Os eletrodos foram posicionados na metade da distância entre o trocanter maior e côndilo lateral do fêmur (figura 5) segundo técnica descrita por JAMMES et al. (1998). BURDEN et al. (1999) relatam que esses cuidados são fatores 
extrínsecos que podem e devem ser controlados nos experimentos pois influenciam nos dados coletados.

Local do posicionamento do eletrodo da EMGs (ventre do músculo vasto lateral).

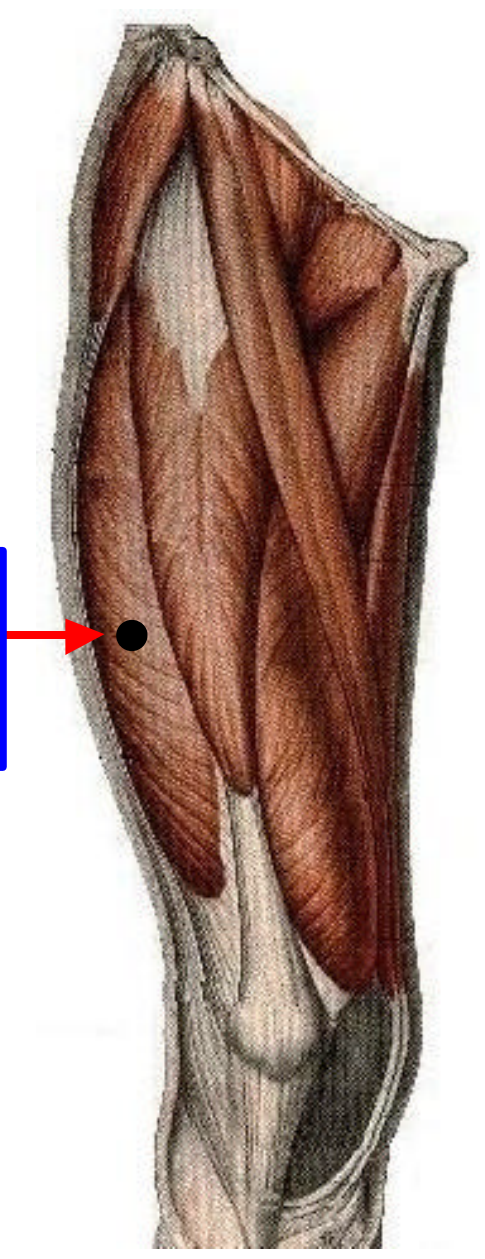

FIGURA 5 - Ilustração do posicionamento do eletrodo no ventre muscular do músculo vasto lateral, na distância média entre trocanter maior e côndilo lateral do fêmur, para registro do sinal eletromiográfico.

Os eletrodos de superfície utilizados foram de carbono ativado, autoadesivos e descartáveis, Carbocone (VERSATEC MFG INC-USA) (figura 6.A), acoplados por meio de terminais específicos (figura 6.C) a um dispositivo diferencial ativo adaptado (figura 6.B), o qual foi responsável pela diferenciação 
entre os dois pólos dos eletrodos. Tanto os terminais quanto o dispositivo diferencial foram fabricados especialmente para esses tipos de eletrodos. $O$ eletrodo de referência foi posicionado sobre a patela do membro inferior dominante do voluntário.

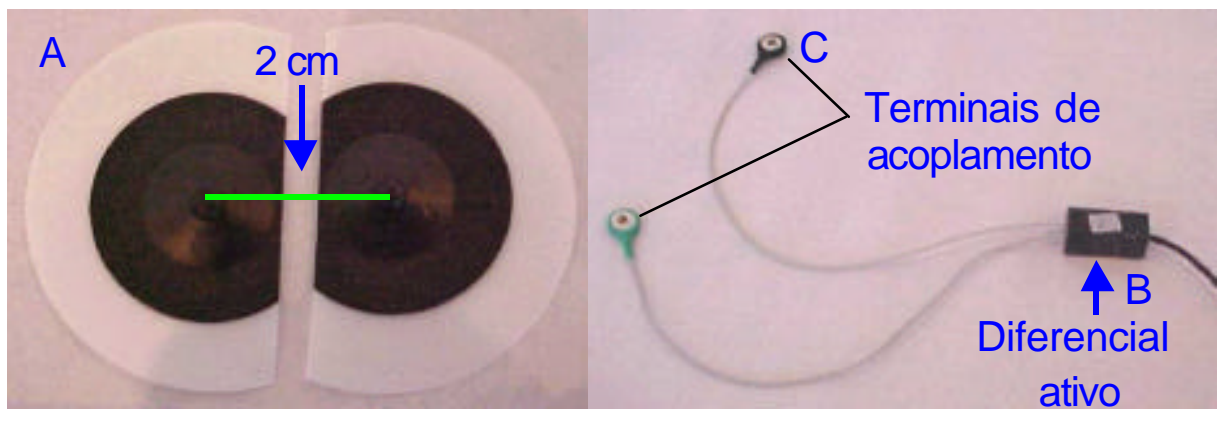

FIGURA 6 - A: eletrodos de superfície de fibra de carbono, B: eletrodo bipolar diferencial ativo e C: terminais de acoplamento ao eletrodo de carbono.

\subsubsection{Coleta dos sinais da eletromiografia de superfície} (EMGs).

A EMGs foi captada do músculo vasto lateral do membro inferior dominante. Esse músculo foi eleito por ser dentro do grupo muscular quadríceps da coxa o mais superficial permitindo assim uma melhor captação do sinal eletromiográfico e também por apresentar uma maior atividade durante exercícios dinâmicos realizados em bicicleta ergométrica (NAGATA et al., 1981; VITASSALO et al., 1985; MATSUMOTO et al., 1991; MANTEIKA et al., 1994; GLASS et al., 1997; ARNAUD et al., 1997; JAMMES et al., 1998).

A coleta da EMGs foi realizada durante os 20 s finais de cada min (JAMMES et al., 1998) durante a realização do TEFDC-R. 


\subsection{Métodos de análises}

\subsubsection{Análise descritiva dos dados dos voluntários}

Os dados relativos às características antropométricas e da avaliação clínica bem como os obtidos durante a realização do TEFDC-R foram analisados de forma descritiva.

\subsubsection{Análise no domínio do tempo}

3.9.2.1 Análise dos dados da freqüência cardíaca obtidos durante a realização do TEFDC-D (protocolo I)

Os dados de freqüência cardíaca (bpm) obtidos nas condições de repouso antes do TEFDC-D e no pico do exercício foram calculados em valores médios a partir dos 3 últimos iR-R (ms) registrados no ECG. Já os estimados foram a partir da fórmula 220-idade (MAHLER et al., 2000).

3.9.2.2 Análise dos dados de freqüência cardíaca obtidos durante a realização do TEFDC-R (protocolo II)

Para os dados de freqüência cardíaca (bpm) obtidos por processamento "on-line", batimento a batimento, em tempo real durante os $15 \mathrm{~min}$ em repouso nas posições supina e sentada foi calculado o índice RMSSD para os iR-R (ms) e para a freqüência cardíaca (bpm). Durante o TEFDC-R, nos $20 \mathrm{~s}$ finais de cada potência do exercício, foram calculados os índices RMSSD dos iR-R (ms) e a freqüência cardíaca (bpm) média. 
O índice RMSSD corresponde à raiz quadrada da somatória do quadrado das diferenças entre os iR-R no registro, dividido pelo número $(M)$ de $\mathrm{IR}-\mathrm{R}$ em um tempo determinado menos 1 (equação 1) (ANTILA, 1979). Os dados foram analisados a partir do aplicativo Analisador Gráfico de Eletrocardiograma (GOUVÊA et al., 1998).

$$
R M S S D=\sqrt{\frac{\sum_{i=1}^{N-1}\left(R R_{i}-R R_{i+1}\right)^{2}}{N-1}}(\text { Equação 1) }
$$

3.9.2.3 Análise da freqüência cardíaca (bpm) e dos iR-R (ms) obtidos durante a realização do TEFDC-R (protocolo II)

Os índices de RMSSD dos iR-R (ms) e a freqüência cardíaca (bpm) foram calculados em séries de intervalos de 6 em 6 s dos 20 segundos finais de cada minuto do TEFDC-R. As séries de janelamentos de $6 \mathrm{~s}$ foram deslocadas de 3 em 3 s, conforme representação esquemática na figura 7.

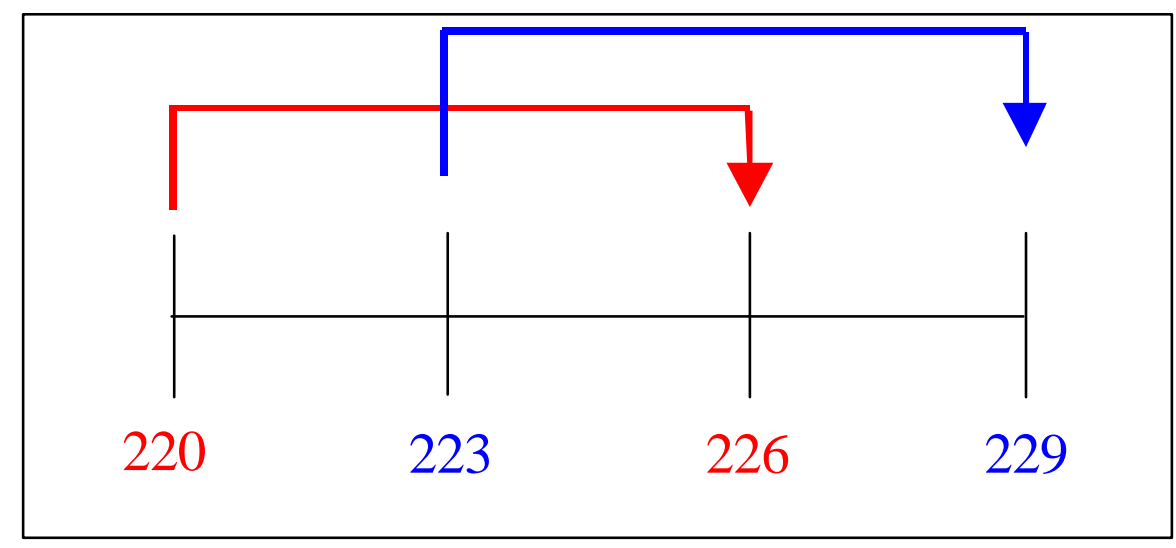

FIGURA 7 - Representação esquemática do janelamento de 6 em 6 segundos para a análise da freqüência cardíaca média e da VFC pelo índice RMSSD. 
Optou-se por este janelamento para se obter os valores de freqüência cardíaca e iR-R correspondentes aos sinais de EMGs coletados nos $20 \mathrm{~s}$ finais de cada min.

\subsubsection{Análise dos dados eletromiográficos de}

\section{superfície obtidos durante a realização do TEFDC-R (protocolo II)}

Os dados de EMGs de cada contração (figura 8) foram selecionados em intervalos de 400 ms (MATEIKA et al., 1994) e analisados no domínio do tempo a partir dos índices de RMS (Root Mean Square) da amplitude dos seus sinais em $\mu \mathrm{V}$, utilizando-se o programa AqDados-5. Foram analisados os intervalos correspondentes às 10 últimas contrações musculares registradas durante os $10 \mathrm{~s}$ finais de cada min do TEFDC-R (JAMMES et al., 1998).

$$
R M S=\sqrt{\frac{t f}{\int_{t i} f^{2}(t) d t}}
$$

Onde:

$t i$ : instante inicial;

$t f$ : instante final;

$f^{2}(t) d t$ : função do sinal amostrado; $\int$ : integral. 


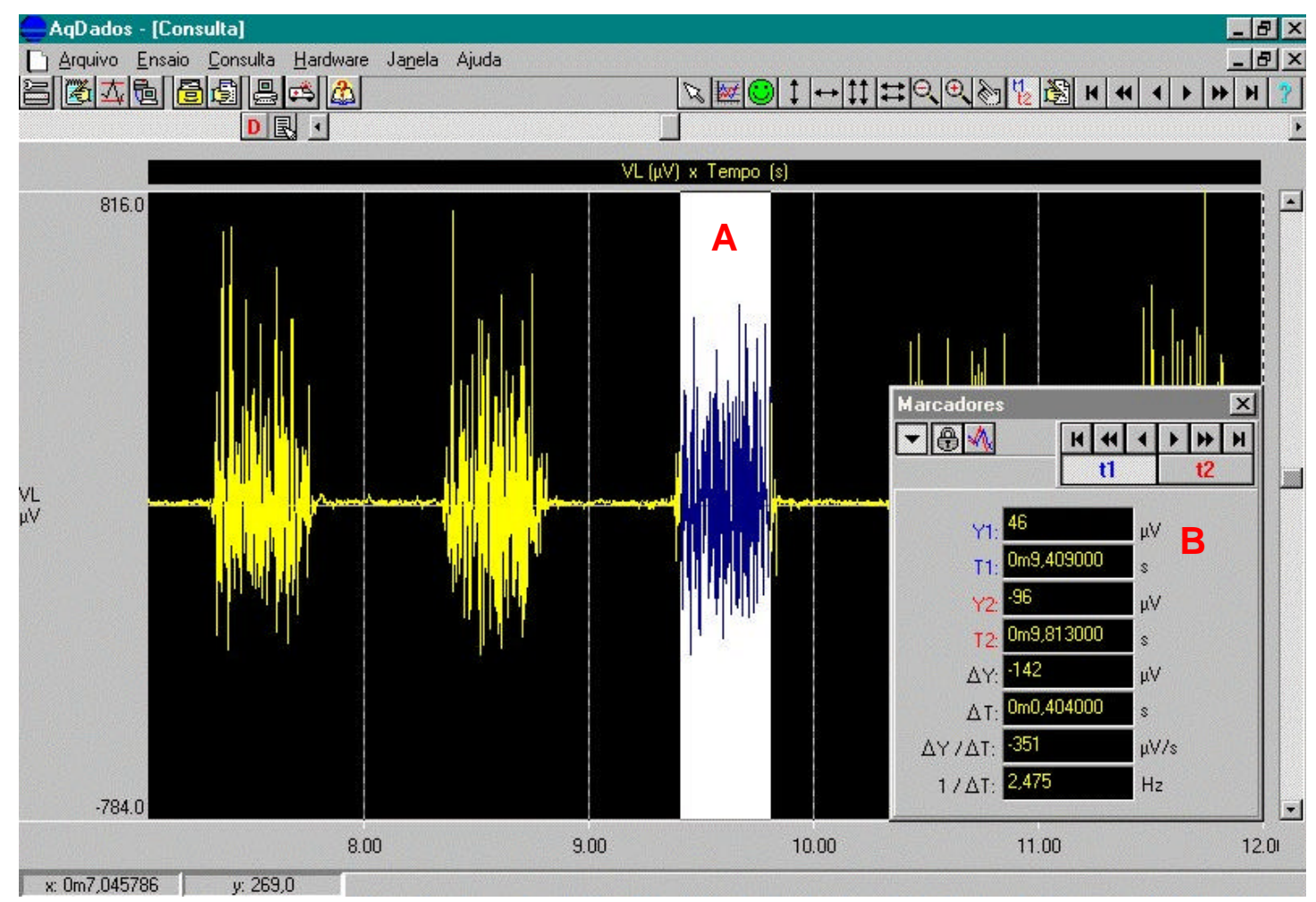

FIGURA 8 - llustração de uma das telas do software AQ-Dados 5 de captação dos sinais de eletromiografia de superfície (EMGs), em tempo real: em A está representado o intervalo do sinal de uma contração muscular do músculo vasto lateral do voluntário LBC na potência de 140 Watts, e em B dados do intervalo do sinal de EMGs a ser analisado no intervalo de tempo de $400 \mathrm{~ms}$

3.10 Normalização dos dados de RMSSD dos iR-R (ms) e de RMS da amplitude do sinal eletromiográfico a partir do valor mediano.

Para comparação entre variáveis cujas unidades e ordem de grandeza são diferentes realizou-se o procedimento de normalização descrito a seguir. Os dados de RMSSD dos iR-R (ms) foram normalizados segundo a seguinte metodologia: cada valor foi dividido pelo valor mediano do conjunto de dados (todas as potências estudadas), gerando um novo conjunto de dados. Foram 
calculados os valores mediano, mínimo e máximo para os dados de cada potência, cujos valores foram plotados em gráfico. O mesmo procedimento de normalização descrito acima foi realizado no conjunto de dados de RMS da amplitude da EMGs $(\mu \mathrm{V})$. Os gráficos foram superpostos para comparação de seus comportamentos.

\subsection{Metodologia estatística}

Para a escolha do teste estatístico (paramétrico ou não paramétrico) verificou-se a distribuição das variáveis estudadas em diferentes condições (figura 9 A e B). A análise de distribuição dos dados mostrou que os mesmos não possuíam distribuição normal. Assim, foram utilizados testes estatísticos não paramétricos.

Os resultados foram apresentados graficamente em "Box-plot" contendo os valores de mediana, $1^{\circ}$ quartil $(25 \%), 3^{\circ}$ quartil $(75 \%)$, valores máximos e mínimos, outliers e extremos. Para tanto se utilizou o aplicativo STATISTICA for Windows, Release 6.0 Stat soft, Inc. 1984-2000.

A análise estatística de significância foi realizada a partir dos testes não paramétricos de Wilcoxon para amostras pareadas, teste de Friedman para medidas repetidas seguido de técnicas de comparações múltiplas com o teste de Dunn, que informa a que nível se deu a significância entre os dados e análise de correlação de Spearman. Foram considerados níveis de significância de á=0,05. 

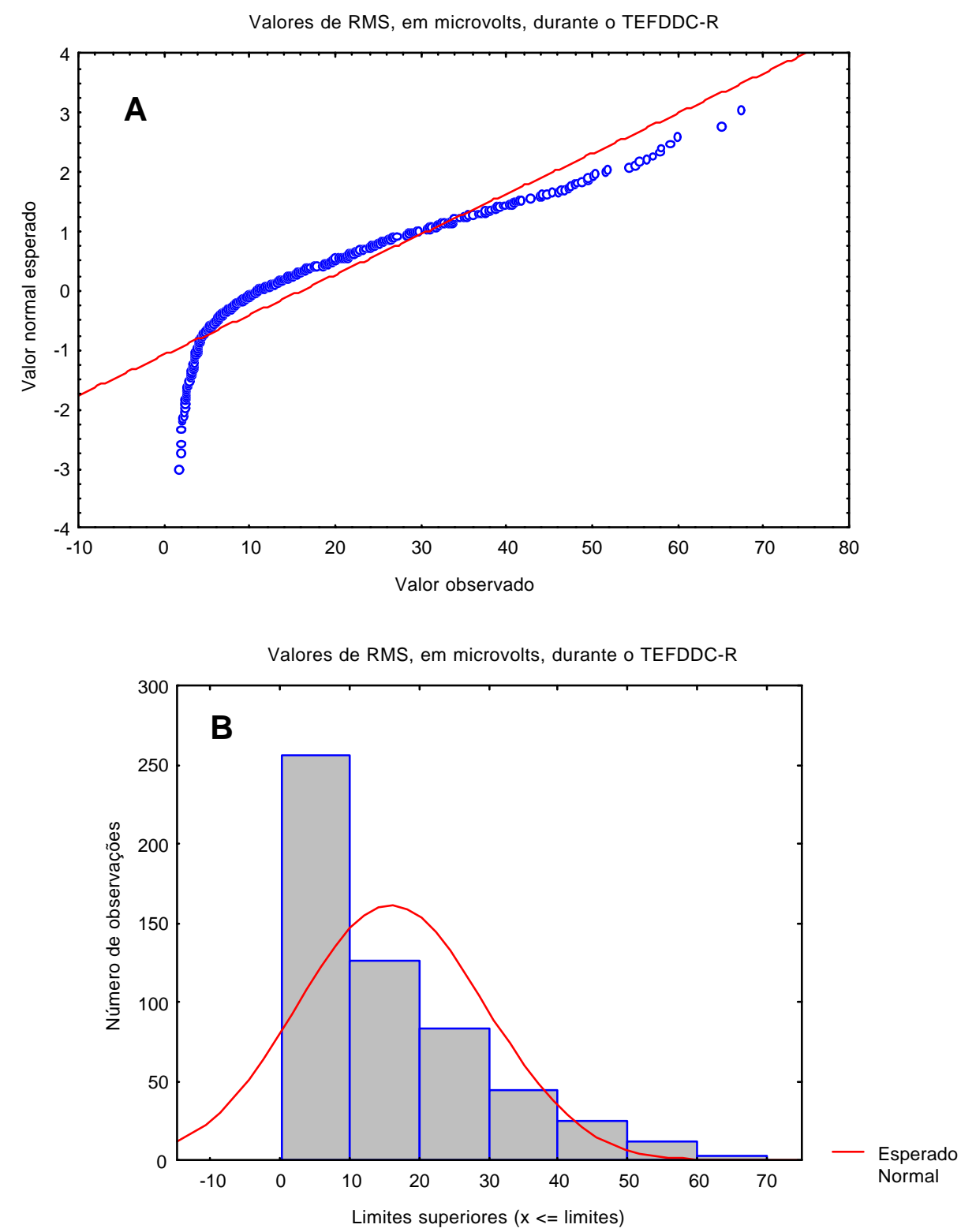

FIGURA 9 - Análise dos valores absolutos do índice de RMS da amplitude dos sinais eletromiográficos $(\mu \mathrm{V})$ dos voluntários estudados $(n=10)$ quanto à distribuição dos dados. Em $A$ estão representado os valores observados em relação aos esperados. Em B curva de Gauss e histograma do número de observações. 


\section{RESULTADOS}

\subsection{Voluntários estudados}

Na tabela 2 estão representados os dados referentes a idade, as características antropométricas (peso, altura e índice de massa corpórea) e o tipo e freqüência de atividade em relação às horas semanais.

TABELA 2 - Idade em anos, características antropométricas (peso em quilogramas $(\mathrm{kg})$, altura em metros $(\mathrm{m})$ e índice de massa corpórea (IMC) em quilogramas por metro ao quadrado $\left.\left(\mathrm{kg} / \mathrm{m}^{2}\right)\right)$, tipo de atividade física $(\mathrm{TAF})$ e horas semanais $(H / S)$ praticadas dos voluntários estudados $(n=10)$.

\begin{tabular}{ccccccc}
\hline Voluntários & $\begin{array}{c}\text { Idade } \\
\text { (anos) }\end{array}$ & $\begin{array}{c}\text { Peso } \\
(\mathrm{Kg})\end{array}$ & $\begin{array}{c}\text { Altura } \\
(\mathrm{m})\end{array}$ & $\begin{array}{c}\text { IMC } \\
\left(\mathrm{kg} / \mathrm{m}^{2}\right)\end{array}$ & $\mathrm{H} / \mathrm{S}$ & TAF \\
\hline CHS & 28 & 69 & 1,78 & 21,83 & 3 & Bicicleta e esteira \\
CAJ & 22 & 69,5 & 1,81 & 21,25 & 3 & Futebol \\
FP & 29 & 81 & 1,83 & 24,25 & 3 & Futebol \\
GHS & 23 & 78 & 1,86 & 22,55 & 3 & Bicicleta e esteira \\
IDM & 20 & 73 & 1,79 & 22,81 & 3 & Bicicleta \\
JC & 22 & 71 & 1,77 & 22,66 & 4 & Bicicleta \\
KGG & 21 & 68 & 1,79 & 21,25 & 3 & Bicicleta \\
LBC & 26 & 88 & 1,86 & 25,5 & 5 & Futebol \\
RSR & 22 & 73 & 1,76 & 23,62 & 4 & Bicicleta \\
RAJ & 24 & 66,5 & 1,78 & 21,04 & 4 & Caminhada \\
\hline Média & 23,7 & 73,7 & 1,80 & 22,67 & 3,5 & \\
D. P. & 3,02 & 6,73 & 0,03 & 1,44 & 0,70 & \\
Mediana & 22,5 & $\mathbf{7 2}$ & $\mathbf{1 , 7 9}$ & $\mathbf{2 2 , 6 0}$ & $\mathbf{3}$ & \\
$1^{\circ}$ Quartil & 22 & 69 & 1,78 & 21,25 & 3 & \\
$3^{\circ}$ Quartil & 26 & 78 & 1,83 & 23,62 & 4 & \\
Mínimo & 20 & 66,5 & 1,76 & 21,04 & 3 & \\
Máximo & 29 & 88 & 1,86 & 25,5 & 5 & \\
\hline
\end{tabular}

D.P.: desvio padrão. 
$\mathrm{Na}$ tabela 3 (apêndice 5) verifica-se que os valores de colesterol total, HDL colesterol, LDL colesterol, VLDL colesterol, triglicérides, ácido úrico, creatinina, uréia e glicemia em jejum estão dentro da faixa de normalidade.

Os exames eletrocardiográficos, em repouso e exercício, não apresentaram anormalidades assim como as radiografias de tórax. Assim, verifica-se que os voluntários que fizeram parte deste estudo não apresentaram alterações indicativas de doenças e/ou acometimentos em particular cardiorrespiratória e musculoesquelética, aos exames que foram submetidos.

\subsection{Respostas das variáveis cardiovasculares durante a realização do TEFDC-D (protocolo I).}

$\mathrm{Na}$ tabela 4 verifica-se os valores obtidos de freqüência cardíaca (bpm) em repouso, estimada para a idade e a do pico do esforço, bem como os valores de pressão arterial sistólica e diastólica mensuradas em repouso e durante o pico do TEFDC-D (protocolo I) dos voluntários estudados $(n=10)$.

Tanto a freqüência cardíaca quanto a pressão arterial sistólica e diastólica, apresentaram comportamentos fisiológicos esperados entre o repouso e o exercício, ou seja, a freqüência cardíaca e a pressão arterial sistólica apresentaram acréscimos dentro da faixa prevista de acordo com os incrementos de potência durante o TEFDC-D, e a pressão arterial diastólica apresentou pequena variação. 
TABELA 4 - Valores de freqüência cardíaca $(F C)$, em batimentos por minuto (bpm), máxima estimada para a idade, em repouso supino e a pico atingida durante a realização do TEFDC-D. Pressão arterial sistólica (PAS) e diastólica (PAD), em milímetros de mercúrio $(\mathrm{mmHg})$, durante a condição de repouso supino e na potência pico, em Watts $(W)$, do TEFDC-D.

\begin{tabular}{|c|c|c|c|c|c|c|c|c|}
\hline \multirow[t]{2}{*}{ Voluntários } & \multirow{2}{*}{\begin{tabular}{|c|} 
Estimada \\
FC \\
$(\mathrm{bpm})$
\end{tabular}} & \multicolumn{3}{|c|}{ Repouso } & \multicolumn{4}{|c|}{ TEFDC-R } \\
\hline & & $\begin{array}{c}\mathrm{FC} \\
(\mathrm{bpm})\end{array}$ & $\begin{array}{c}\text { PAS } \\
(\mathrm{mmHg})\end{array}$ & $\begin{array}{c}\text { PAD } \\
(\mathrm{mmHg})\end{array}$ & $\begin{array}{c}\text { FC } \\
(\mathrm{bpm})\end{array}$ & $\begin{array}{c}\text { PAS } \\
(\mathrm{mmHg})\end{array}$ & $\begin{array}{c}\text { PAD } \\
(\mathrm{mmHg})\end{array}$ & $\begin{array}{l}\text { Potência pico } \\
\text { (W) }\end{array}$ \\
\hline $\mathrm{CHS}$ & 192 & 66,8 & 120 & 70 & 190 & 190 & 75 & 150 \\
\hline CJr & 198 & 76,08 & 110 & 65 & 180 & 180 & 80 & 200 \\
\hline $\mathrm{FP}$ & 191 & 71,31 & 100 & 60 & 170 & 170 & 80 & 175 \\
\hline GHS & 197 & 68,61 & 100 & 60 & 180 & 180 & 80 & 200 \\
\hline IDM & 200 & 63 & 120 & 70 & 185 & 185 & 80 & 175 \\
\hline $\mathrm{JC}$ & 198 & 64,26 & 110 & 80 & 190 & 190 & 90 & 225 \\
\hline KGG & 199 & 61,54 & 115 & 75 & 185 & 185 & 90 & 175 \\
\hline LBC & 194 & 74,87 & 110 & 80 & 190 & 190 & 90 & 225 \\
\hline RAJ & 198 & 68,95 & 110 & 70 & 180 & 180 & 80 & 175 \\
\hline RSR & 196 & 81,01 & 110 & 65 & 180 & 180 & 75 & 175 \\
\hline Média & 196,3 & 69,64 & 110,5 & 69,5 & 183 & 183 & 82 & 187,5 \\
\hline D. P. & 3,02 & 6,22 & 6,85 & 7,24 & 6,32 & 6,32 & 5,86 & 24,29 \\
\hline Mediana & 197,5 & 68,78 & 110 & 70 & 182,5 & 182,5 & 80 & 175 \\
\hline $1^{\circ}$ Quartil & 194 & 64,26 & 110 & 65 & 180 & 180 & 80 & 175 \\
\hline $3^{\circ}$ Quartil & 198 & 74,87 & 115 & 75 & 190 & 190 & 90 & 200 \\
\hline Máximo & 200 & 81,01 & 120 & 80 & 190 & 190 & 90 & 225 \\
\hline Mínimo & 191 & 61,54 & 100 & 60 & 170 & 170 & 75 & 150 \\
\hline
\end{tabular}




\subsection{Análise da freqüência cardíaca e da variabilidade da freqüência} cardíaca em repouso

\subsubsection{Análise visual gráfica}

A figura 10 exemplifica os dados de freqüência cardíaca obtidos em repouso nas condições supina e sentada, captada batimento a batimento, em tempo real, durante $900 \mathrm{~s}$ do voluntário CJR antes de realizar o TEFDC-R.

Pela análise visual verificam-se maiores valores de freqüência cardíaca na posição sentada quando comparada com a supina.

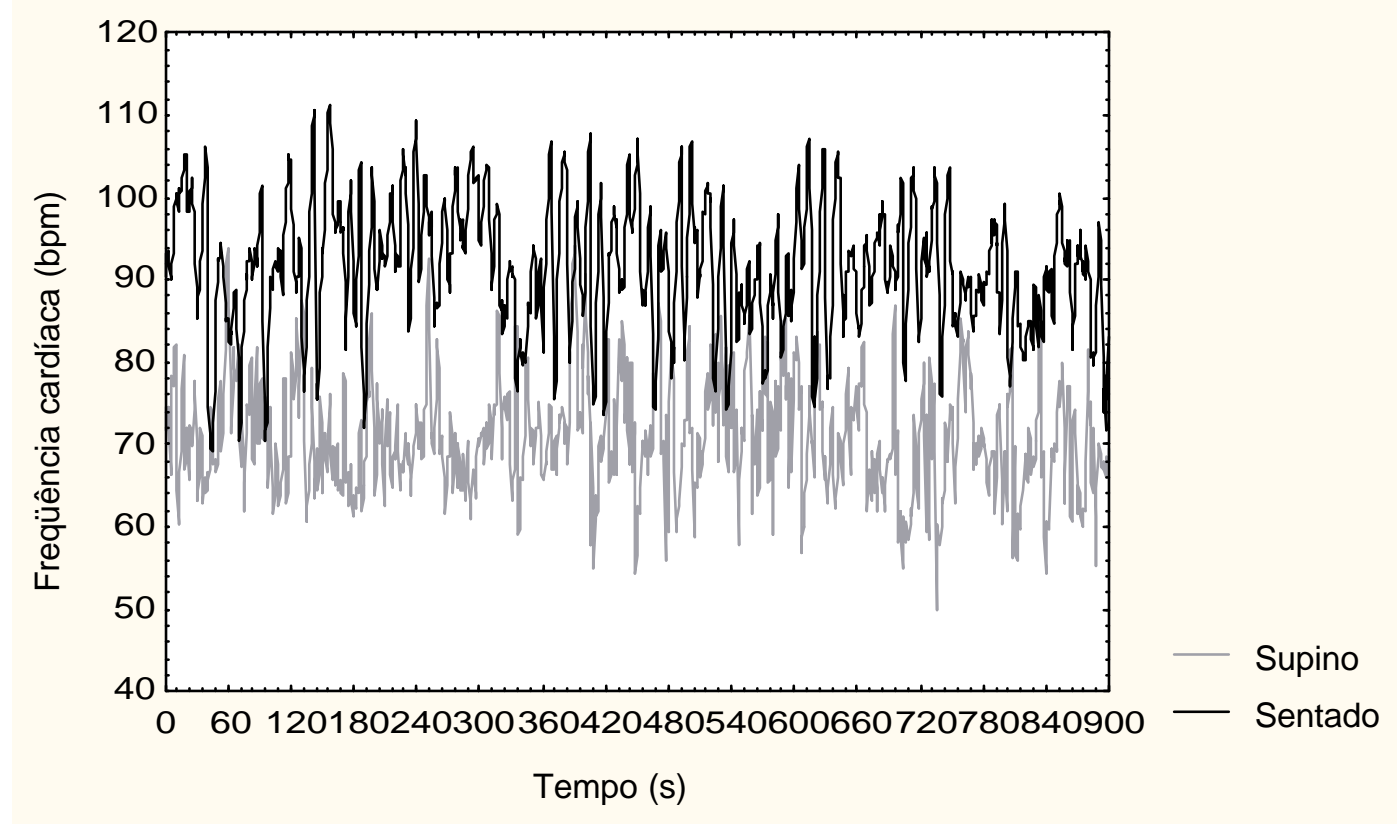

FIGURA 10 - Freqüência cardíaca, em batimentos por minuto (bpm), registrada em tempo real, durante os $900 \mathrm{~s}$ nas condições de repouso supino e sentado antes da realização do TEFDC-R de um dos voluntários estudados (CJR). 


\subsubsection{Análise no domínio do tempo}

Observa-se na figura 11 que a freqüência cardíaca (bpm) dos voluntários estudados durante as condições de repouso na posição supina foi inferior em relação à da posição sentada e essa diferença foi estatisticamente significante $(p<0,05)$. Quanto à variabilidade dos dados (diferença entre $01^{\circ}$ e $3^{\circ}$ quartis) observa-se que essa foi maior na posição supina em relação a posição sentada. Quando analisamos os iR$R$ (ms), calculados em média de 15 minutos, entre as posições supina e sentada (figura 12) verifica-se que o valor em mediana dos iR-R (ms) em repouso supino em relação a posição sentada foi superior com diferença estatística significante $(p<0,05)$.

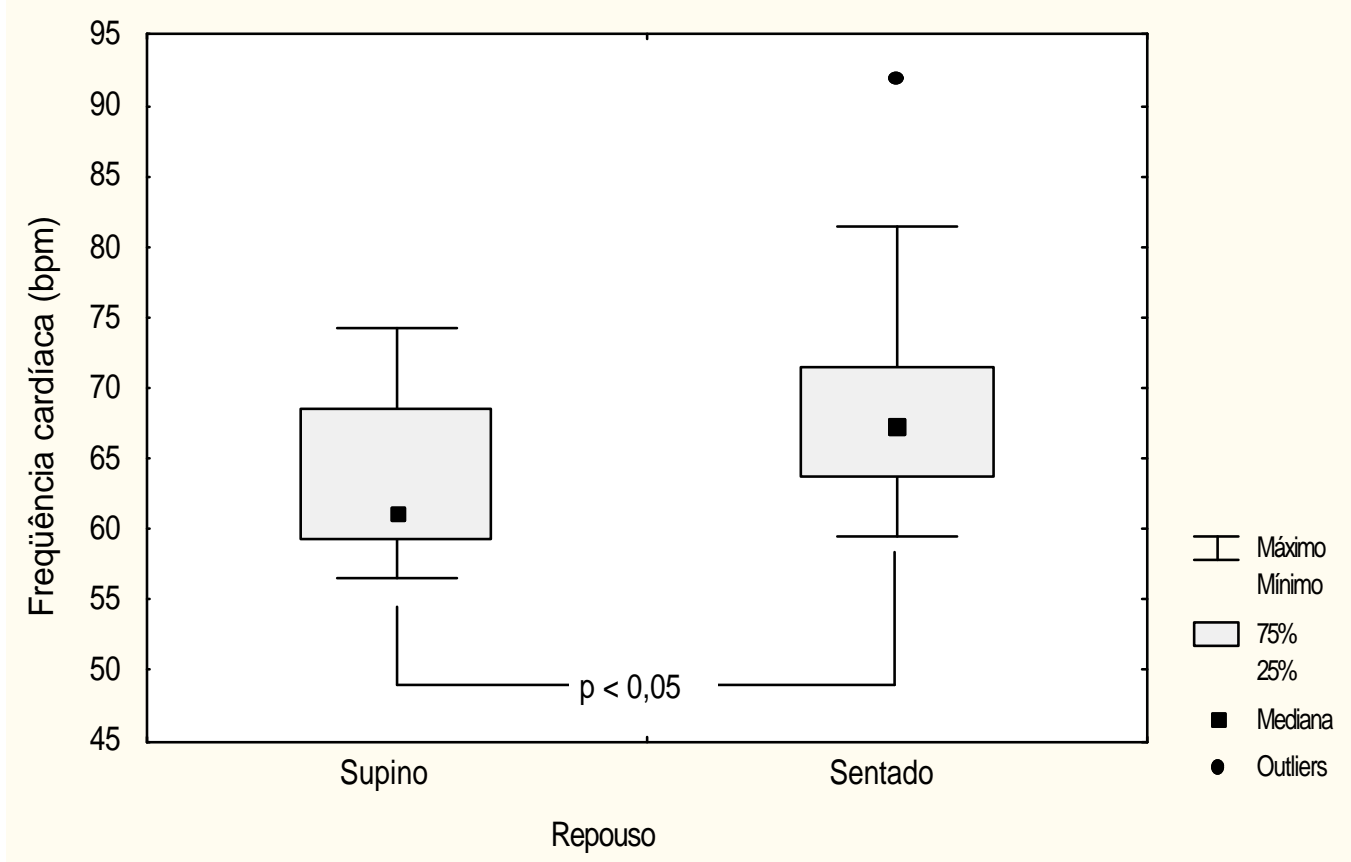

FIGURA 11 - Freqüência cardíaca média, em batimentos por minuto (bpm), observada nas condições de repouso durante 15 min nas posições supina e sentada dos voluntários estudados $(n=10)$. Nível de significância $\alpha=0,05$ 


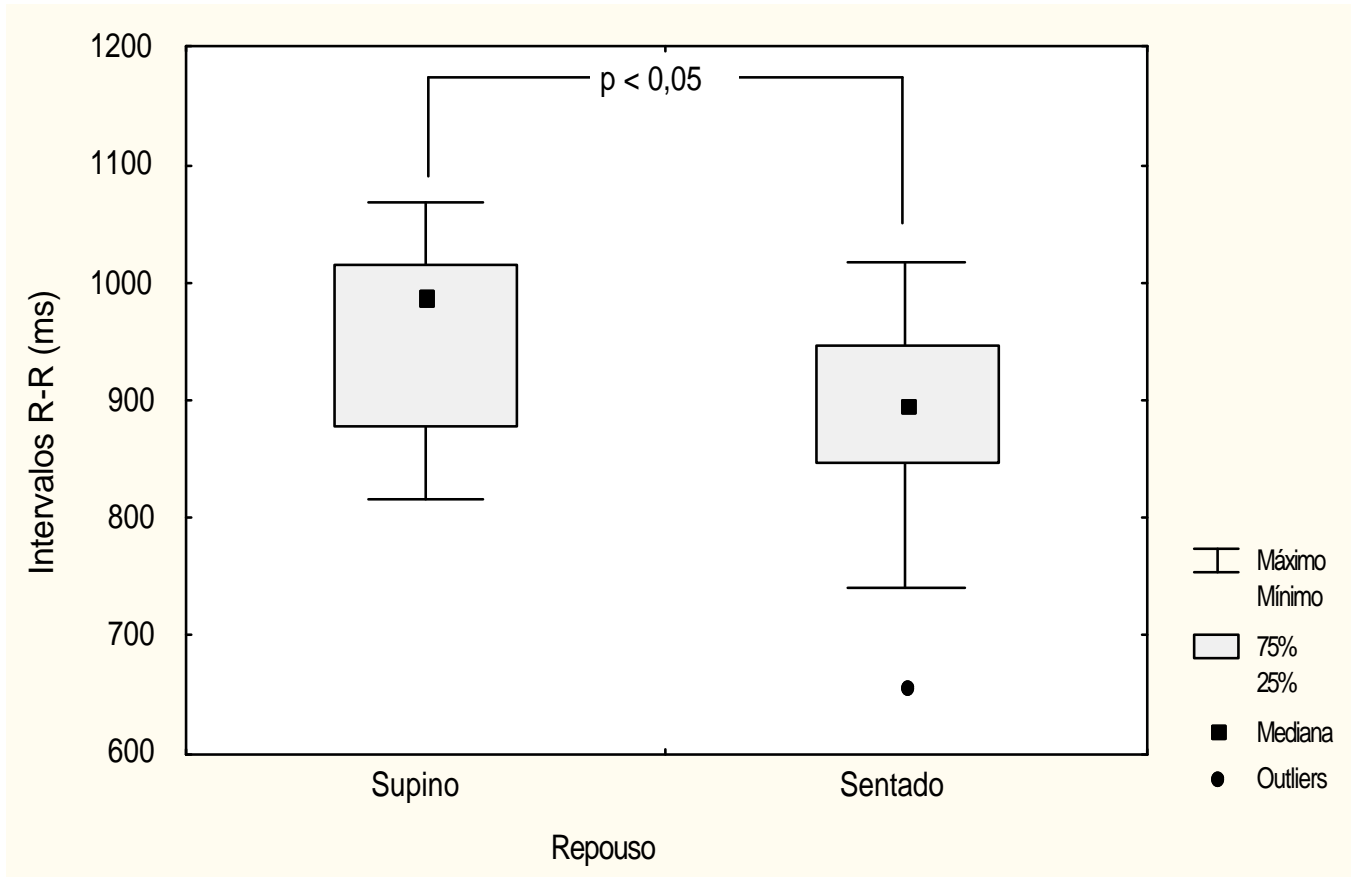

FIGURA 12 - Intervalos RR (ms) calculados em média dos 15 minutos em repouso, nas posições supina e sentada, dos voluntários estudados $(n=10)$. Nível de significância $\alpha=0,05$.

Ao se analisar a VFC a partir do índice de RMSSD dos iR-R (ms), obtidos durante os 15 min em repouso, verifica-se na figura 13 que os valores na posição supina foram superiores quando comparados com a sentada, apresentando diferença estatística significante $(p<0,05)$. 


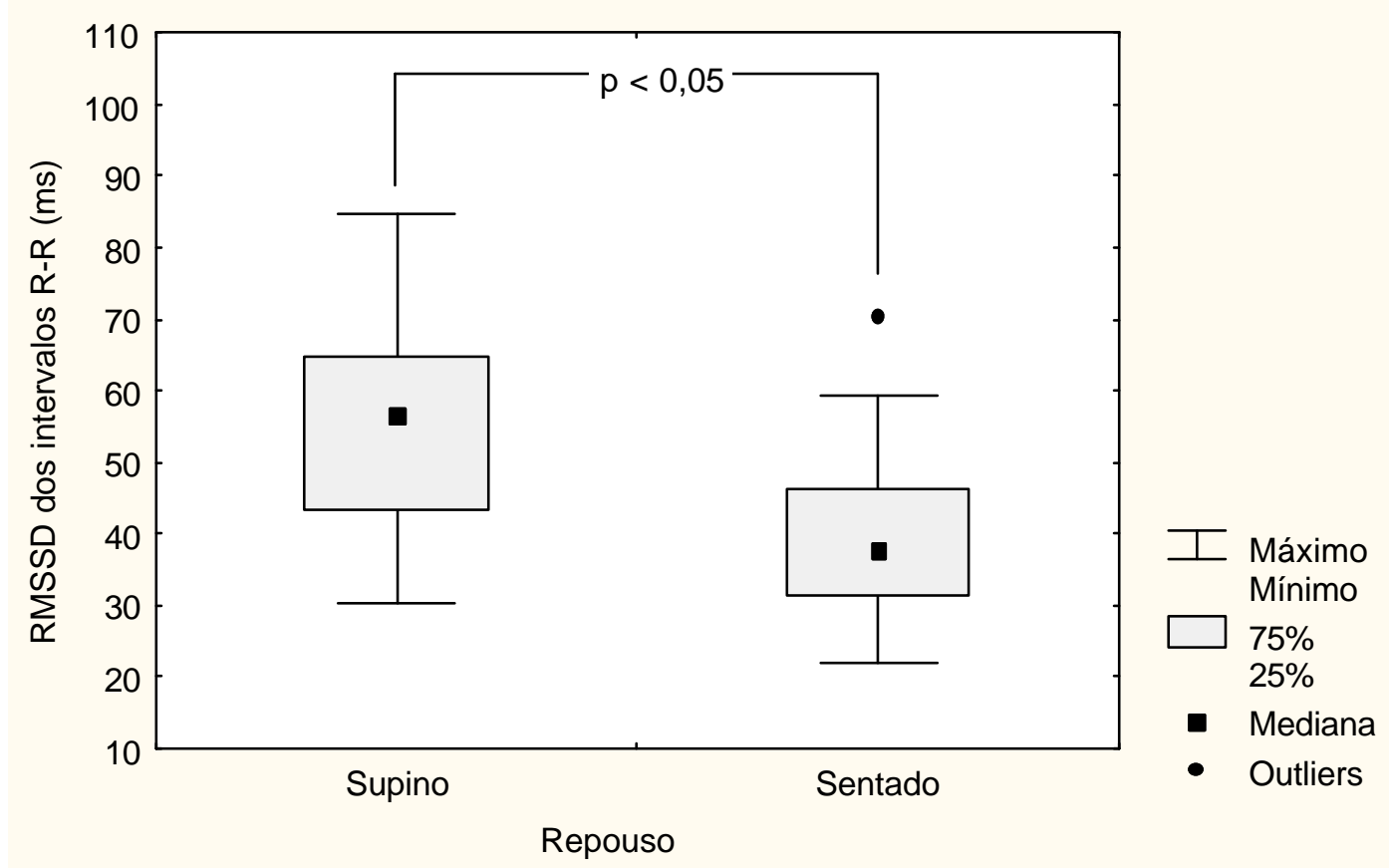

FIGURA 13 - Índice RMSSD dos iR-R (ms) obtidos das condições de repouso durante 15 min na posição supina e sentada dos voluntários estudados $(n=10)$. Nível de significância $\alpha=0,05$

Observa-se na figura 14 que a VFC analisada partir do índice de RMSSD da freqüência cardíaca (bpm), obtida durante os 15 minutos em repouso, apresenta valores superiores na posição supina quando comparados com a sentada não apresentando diferença estatística significante $(p>0,05)$. 


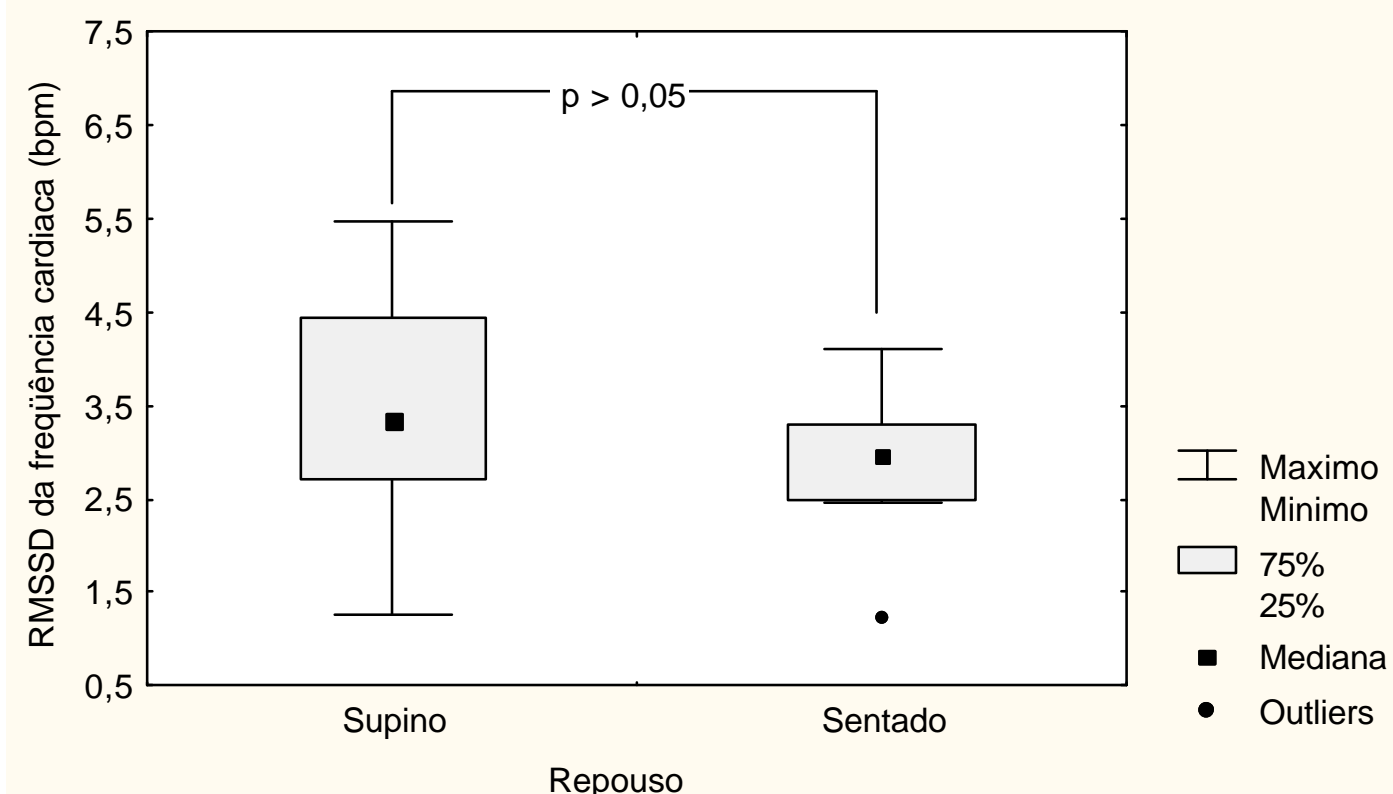

FIGURA 14 - Índices RMSSD da freqüência cardíaca (bpm) obtidos nas condições de repouso durante 15 min na posição supina e sentada dos voluntários estudados $(n=10)$. Nível de significância $\alpha=0,05$

\subsection{Análise visual gráfica da freqüência cardíaca e do sinal da EMGs durante o TEFDC-R (protocolo II)}

A figura 15 apresenta em A a resposta do sinal eletromiográfico (amplitude normalizada) de um dos voluntários estudados (FP) durante o repouso inicial (1) e na realização do TEFDC-R (2). Em B encontra-se a resposta da freqüência cardíaca (bpm) registrada batimento a batimento, em tempo real, durante a condição de repouso pré-exercício (fase 1) e na realização do TEFDC-R dos voluntários estudados. Em destaque, encontra-se a freqüência cardíaca média calculada a partir das respostas individuais. Nota-se uma elevação rápida da freqüência cardíaca no início do exercício (fase 2) e a partir dos 61 s tendendo a uma diminuição até 81 s (fase 3) para em seguida apresentar um aumento discreto até $107 \mathrm{~s}$ 
(fase 4). Após essa fase, a freqüência cardíaca apresenta diminuição dos valores com uma maior variabilidade (fase 5). Com o incremento da potência, verifica-se uma segunda fase de elevação que ocorre entre 259 e 430 s (fase 6) mas ainda com pouca diferença na variabilidade. A partir desse intervalo ocorre uma maior elevação da freqüência cardíaca associada a uma diminuição de sua variabilidade até o término do exercício em 600 s (fase 7). 

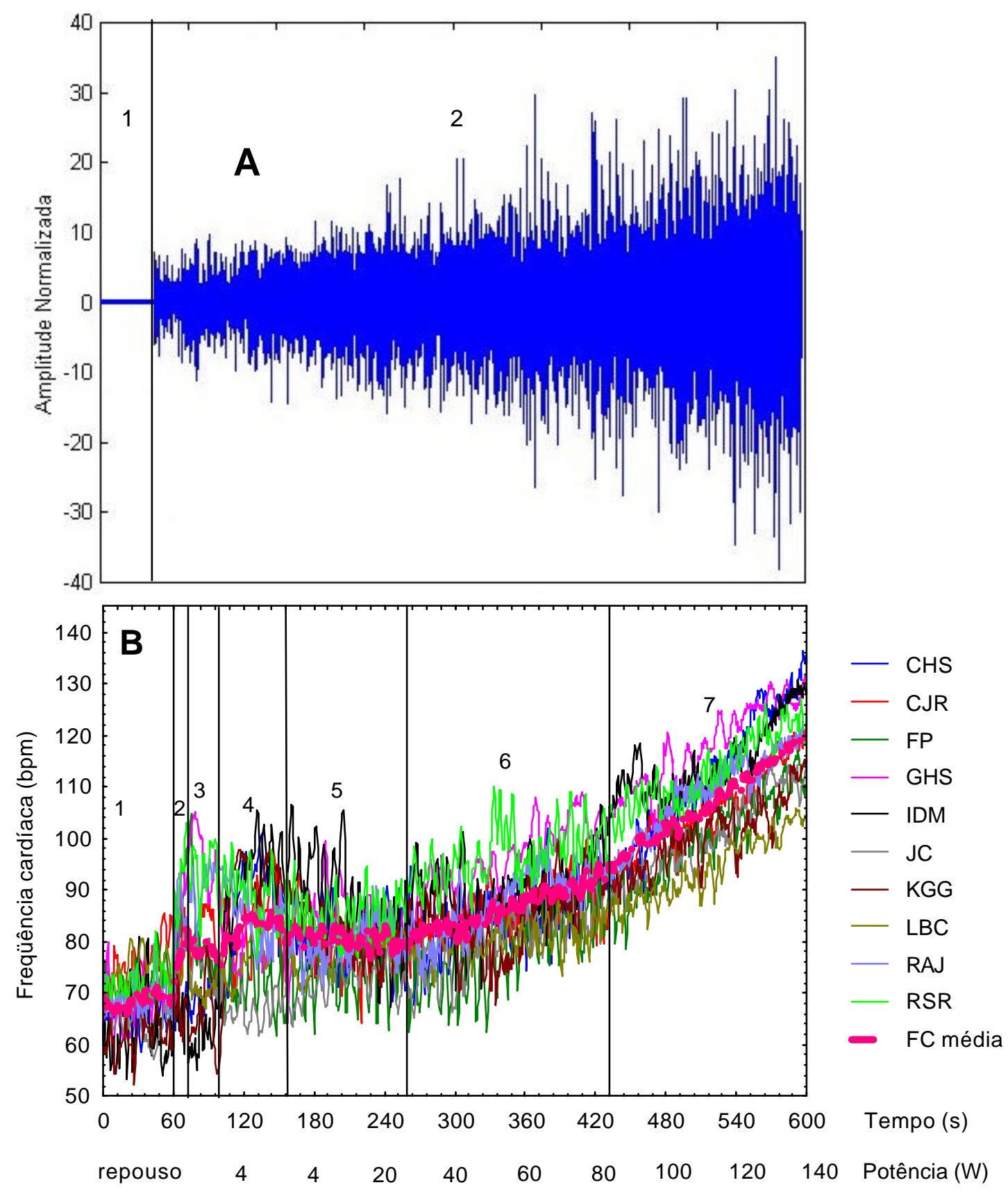

FIGURA 15 - A: Sinal eletromiográfico (amplitude normalizada) do voluntário FP durante o repouso inicial (1) e na condição de exercício (2). B: Freqüência cardíaca (bpm) registrada batimento a batimento, em tempo real, dos voluntários estudados ( $n=10)$, obtidas durante os $60 \mathrm{~s}$ de repouso (1) pré-exercício. De 2 a 7 representa as fases do comportamento da freqüência cardíaca no período de exercício do TEFDC-R. Em destaque a representação da freqüência cardíaca média entre o repouso e a potência de 140 Watts $(\mathrm{W})$. 
4.5 Análise da freqüência cardíaca, da variabilidade da freqüência cardíaca e do sinal de EMGs no domínio do tempo e correlações entre as variáveis estudadas e os intervalos de potências durante o TEFDC-R.

A figura 16 apresenta os valores de freqüência cardíaca média (bpm) no TEFDC-R. Verifica-se que, com o incremento das potências, ocorre uma elevação da freqüência cardíaca apresentando diferença estatística significante $(p<0,05)$, entre a potência inicial de $4 \mathrm{~W}$ e os intervalos de potências de 55 e 60 W, 75 e 80 W, 95 e 100 W, 115 e 120 W, 135 e 140 W.

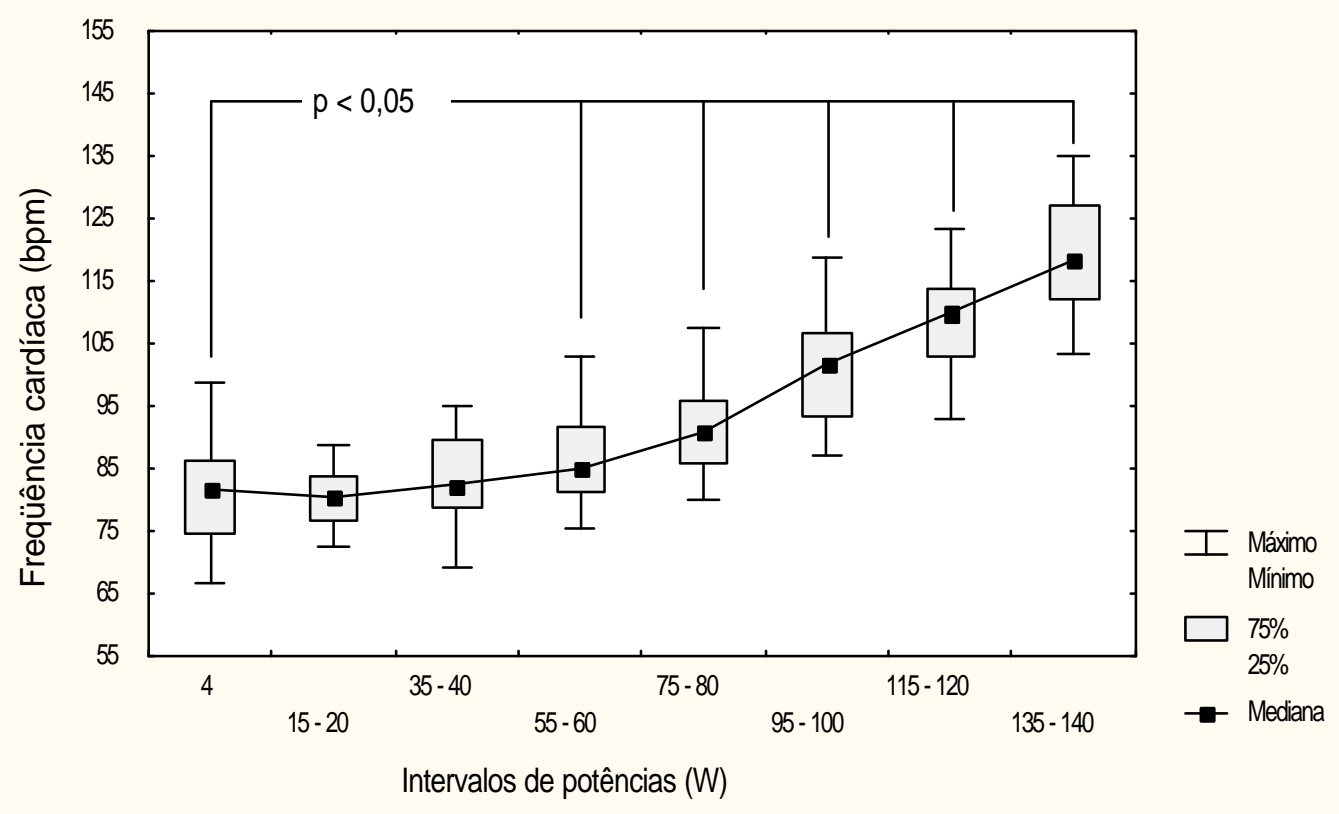

FIGURA 16 - Freqüências cardíacas (bpm) obtidas durante a realização do TEFDC-R na potência de $4 \mathrm{~W}$ e nos intervalos de potências entre 15 e $20 \mathrm{~W}, 35$ e $40 \mathrm{~W}, 55$ e $60 \mathrm{~W}, 75$ e 80 W, 95 e $100 \mathrm{~W}, 115$ e $120 \mathrm{~W}, 135$ e $140 \mathrm{~W}$ dos voluntários estudados $(n=10)$. Nível de significância $\alpha=0,05$ 
A figura 17 apresenta os valores do índice de variabilidade da freqüência cardíaca, RMSSD dos iR-R (ms), na potência de $4 \mathrm{~W}$ e os valores obtidos nos intervalos entre 15 e 20 W, 35 e 40 W, 55 e 60 W, 75 e 80 W, 95 e 100 W, 115 e 120 W, 135 e 140 W dos voluntários estudados $(n=10)$. Verifica-se que, com o incremento das potências, ocorre um decréscimo dos índices de RMSSD, apresentando diferença estatisticamente significante $(p<0,05)$, entre o intervalo de potência de $4 \mathrm{~W}$ em relação aos intervalos de 55 e 60 W, 75 e 80 W, 95 e 100 W, 115 e 120 W, 135 e 140 W.

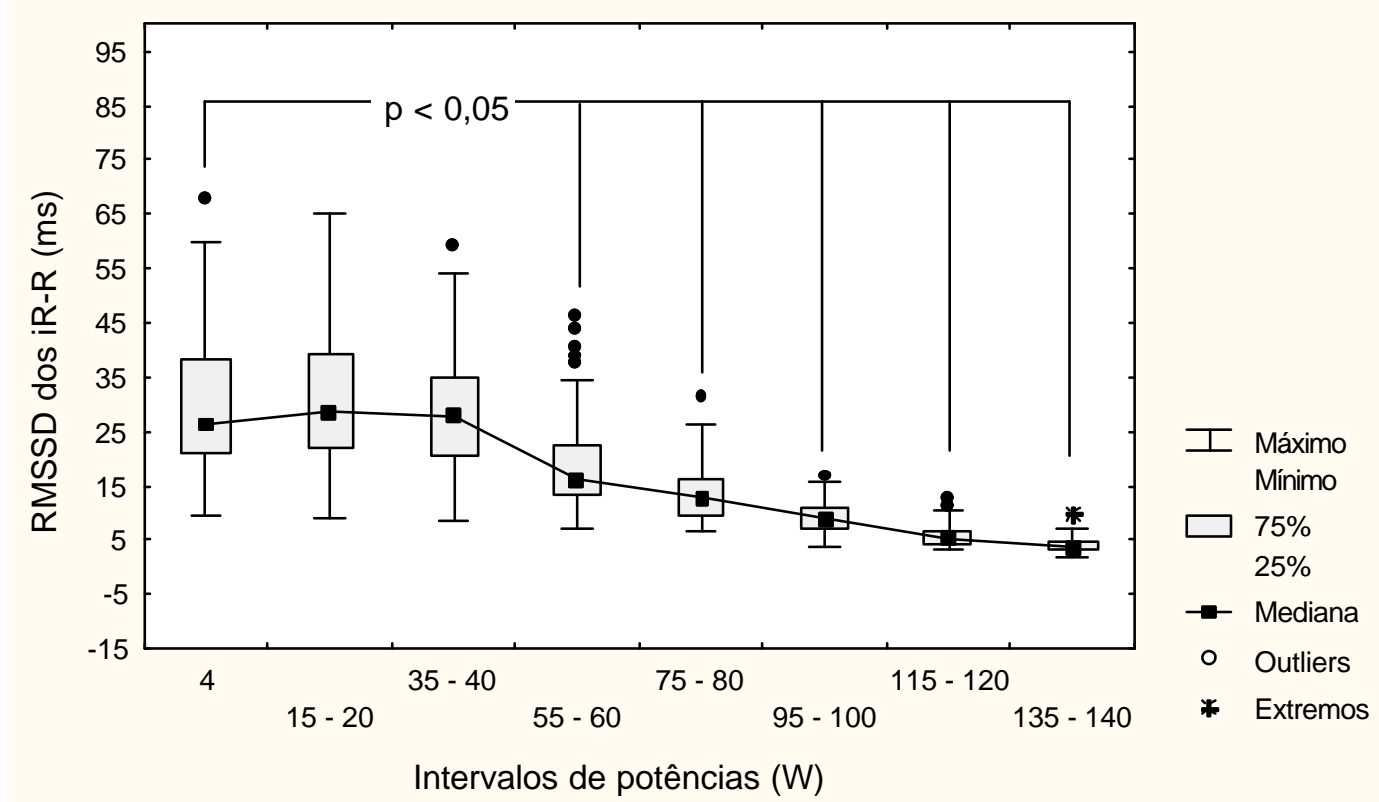

FIGURA 17 - Índices do RMSSD obtidos dos iR-R (ms) durante a realização do TEFDC-R na potência de $4 \mathrm{~W}$ e nos intervalos de potências entre15 e $20 \mathrm{~W}, 35$ e $40 \mathrm{~W}, 55$ e $60 \mathrm{~W}, 75$ e $80 \mathrm{~W}, 95$ e $100 \mathrm{~W}, 115$ e $120 \mathrm{~W}, 135$ e $140 \mathrm{~W}$ dos voluntários estudados $(n=10)$. Nível de significância $\alpha=0,05$ 
Na figura 18 encontram-se os valores do índice RMS da EMGs $(\mu \mathrm{V})$ na potência de $4 \mathrm{~W}$ e os valores calculados nos intervalos entre $17 \mathrm{e}$ $20 \mathrm{~W}, 37$ e $40 \mathrm{~W}, 57$ e $60 \mathrm{~W}, 77$ e $80 \mathrm{~W}, 97$ e $100 \mathrm{~W}, 117$ e $120 \mathrm{~W}, 137$ e 140 W dos voluntários estudados $(n=10)$. Verifica-se que, com o incremento das potências, ocorre um aumento do RMS apresentando diferença estatística significante $(p<0,05)$, entre a potência inicial de $4 \mathrm{~W}$ e os intervalos de 57 e $60 \mathrm{~W}, 77$ e $80 \mathrm{~W}, 97$ e $100 \mathrm{~W}, 117$ e $120 \mathrm{~W}, 137$ e $140 \mathrm{~W}$.

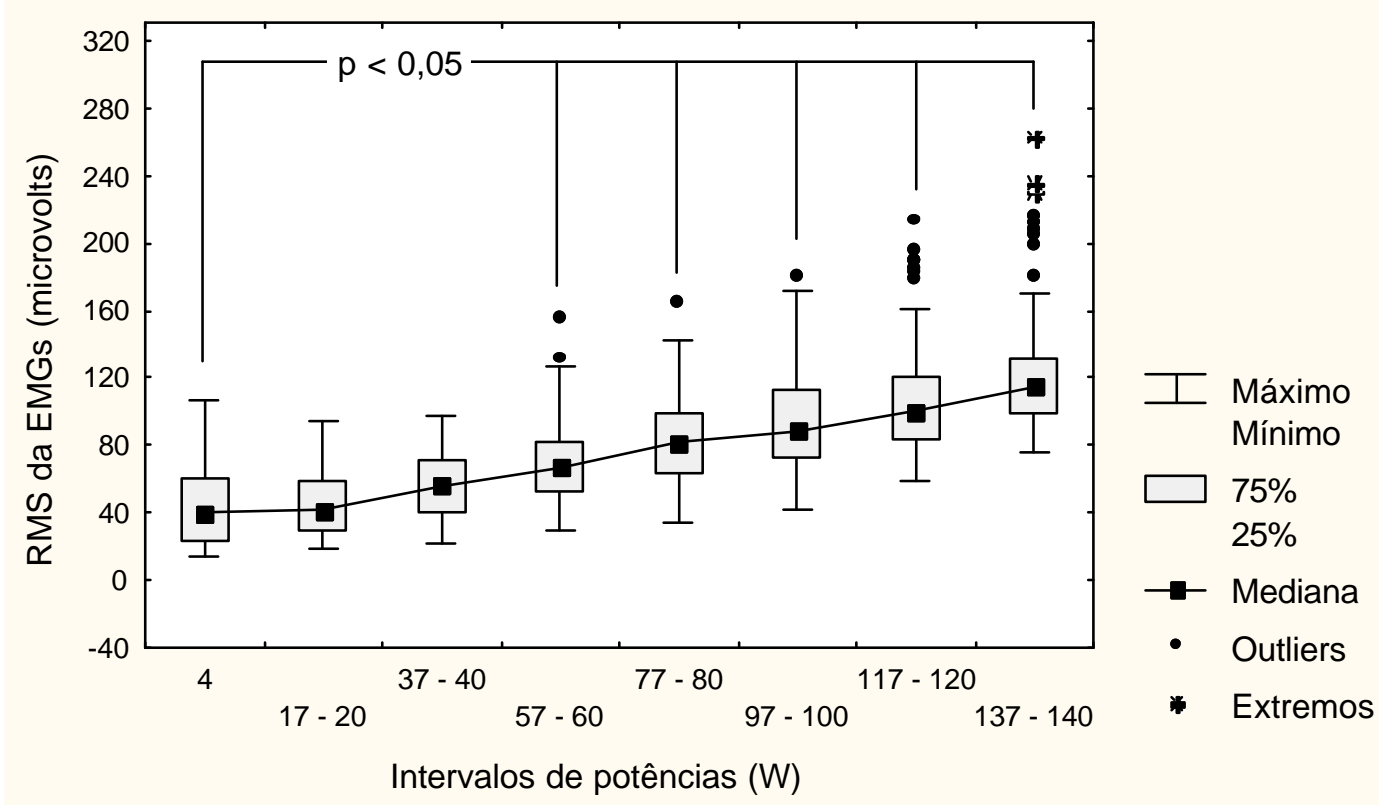

FIGURA 18 - Índices de RMS da amplitude da EMGs, em $\mu \mathrm{V}$, durante a realização do TEFDC-R na potência de $4 \mathrm{~W}$ e nos intervalos de potências entre 17 e $20 \mathrm{~W}, 37$ e $40 \mathrm{~W}, 57$ e $60 \mathrm{~W}, 77$ e $80 \mathrm{~W}, 97$ e $100 \mathrm{~W}, 117$ e $120 \mathrm{~W}, 137$ e $140 \mathrm{~W}$ dos voluntários estudados $(n=10)$. Nível de significância $\alpha=0,05$ 


\subsection{Correlação entre freqüência cardíaca, variabilidade da} freqüência cardíaca e a eletromiografia de superfície.

Para a realização das análises de correlações foram calculadas médias entre os 10 valores obtidos do índice de RMS obtendo-se 6 valores para assim serem correspondidos com a freqüência cardíaca (bpm) e o RMSSD dos iR-R (ms). As médias foram realizadas entre os valores das janelas 1 e 2, 3 e 4, 5 e 6, 6 e 7, 8 e 9, 9 e 10.

A figura 19 representa que a correlação negativa entre os índices de RMS e de RMSSD foi $r_{s}=-0,64$ e estatisticamente significante $(\mathrm{p}<0,05)$.

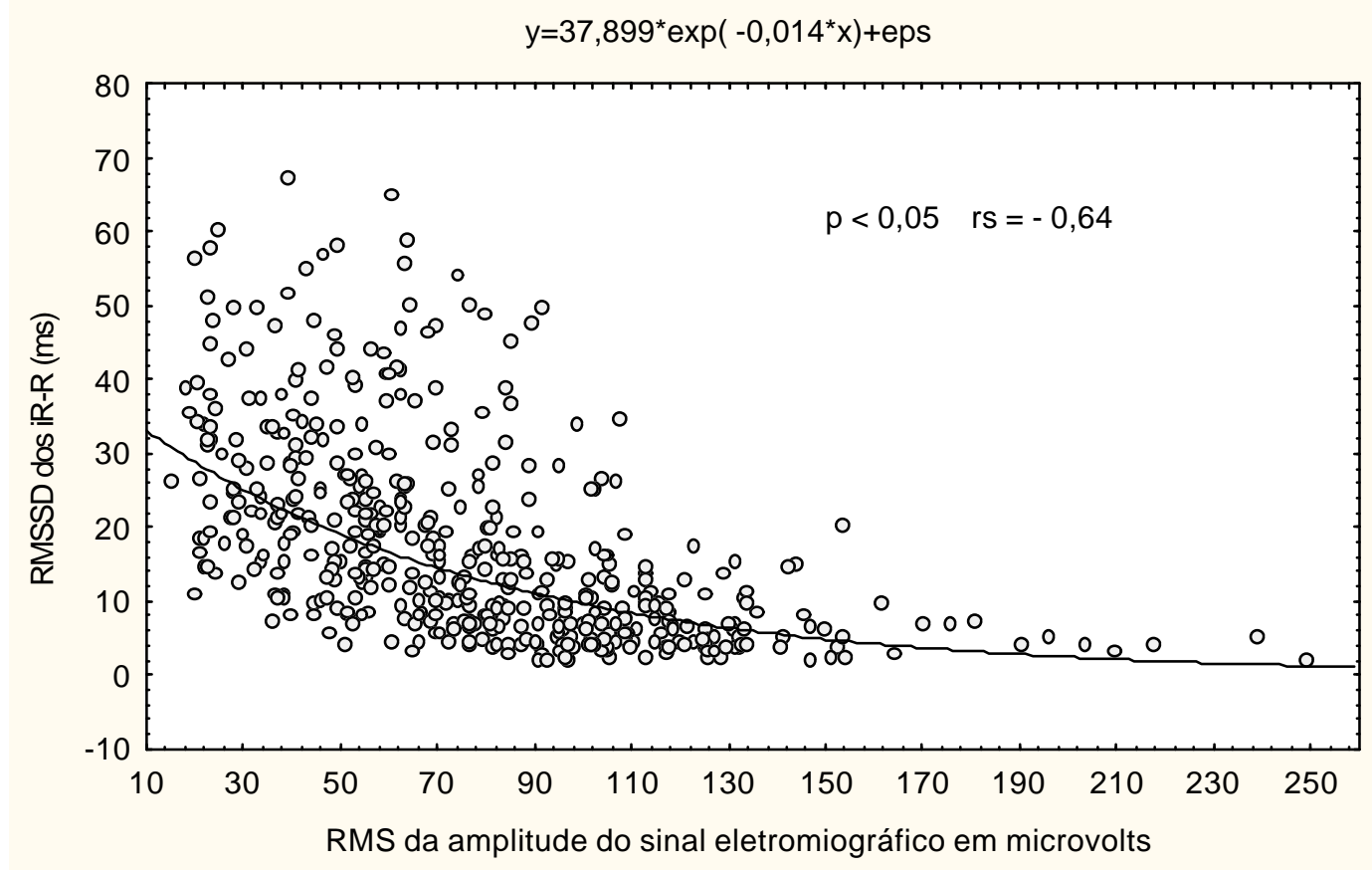

FIGURA 19 - Correlação entre os índices de RMSSD dos iR-R (ms) e do RMS dos sinais eletromiográficos, em $\mu \mathrm{V}$, do músculo vasto lateral, durante $\mathrm{O}$ TEFDC-R dos voluntários estudados ( $n=10)$. Nível de significância $\alpha=0,05$. 
Na figura 20 encontra-se representada a correlação positiva entre o índice de RMS e os valores de freqüência cardíaca (bpm) apresentando $r_{s}=0,61$ e estatisticamente significante $(p<0,05)$.

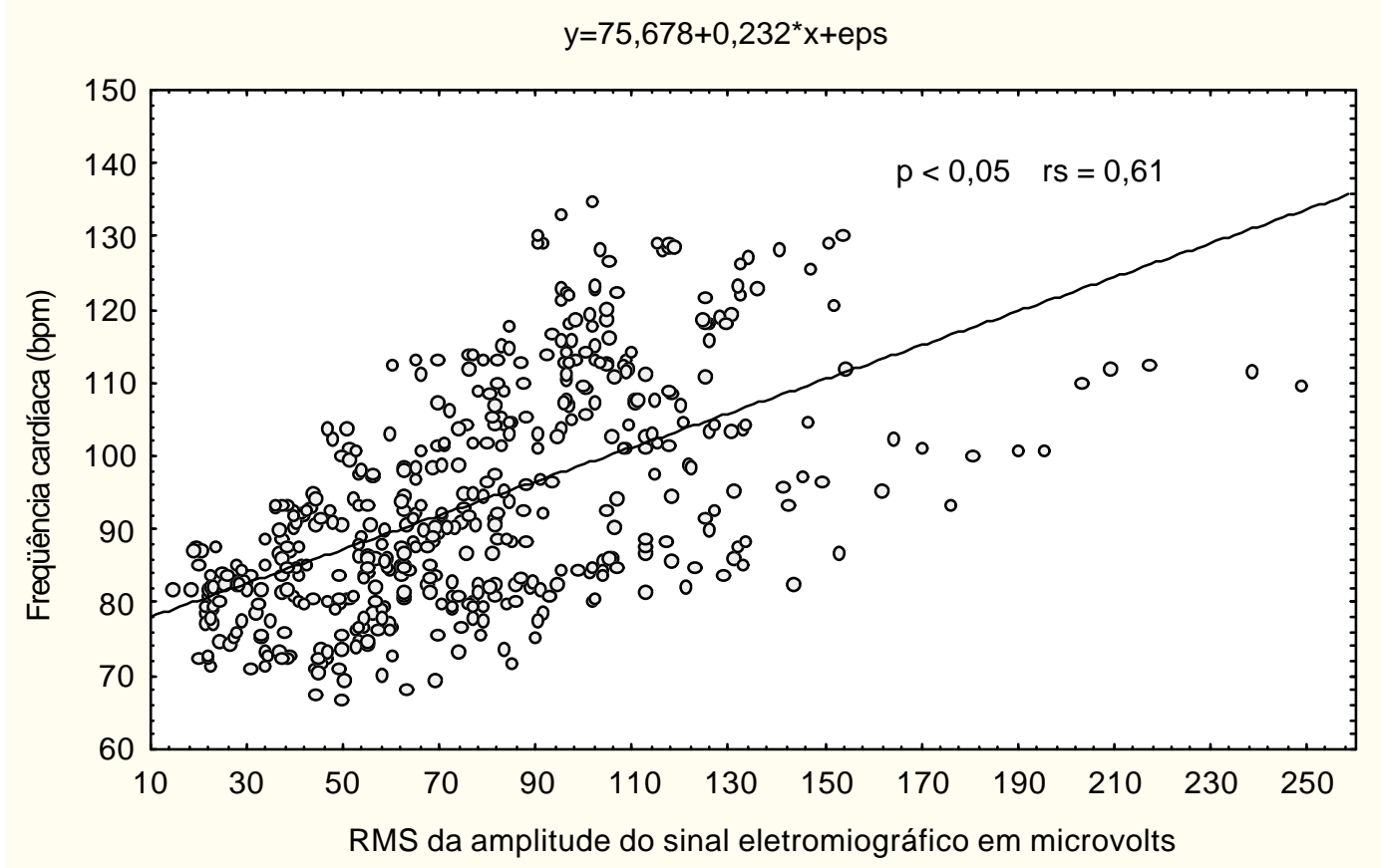

FIGURA 20 - Correlação entre a freqüência cardíaca (bpm) e o índice de RMS dos sinais eletromiográficos, em $\mu \mathrm{V}$, do músculo vasto lateral, durante 0 TEFDC- $R$ dos voluntários estudados $(n=10)$. Nível de significância $\alpha=0,05$.

A figura 21 representa a correlação negativa, com $r_{s}=-0,76$ e estatisticamente significante $(p<0,05)$, entre o índice de RMSSD dos iR-R (ms) e a freqüência cardíaca (bpm). 
$y=693,647^{*} \exp \left(-0,042^{*} x\right)+e p s$

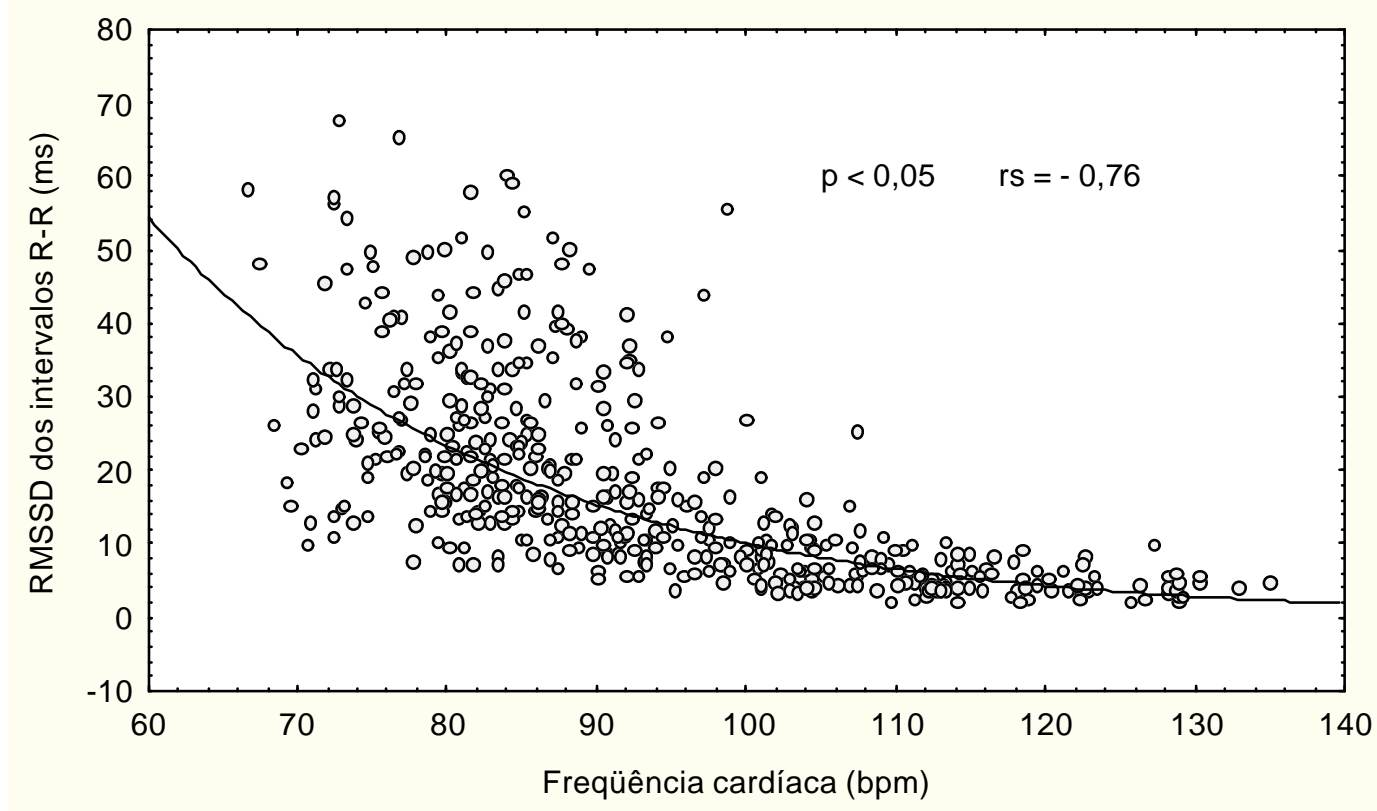

FIGURA 21 - Correlação entre a freqüência cardíaca (bpm) e o índice RMSSD dos iR-R (ms) durante o TEFDC-R dos voluntários estudados $(n=10)$. Nível de significância $\alpha=0,05$.

\subsection{Análise dos dados de RMSSD e RMS normalizados}

A figura 22 apresenta os dados dos índices de RMSSD dos iR-R (ms) e do RMS da amplitude dos sinais de EMGs $(\mu \mathrm{V})$ em valores normalizados pela proporcionalidade em relação ao maior valor mediano do conjunto de dados. Verifica-se ainda pelo ajuste do método dos mínimos quadrados ao conjunto de dados que ocorre uma diminuição mais acentuada da VFC associada ao aumento da atividade muscular a partir do intervalo de potência entre 55 e $60 \mathrm{~W}$. 


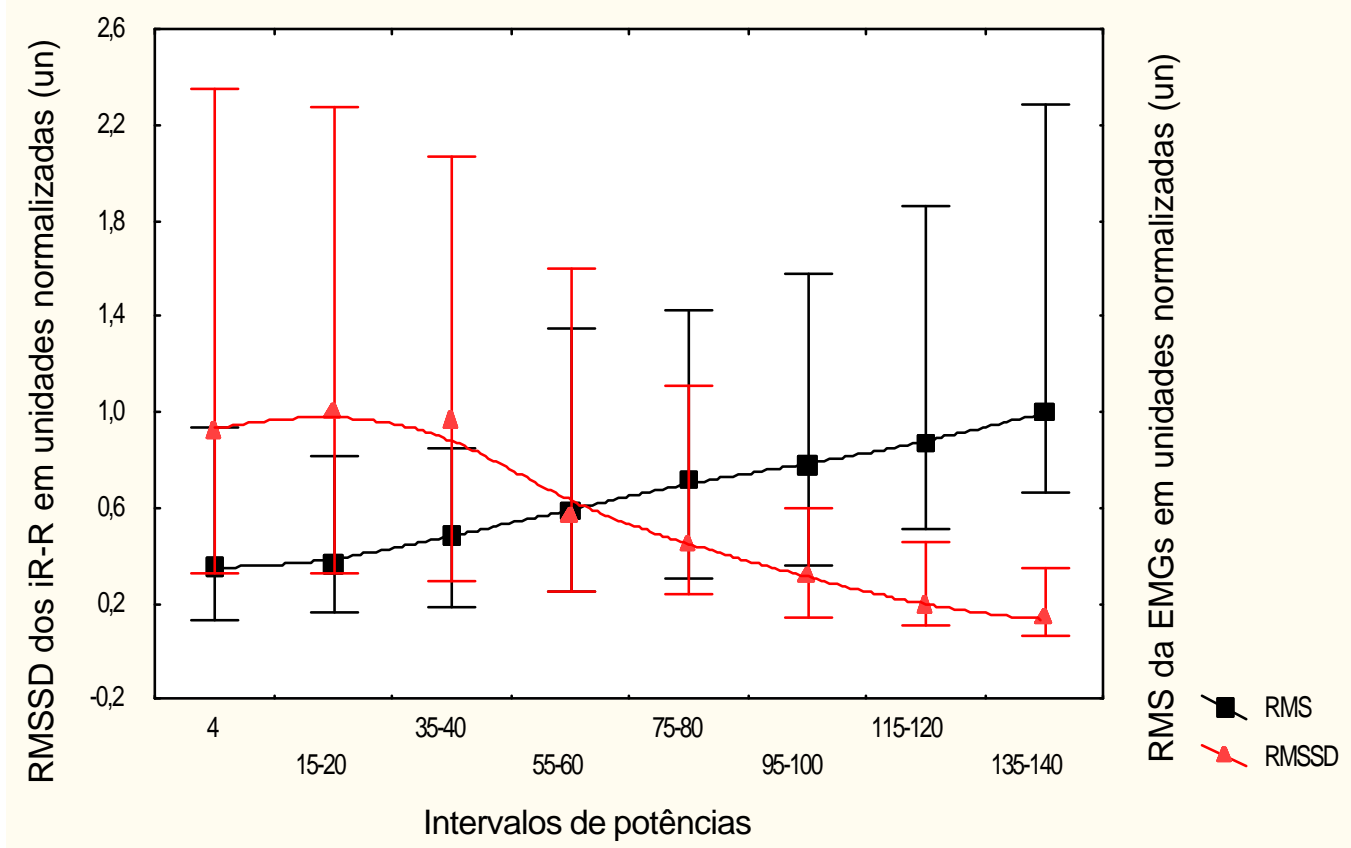

FIGURA 22 - Ajuste do método dos mínimos quadrados ao conjunto de dados proporcionalizados em relação aos valores máximos medianos da série de RMSSD dos iR-R (ms) e dos RMS dos sinais de EMGs $(\mu \mathrm{V})$ obtidos nos intervalos de potências de 4W, 15 a 20W, 35 a 40 W, 55 a 60W, 75 a 80 W, 95 a $100 \mathrm{~W}, 115$ a $120 \mathrm{~W}$ e de 135 a $140 \mathrm{~W}$ do TEFDC$R$, dos voluntários estudados $(n=10)$. 


\section{DISCUSSÃO}

As respostas fisiológicas dos sistemas orgânicos, tanto em repouso como durante o exercício físico, são fortemente influenciadas por vários fatores, tais como: idade, sexo, nível de aptidão física, estado de saúde, hábitos relativos ao consumo de bebida alcoólica, fumo, condições ambientais (temperatura, umidade relativa do ar, pressão barométrica e altitude), influência da respiração, ciclo circadiano, posição corporal, características antropométricas, tipo e duração do exercício realizado, entre outros (BEVERGARD et al., 1967; MOOLGAARD et al., 1991; GALLO JR et al., 1995; SILVA, 1998; TULPPO et al., 1998; SILVA et al., 2000; SILVA et al., 2001). Assim, a presente investigação foi conduzida com critérios padronizados para minimizar as influências dos fatores citados.

Tanto a freqüência cardíaca como a pressão arterial controle e o ECG obtidos em repouso (tabela 4) e durante o TEFDC-D, apresentam-se dentro dos valores previstos tanto para a idade como para a classificação do nível de aptidão cardiorrespiratória. 


\subsection{Comportamento da freqüência cardíaca e de sua} variabilidade nas condições de repouso

Os valores médios dos iR-R (ms) apresentados no presente estudo (supino: $961,46 \pm 79,96$; sentado: 876,98 $\pm 107,20$ ), encontram-se próximos a faixa de normalidade para homens adultos jovens ativos apresentados por GOLDSMITH et al. (1992). Os autores relatam que para sedentários o valor é de 678 ms e para atletas de 1017 ms. Em relação ao índice RMSSD dos iR-R (ms), MIGLIARO et al. (2001) estudando jovens ativos com idade compreendida entre 15 e 20 anos, relatam que o índice foi de 49,0 $\pm 29 \mathrm{~ms}$. Este valor é próximo ao mediano encontrado em nossa investigação que foi de 56,48 ms. Por outro lado, os nossos valores são superiores aos encontrados por PITZALIS et al. (1996) que estudaram homens e mulheres jovens saudáveis, com idade média de $28 \pm 2$ anos, e observaram que os valores de RMSSD dos iR-R (ms), avaliados na posição supina em 3 dias diferentes com intervalo de 15 dias entre a primeira e a segunda coleta e de 210 dias entre a primeira e a terceira, foram respectivamente $33,9 \pm 9,3$; $34,4 \pm 10,1$ e $34,4 \pm 7,2$. Os autores analisaram os dados dos 2 grupos em conjunto e não relatam se os voluntários eram sedentários ou ativos, dificultando assim, a comparação com os nossos resultados.

Com relação à freqüência cardíaca (bpm), esta apresenta uma faixa de normalidade em repouso compreendida entre 60 e 80 bpm (FOSS et al., 2000). Os valores encontrados no presente estudo situam-se dentro desta faixa com média de $63,33 \pm 5,72$ bpm e é próximo ao valor apresentado por MIGLIARO et al. (2001) que foi, em média, de 65,1 $\pm 13,2$ bpm. 
A freqüência cardíaca média (bpm), encontrada no presente estudo, na condição de repouso supino apresentou valores inferiores quando comparada à sentada, já o índice RMSSD dos iR-R (ms) no repouso apresentou maiores valores em supino apontando uma VFC aumentada nesta condição. Ambos com diferença estatisticamente significante $(p<0,05)$.

Tem sido referido que na condição de repouso tanto o vago quanto o simpático encontram-se tonicamente ativos com uma predominância vagal (MALIANI et al., 1991; GREORIE et al., 1996; CHACON-MIKAHIL et al., 1998; MARÃES, 1999). Essa predominância pode ser observada a partir da diminuição dos valores de freqüência cardíaca associada ao aumento da VFC e, segundo STEIN et al. (1999), índices no domínio do tempo utilizados para avaliar a VFC, dentre eles o RMSSD dos iR-R (ms), refletem a modulação vagal sobre o nó sinusal.

Os dados de freqüência cardíaca média, apresentados, concordam com outros encontrados na literatura que investigaram voluntários jovens saudáveis (MARÃES, 1999; SILVA et al., 2001). Os dados referentes ao índice RMSSD dos iR-R (ms) são concordantes a SILVA et al., (2001) e não estão de acordo com os dados de MARÃES (1999) que não apresentaram diferença significante entre as posições estudadas, sugerindo que a mudança de postura não influenciou na modulação vago-simpática. Já nossos resultados, sugerem que a modulação autonômica sobre o coração sofre influência da atuação da gravidade sobre as diferentes posições. 
A mudança postural altera a dinâmica cardiovascular e desencadeia mecanismos reflexos cardiovasculares que podem ser utilizados para estudos das respostas autonômicas cardiovasculares (ROBINSON, 1966).

Quando o indivíduo passa da posição supina para a posição ereta ou sentada, ocorre uma redistribuição do fluxo sangüíneo e parte deste vai para os membros inferiores onde ocorre uma dilatação progressiva das veias localizadas nos mesmos o que reduz o débito cardíaco. BEVERGARD et al. (1967), descrevem que na posição supina em repouso, o volume de ejeção é quase máximo, em contraste, a força da gravidade na posição ereta age contrariando o fluxo de retorno do sangue para o coração (retorno venoso), resultando em menor volume de ejeção e conseqüentemente uma redução momentânea do débito cardíaco e, para que ocorra o ajuste adequado no débito cardíaco a freqüência cardíaca aumenta.

\subsection{Comportamento da freqüência cardíaca e de sua variabilidade e} da atividade muscular na condição de exercício durante o TEFDC-R.

$\mathrm{Na}$ literatura não foram encontrados em um mesmo experimento estudos envolvendo concomitantemente as 3 variáveis estudadas por nós, mas sim, as mesmas avaliadas em diferentes estudos.

Nossos resultados referentes a freqüência cardíaca no início e com o decorrer do exercício físico progressivo do tipo rampa, são concordantes com os resultados apresentados em outros estudos tanto com os realizados em esteira (CONCONI et al., 1982; ZACHAROGIANNIS et al., 1993) como em bicicleta (ALONSO et al., 1998; CATAl, 1999; HOFMAN et al., 2001; 
LUCÍA et al., 2002). No início do exercício ocorre um acentuado aumento da freqüência cardíaca que é atribuído à diminuição da estimulação vagal sobre o nó sinusal (GALLO JR et al., 1995; PIERPONT et al., 2000; FOSS et al., 2000). Após esse período, verifica-se um decréscimo da freqüência cardíaca (figura $15 \mathrm{~B}$ ) que pode estar associado com a retomada vagal. O período que se segue é notada uma elevação mais lenta da freqüência cardíaca com o decorrer do exercício. Tal comportamento tem sido denominado componente lento da freqüência cardíaca e, vem sendo atribuído a uma menor atuação vagal associada a uma predominância do sistema simpático sobre a modulação do coração (GALLO JR. et al., 1987; CATAl, 1999; MARÃES, 1999).

No que se refere à resposta da VFC durante o TEFDC-R, nossos resultados, apresentam uma diminuição da VFC da transição do repouso para o exercício físico dinâmico e torna-se mais acentuada com o incremento de potência. Resultados estes similares aos de SILVA et al. (2001) que observaram que a diferença significante ocorre entre as potências de 4 e $80 \mathrm{~W}$. Já neste estudo a diferença foi entre as potências de $4 \mathrm{~W}$ e os intervalos entre 55 e $60 \mathrm{~W}$. ALONSO et al. (1998), estudando homens jovens e saudáveis em exercício físico dinâmico em cicloergômetro com protocolo progressivo em degrau, também referem resultados semelhantes quanto ao comportamento da VFC e fazem menção que a diminuição mais acentuada da mesma teve coincidência com o limiar de anaerobiose. OSTERHUES et al. (1997), sugerem que tal diminuição se 
deve ao predomínio da atividade simpática sobre o nódulo sinusal e, conseqüentemente sobre a modulação da VFC.

Quanto a atividade muscular, avaliada a partir do índice RMS da amplitude do sinal de EMGs em $\mu \mathrm{V}$, nossos dados concordam com outros estudos que utilizaram exercício físico dinâmico progressivo em cicloergômetro (PETROFSKY, 1979; NAGATA et al., 1981; MIYASHITA et al., 1981; SHINOHARA et al., 1997; JAMMES et al., 1997 e 1998) bem como, com os que utilizaram protocolo de exercício descontínuo (VITASSALO et al., 1985). Estes autores referem haver um aumento linear da amplitude do sinal eletromiográfico e uma perda nesta linearidade (aumento abrupto) a partir de um certo nível de trabalho imposto. JAMMES et al. (1997), estudando homens jovens, descrevem que o RMS apresentou a perda da linearidade com correlação significativa $(r s=0,81, p<0,05)$ com a ocorrência do limiar de anaerobiose, obtido a partir do método ventilatório. NAGATA et al. (1981) também encontraram uma não linearidade na curva EMGs integrada / trabalho realizado, dados esses concordantes com os de MORITANI et al. (1980). Estes autores reportam que este achado também foi coincidente com o limiar de anaerobiose. Já, SEBURN et al. (1992), avaliaram a EMGs e o lactato plasmático de 6 ciclistas treinados durante exercício progressivo em cicloergômetro, e relatam não ter ocorrido perda da linearidade do sinal e, conseqüentemente, sugerem que a EMGs não é um método capaz para determinar o limiar de anaerobiose. GLASS et al. (1997), estudando ciclistas não encontraram correlação entre o limiar anaeróbio ventilatório e os limiares obtidos pela EMGs e pela concentração de lactato. 
Já, alguns autores associam a perda de linearidade do sinal eletromiográfico com o recrutamento de diferentes tipos de fibras musculares. PETROFSKY (1979), analisando a EMGs do músculo vasto lateral, relata que a referida perda de linearidade deve-se provavelmente a uma associação entre o aumento do recrutamento e a freqüência de disparo das UMs das fibras musculares do tipo II. Tal combinação, segundo o autor, pode estar associada a um esgotamento progressivo das fibras musculares de contração lenta (tipo l) em altas cargas de trabalho, com isso, é necessário que esses aumentos ocorram para que auxiliem na manutenção do trabalho exigido. GAMET et al. (1993), descrevem que as UMs responsáveis pelo recrutamento das fibras musculares do tipo I são ativadas primeiro porém, as fibras musculares do tipo II são ativadas gradualmente com o incremento dos níveis de força.

MYIASHITA et al. (1981) estudaram mulheres jovens e saudáveis durante exercício físico com incremento de potência do tipo degrau em cicloergômetro e referem que a EMGs é um método que reflete a atividade das fibras musculares e, é esperado que o sinal apresente uma alteração quantitativa quando o limiar de anaerobiose é alcançado pois, a partir desse momento ocorre um maior recrutamento das fibras musculares do tipo II que se utilizam de fonte energética anaeróbia.

Apesar destas informações, nossos dados não são suficientes para suportar a idéia de que o incremento brusco da amplitude do sinal eletromiográfico pode representar a ocorrência do limiar de anaerobiose pelo motivo de que a metodologia empregada no presente estudo não tinha como 
intuito determinar o limiar de anaerobiose já que não foram realizadas coletas de variáveis que identificassem o mesmo, por exemplo, a dosagem de lactato sangüíneo e/ou a análise de variáveis metabólicas ventilatórias.

Com o intuito de ajustar as demandas metabólicas durante a contração muscular impostas pelo exercício físico, algumas variáveis hemodinâmicas apresentam elevação dentre elas a freqüência cardíaca (ZACHAROGIANNIS et al., 1993; CONCONI et al., 1982; ALONSO et al.,1998). Alguns autores (FRANKLIN et al., 1980; ALONSO et al., 1998; MC ARDLE et al.,1998; LUCíA et al., 2000) referem que a freqüência cardíaca realmente apresenta uma relação proporcional ao $\mathrm{VO}_{2}$ durante a realização de exercício dinâmico progressivo. Os músculos ativos necessitam de suprimento adequado de $\mathrm{O}_{2}$ para realizar a quebra de ATP e produzir energia necessária para a realização da contração muscular. Além do que, no exercício físico dinâmico ocorre um aumento progressivo do recrutamento de fibras musculares em atividade e este é proporcional ao nível de trabalho imposto (PETROFSKY, 1979; NAGATA et al., 1981; SHINOHARA et al., 1997; JAMMES et al., 1997; JAMMES et al., 1998).

Assim, analisando-se de forma conjunta as variáveis estudadas desde o início da contração muscular, observada pelo estudo da atividade do músculo vasto lateral, ocorre uma concomitante elevação rápida da freqüência cardíaca com diminuição de sua variabilidade e com o decorrer do TEFDC-R estas variáveis apresentaram mudanças em suas respostas em intervalos próximos de potências, sendo entre 55 e $60 \mathrm{~W}$ para a freqüência cardíaca (bpm) e o RMSSD e entre 57 e 60 para o RMS, 
demonstrando assim uma interação em suas respostas frente ao exercício físico. Esta interação entre as respostas musculares e cardiovasculares deve-se ao fato de o comando central enviar sinais de comando motor, originados em neurônios subtalâmicos, envolvidos com a contração muscular no início do exercício. Estes sinais ativam em paralelo ambos os sistemas, cardiovascular e muscular, de forma proporcional ao nível de trabalho imposto (MITCHELL et al., 1983; ROWELL, 1992; FOSS et al., 2000).

Já, no que se refere às mudanças nas respostas hemodinâmicas em um determinado nível de esforço, ROWELL et al. (1990) e ROWELL (1990) relatam que em baixas intensidades de exercício os quimiorreceptores musculares parecem não estarem tonicamente ativos bem como não há evidência que demonstre o aumento da atividade simpática existindo um equilíbrio entre oferta e demanda metabólica. Mas os mesmos quimiorreceptores podem explicar parte do aumento da atuação simpática durante o exercício quando tal equilíbrio é alterado como, por exemplo, em níveis moderados e altos de potências onde ocorre acúmulo de lactato a nível muscular e acidez metabólica (WASSERMAN et al., 1999).

Tal processo está associado à ação das fibras aferentes dos grupos III e IV cuja principal função é o envio de informações concernentes às alterações mecânicas (mecanoreceptores) e metabólicas (metaboloreceptores) ocorridas, a nível muscular, para o sistema nervoso central para que este organize os ajustes necessários. Estes estímulos informam, em paralelo, a área de controle cardiovascular, localizada no 
bulbo, e esta por meio do sistema nervoso autônomo e seus eferentes simpático e parassimpático vão modular o coração ajustando a freqüência cardíaca de acordo com a demanda metabólica imposta aumentando o número de batimentos cardíacos quando necessário (MITCHELL et al., 1983; ROWELL et al., 1990; HANON et al., 1998). Este aumento na demanda pode estar relacionado a ordem do recrutamento das UMs e a freqüência de disparo das fibras musculares, ou seja, se fibras musculares do tipo I ou II estão mais ativadas. Alguns autores (PETROFSKY, 1979; MYIASHITA et al., 1981; GAMET et al., 1993) sugerem que com o incremento de potência durante o exercício físico dinâmico ocorre um aumento do recrutamento das fibras musculares do tipo II com o objetivo de manter o nível de trabalho exigido. Com isso, ocorre um aumento da demanda metabólica, relacionado ao recrutamento adicional de fibras musculares, e um incremento gradativo da freqüência cardíaca, com conseqüente diminuição de sua variabilidade atribuída à diminuição da atividade parassimpática e da predominância da ativação do simpático sobre a modulação do coração (GALLO JR et al., 1995; MARÃES, 1999). 


\section{CONCLUSÕES}

A partir da análise do conjunto de dados obtidos no presente estudo, nas condições experimentais empregadas, os nossos resultados sugerem que:

\subsection{Condição de repouso}

Nossos dados sugerem que houve uma alteração no balanço vagosimpático com predominância vagal na posição supina quando comparada com a sentada.

\subsection{Condição de exercício}

A partir da inspeção visual gráfica detectourse um aumento inicial rápido da freqüência cardíaca no início do exercício que pode ser atribuído a retirada da atuação do componente parassimpático sobre a modulação autonômica do coração.

O aumento da freqüência cardíaca com concomitante redução da VFC, associado ao incremento de potência, é atribuído a menor participação da atuação vagal e um predomínio da atividade simpática sobre o nó sinusal. 
O aumento gradativo e significante da amplitude do sinal da EMGs está relacionado ao maior recrutamento de fibras musculares que pode ser atribuído ao início da fadiga muscular.

De uma forma geral nossos resultados mostram a associação entre o incremento de potências durante o exercício físico com o aumento do recrutamento de fibras musculares com concomitante aumento da freqüência cardíaca e diminuição da VFC. Essa associação é atribuída tanto ao comando de controle central como dos mecanismos reflexos periféricos, ativados a partir das aferências das fibras musculares do grupo III (ergoceptores) e do grupo IV (metaboloreceptores). Sugerindo o trânsito de informações advindos do córtex motor ativando as fibras musculares e paralelamente à área cardiovascular, modulando o sistema nervoso autonômico do coração. 


\section{REFERÊNCIAS BIBLIOGRÁFICAS}

Referências elaboradas conforme NBR 6023 de agosto de 2000, Associação Brasileira de Normas e Técnicas.

AKSELROD, S.,; GORDON, D.; UBEL, F.A.; SHANNON, D.C.; BARGER, A. C.; CONEN, R.J. Power spectrum analysis of heart rate fluctuation: a quantitative probe of beat-to-beat cardiovascular control. Science 213(10): 220-22, 1981.

ALONSO, D. O.; FORJAZ, C. L. M.; REZENDE, L. O.; BRAGA, A. M. F. W.; BARRETO, A. C. P.; NEGRÃO, C. E.; RONDON, M. U. P. B. Comportamento da freqüência cardíaca e de sua variabilidade durante diferentes fases do exercício físico progressivo máximo. Arquivos Brasileiros de Cardiologia, v. 17, n. 6, p. 787-792, 1998.

ANTILA, K. Quantitative characterization of heart rate during exercise. Scandinavian Jour. of Cl. And Lab. Invest. Suplementum, 13-58, Turku, Finland, 1979.

ARNAUD, S.; ZATTARA-HARTMANN, M. C.; TOMEI, C.; JAMMES, Y. Correlation between muscle metabolism and changes in m-wave and surface electromyogram: dynamic constant load leg exercise in untrained subjects. Muscle \& Nerve. 20: 1197-1199.

BEVEGARD, G.E.P., SHEPHERD, J.T. Regulation of the circulation during exercise in man. Physiology Review. v.47, p.178-208, 1967.

BASMAJIAN, J. V., DE LUCA, C.,J., Muscles alive, their functions revealed by electromyography, $5^{\text {a }}$ edição, 1985.

BROOKS, G.A., Current concepts in lactate exchange. Med. Sci. Sports Exerc., 23: 895-906, 1991.

BURDEN, A. \& BARTLETT, R. Normalisation of EMG amplitude: na evaluation and comparison of old and new methods. Medical Engineering \& Physics, 21, p.247-257, 1999. 
CATAI, A.M. Estudo da capacidade aeróbia e da variabilidade da freqüência cardíaca em homens jovens e de meia-idade submetidos à treinamento físico aeróbio. 1999. 301 f. Tese (Doutorado em Biologia)-Instituto de Biologia, Universidade Estadual de Campinas. Campinas, SP.

CATAI, A.M.; CHACON-MIKAHIL, M. P. T.; MARTINELLI, F. S.; FORTI, V. A. M.; SILVA, E.; GOLFETTI, R.; MARTINS, L. E. B.; SZRAJER, J. S.; WANDERLEY, J. S.; LIMA-FILHO, E. C.; MILAN, L. A.; MARIN-NETO, J. A.; MACIEL, B. C.; GALLO-JÚNIOR, L. Effects of aerobic exercise training on heart rate variability during wakefulness and sleep and cardiorespiratory responses of young and middle-aged healthy men. Brazilian Journal of Medical and Biological Research, 35, 741-752, 2002.

CHACON-MIKAHIL, M.P.T.; FORTI, V.A.M.; CATAI, A.M.; SZRAJER, J.S.; GOLFETTI, R.; MARTINS, L.E.B.; LIMA-FILHO, E.C.; WANDERLEY, J.S.; MARIN NETO, J. A.; MACIEL, B.C.; GALLO-JÚNIOR, L. Cardiorespiratory adaptations induced by aerobic training in middle-aged men: the importance $f$ a decrease in sympathetic stimulation for the contribution of dynamic exercise tachycardia. Brazilian Journal of Medical and Biological Research, 31, 705-712, 1998.

CONCONI, F.; FERRARI, M.; ZIGLIO, P.G.; DROGHETI, P. and CODECA, L. Determination of the Anaerobic Threshold by Noninvasive Field Test in Runners. J. Apl. Physiol. Envir. Exerc. Physiol., 52(4), p. 869-873, 1982.

DE LUCA, C.J.; LeFEVER, R.S.; McGUE, M.P.; XENAKIS, A.P. Control scheme governing concurrently active human motor units during voluntary contractions. J. Physiol., 329, p. 129-142, 1982.

DE LUCA, C.J. \& ERIM, Z. Common drive of motor units in regulation of muscle force. Trends Neurosci, 17, p. 299-305, 1994.

FOSS, M. L.; KETEYIAN, S. J. Controle cardiorrespiratório. In: Fox: bases fisiológicas do exercício e do esporte. Tradução: Giusepe Taranto. Rio de Janeiro: Guanabara Koogan, 2000. 6ª edição, p. 226-241.

FRANKLIN, B.; HODGSON, J.; BUSKIER, E. R. Relationship between percent maximal $\mathrm{O}_{2}$ uptake and percent maximal heart rate in women. Research Quarterly for Exercise and Sport, v. 51, n. 4, p.616-624.

FREITAS, A. F. Sistema nervoso autônomo e aparelho cardiovascular: um paradigma de auto-organização, complexidade e caos. Rev. Port. Cardiol., 19(2), p. 161-191, 2000.

GALLO JR., L.; MACIEL, B. C.; MARIN NETO, J. A.; MARTINS, L. E. B.; LIMA FILHO, E. C.; GOLFETTI, R.; CHACON, M. P. T.; FORTI, V. A. M. 
Control of heart rate during exercise in health and disease. Braz. J. Med. Biol. Res., 28, p. 11-12, 1995.

GALLO JR., L.; MORELO FILHO, J.; MACIEL, B. C.; MARIN NETO, J. A.; MARTINS, L. E. B.; LIMA FILHO, E. C. Functional Evaluation of Sympathetic and Parasympathetic System in Chagas' Disease Using Dynamic Exercise. Cardiovascular Research, p. 922-927, 1987.

GAMET, D.; DUCHENE, J.; GARAPON-BAR; GOUBEL, F. Surface electromyogram power spectrum in human quadriceps muscle during incremental exercise. Journal Applied Physiology, 74 (6), p. 2704-2710, 1993.

GLASS, C.; KNOLWLTON, R. G.; SANJABI, P. B.; SULLIVAN, J. J. The effect of exercise induced glycogen depletion on the lactate, ventilatory and electromyographic thresholds. The Journal of Sports Medicine and Physical Fitness, 37: 32-40, 1997.

GOUVÊA, E. C. CATAI, A. M., SILVA, E., OLIVEIRA, L. MILAN, L. A., GALLO Jr. Implementação e incorporação dos módulos de análise de dados e emissão de relatórios ao sistema computacional de eletrocardiografia de esforço. Anais do V Congresso de Iniciação Científica da UFSCar (CICUFSCar), 1998, São Carlos. Anais eletrônicos. São Carlos: UFSCar, 1998.

GOLDSMITH, R. L.; BIGGER, J. T. JR; STEINMAN, R. C.; FLEISS, J. L. Comparasion of 24-hour parasympathetic activity in endurance-trained and untrained young men. Journal American College Cardiology, 20 (3): 552-8, 1992.

GREGOIRE, J.; TUCK, S.; YAMAMOTO, Y.; HUGHSON, R.L. Heart rate variability at rest and exercise: influence of age, gender, and physical training. Can. J. Apl. Physiol., 21-6:455-470, 1996.

HANON, C.; THÉPAUT-MATHIEU, C.; HAUSSWIRTH, C.; LE CHEVALIER, $\mathrm{J}$. M. Electromyogram as an indicator of neuromuscular fatigue during incremental exercise. European Journal Applied Physiology, 78, p.315-323, 1998.

HOFMANN, P.; VON DUVILLARD, S.P.; SEIBERT, F.J.; POKAN, R.; WONISH, M.; LEMURA, L. M.; SCHWABERGER. \% HR max target rate is dependent on heart rate performance curve deflection. Medicine \& Science in Sports \& Exercise, 33 (10): 1726-1731, 2001.

JAMMES, Y., CAQUELARD, F., BADIER, M. Correlation between surface electromyogram, oxygen uptake and blood lactate concentration during dynamic leg exercises. Respiration Physiology, 112, p. 167-174, 1998. 
JAMMES, Y., ZATTARA-HARTMANN, M. C., CAQUELARD, F., ARNAUD, S., TOMEI, C. Electromyographic changes in vastus lateralis during dynamic exercise. Muscle \& Nerve, 20, p. 247-249, 1997.

KALIA, M., MEI, S.S., KAO, F.F. Central projections from ergoceptors (C fibers) in muscle involved in cardiopulmonary responses to static exercise. Circ. Res., 48(6):I48-I62 (Suppl. I), 1981.

LINDQUIST, A. Noninvasive methods $b$ study autonomic nervous control of circulation. Acta Phys. Scand., 138: 21-22, 1990.

LONGO, A.; FERREIRA, D.; CORREIA, M.J. Variabilidade da freqüência cardíaca. Rev. Port. Cardiol., 14(3), p. 241-262, 1995.

LUCÍA, A.; HOYOS, J.; PÉREZ, M.; CHICARRO, J. L. Heart rate and performance parameters in elite cyclists: a longitudinal study. Medicine \& Science in Sports \& Exercise, v. p. 1777-1782, 2000.

LUCÍA, A.; HOYOS, J.; SANTALLA, A.; PÉREZ, M.; CARVAJAL, A.; CHICARRO, J. L. Lactic acidosis, potassium, and the heart rate deflection point in professional road cyclists. Br. J. Sports Medicine, 36, p. 113-117, 2002.

MACIEL, B.C.; GALLO Jr., L.; MARIN-NETO, J.A.; LIMA FILHO, E.C. and MARTINS, L.E.B. Autonomic Nervous Control of the Herat Rate During Dynamic Exercise in Normal Man. Clinical Science, v. 71, 457-460, 1986.

MAHLER, D. A.; FROELICHER, V. F.; MILLER, N. H.; YORK, T. D. Cálculos metabólicos: apêndice D. In: Manual do ACMS para teste de esforço e prescrição de exercício. Tradução: Paulo Chermont P. Estima. Rio de Janeiro: Revinter, 2000. 5ª edição. p. 237-250.

MALLIANI, A.; LOMBARDI, F.; PAGANI, M.; CERUTTI, S. Cardiovascular eural regulation explored in the frequency domain. Circulation, v. 84 (2) p. 482-492, 1991.

MARÃES, V.R.F.S. Estudo da variabilidade da freqüência cardíaca durante o exercício físico dinâmico em voluntários sadios. 1999. Dissertação (Mestrado)-Instituto de Biologia, Universidade Estadual de Campinas, Campinas.

MARTINELLI, F.S. Respostas da freqüência cardíaca e da pressão arterial sistêmica às manobras posturais passiva e de valsalva, em indivíduos sedentários e atletas corredores de longa distância. 1996. Dissertação (Mestrado)-Faculdade de Educação Física, Universidade Estadual de Campinas, Campinas. 
MANTEIKA, J. H.; DUFFIN, JAMES. The ventilation, lactate ande electromyographic thresholds during incremental exercise tests in normoxia, hypoxia and hyperoxia. Eur. J. Appl. Physiol., 69, p. 110-118, 1994.

MATSUMOTO, T., ITO, K., MORITANI, T. The relationship between anaerobic threshould and electromyographic fatigue threshold in college women. Eur. J. Apl. Physiol. Occup. Physiol., v. 63, 1, p. 1-5, 1991.

McARDLE, W. D.; KATCH, F. I.; KATCH, V. L. Diferenças individuais e mensurações das capacidades energéticas. In: Fisiologia do exercício: energia, nutrição e desempenho humano. Tradução: Giusepe Taranto. Rio de Janeiro: Guanabara Koogan, 1998. 4ª edição. p. 181-205; 148-159.

MIGLIARO, E. R.; CONTRERAS, P.; BECH, S.; ETXAGIBEL, A.; CASTRO, M.; RICCA, R. VICENTE, K. Relative ifluence of age, resting heart rate and sedentary life style in short-term analysis of heart rate variability. Brazilian Journal of Medical and Biological Research, 34, p. 493-500, 2001.

MILNER-BROWN, H.S.; STEIN, R.B.; YEMM, R. The orderly recruitment of human motor units during voluntary isometric contraction. J. Physiol., 230, p. 371-390, 1973.

MITCHELL, J.H., KAUFMAN, M.P., IWAMOTO, G.A. The exercise pressor reflex: its cardiovascular effects, afferent mechanisms, and central pathways. Ann. Rev. Physiology, 45:229-242, 1983.

MIYASHITA, M.; KANEHISA, H.; NEMOTO, I. EMG related to anaerobic threshold. J. sports Med, 21, p. 209-217, 1981.

MOLGAARD, H., SORENSEN, K. E. \& BJERREGAARD, P. Circadian variation and influence of risk factors on heart rate variability in healthy subjects. Am. J. Cardiol. v. 68, p. 777-784, 1991.

MORITANI, T \& DE VRIES, H. A. Anaerobic threshold determination by surface electromyography. Med. Sci. Sport, 12 (2), 86, 1980.

MORITANI, T. \& YOSHITAKE, Y. The use of electromyography in applied physiology. Journal of Electromyography and Kinesiology. V. 8, n. 6, p.363381, 1998.

NAGATA, A.; MURO, M.; MORITANI, T.; YOSHIDA, T. Anaerobic threshold determination by blood lactate and signals myoelectric. Japanese Journal of Physiol, 31, p. 585-597, 1981.

O'SULLIVAN, S.; THOMAS, J.S. Reabilitação Física: avaliação e tratamento. São Paulo: Manole, 1993. $2^{\mathrm{a}}$ edição. p. 183-223. 
OSTERHUES, HH.; HANZEL, S. R.; KOCHS, M.; HOMBACH, V. Influence of physical activity on 24-hour measurements of heart rate variability in patients with coronary artery disease. Am. J. Cardiol. v. 80, pp. 1434-1437, 1997.

OLIVEIRA, L. BARCELLOS, S.R., CIONE, M.A., FERREIRA, V.C.,LIPORONE, M.A., CATAI, A.M., MARTINS, L.E.B., TREVELIN, L.C., GALLO JR., L., SILVA, E. Sistema computacional para a captação e processamento em tempo real de sinais de eletrocardiograma. Anais da XI Reunião Anual da Federação de Sociedades de Biologia Experimental FESBE, Caxambu, MG, p. 317, 1996.

PETROFSKY, J. S. Frequency and amplitude analysis of the EMG during exercise on the bicycle ergometer. European Journal Applied Physiology, 41 p. $1-15,1979$.

PIERPONT, G. L.; STOLPMAN, D. R.; GORNICK, C. C. Heart rate recovery post-exercise as an index of parasympathetic activity. Journal of the Autonomic Nervous System, 80, p. 169-174, 2000.

PITZALIS, M. V.; MASTROPASQUA, F.; MASSARI, F.; FORLEO, C.; DI MAGGIO, M.; PASSANTINO, A.; COLOMBO, R.; DI BIASE, M.; RIZZON, P. Short - and long - term reproducibility of time and frequency domain heart rate variability measurements in normal subjects. Cardiovascular Research, 32, 226-233, 1996.

POWERS, S. K., HOWLEY, E. T. Fisiologia do exercício: teoria e aplicação ao condicionamento e ao desempenho. Tradução Marcos lkeda. São Paulo: Manole, 2000. $1^{\mathrm{a}}$ edição. p.107-124; p.151-176.

RIBEIRO, T.F. Avaliação da modulação autonômica da atividade eferente do coração pela variabilidade da freqüência cardíaca em mulheres sedentárias em repouso e em exercício físico. 106 f. 2001. Dissertação (Mestrado em Fisioterapia)-Centro de Ciências Biológicas e da Saúde, Universidade Federal de São Carlos, São Carlos.

RIBEIRO, T. F.; CUNHA, A.; LOURENÇO, G. C. D.; MARÃES, V. R. F. S.; CATAI, A. M.; GALLO JR, L.; SILVA, E. Estudo da variabilidade da freqüência cardíaca em dois voluntários de meia idade, um coronariopata e outro saudável: relato de caso. Revista da Sociedade de Cardiologia do Estado de São Paulo, v. 10, n. 1 (supl. A), 2000.

ROBINSON, B. F.; EPSTEIN, S. E.; BEISER, G. D.; BRAUNWALD, E. Control of heart rate by autonomic nervous system: studies in man on the interrelation between baroreceptor mechanisms and exercise. Circulation Research, v. XIX, p. 400-411, 1966. 
ROWELL, L. B. Human circulation: regulation during physical stress. Oxford University Press, 1를 Edição, New York, 1986.

ROWELL, L. B.; O' LEARY, D. S. Reflex control of the circulation during exercise: chemoreflexes and mechanoreflexes. Journal Applied Physiology, 69 (2), p. 407-418, 1990.

ROWELL, L. B. Reflex control of the circulation during exercise. International Journal of Sports and Medicine, v. 13, suppl 1, p. S25-S27, 1992.

SEBURN, K. L.; SANDERSO, D. J.; BELCASTRO, A. N.; MCKENZIE, D. C. Effect of manipulation of plasma lactate on integrated EMG during cycling. Medicine and Science in Sports and Exercise, 24: (8), p 911-916, 1992.

SHINOHARA, M.; KOUZAKI, M.; YOSHIHISA, T.; FUKUNAGA, T. Mechanomyography of the human quadriceps muscle during incremental cycle ergometry. European Journal Applied Physiology, 76, p. 314-319, 1997.

SILVA, C. S.; NOGUEIRA, E. C. V.; MARQUES, L. S.; TEIXEIRA, L. C. A.; CATAI, A. M.; OLIVEIRA, L.; GOUVEAA, E. C.; GALLO Jr, L.; SILVA, E. Influência circadiana na modulação da variabilidade da freqüência cardíaca em repouso e durante esforço físico dinâmico. Anais da XV Reunião Anual da Federação de Sociedades de Biologia Experimental - FeSBE, p. 197, Caxambu-MG, 2000.

SILVA, C.S.; MARQUES, L. S.; MORAES, F. R.; CATAI, A. M.; OLIVEIRA, L.; SILVA, E. Investigação da variabilidade da freqüência cardíaca de mulheres nos períodos manhã e noite. Revista Brasileira de Fisioterapia, v.5, n. 2, p. 65-71, 2001a.

SILVA, C. S.; MORAES, F. R.; GARCIA, A. P. U.; CATAI, A. M.; SILVA, E. Resposta da variabilidade da freqüência cardíaca (VFC) e da eletromiografia de superfície (EMGs) durante esforço físico dinâmico em cicloergômetro. Anais da XVI Reunião Anual da Federação de Sociedades de Biologia Experimental - FeSBE, p. 390, Caxambu-MG, 2001b.

SILVA, E.; CATAI, A.M.; TREVELIN, L.C.; GUIMARÃES, J.O.; SILVA Jr., L.P.; SILVA, L.M.P.; OLIVEIRA, L.; MILAN, L.A.; MARTINS, L.E.B.; GALLO Jr., L. Design of a computerized system to evaluate the cardiac function during dynamic exercise. Annals of the World Congress on Medial Phys. and Biom. Engineering, v. 1, p. 419, RJ, 1994.

SILVA, E. Influência do exercício isométrico nas respostas da freqüência cardíaca e eletromiográficas no homem. 1998. 139 f. Tese (Doutorado em Ciências)-Instituto de Biologia, Universidade Estadual de Campinas, Campinas. 
SKINNER e MACLELLAN (1980). The transition from aerobic to anaerobic metabolism. Research Quarterly for Exercise and Sport. v. 51. n.1, p. $234-$ $248,1980$.

SMITH, J.J.; KAMPINE, J.P. Regulation of arterial blood pressure. In: Circulatory physiology - the essentials. $3^{\circ}$ edição. Baltimore: Willians \& Wilkins. Cap 10, p. 161-180, 1990.

STEIN, P. K.; KLEIGER, R. E. Insights from the study of heart rate variability. Annual Rev. Med., 50, p.249-261, 1999.

TANJI, J., KATO, M. Recruitment of motor units in voluntary contraction of a finger muscle in man. Exp. Neurol., 40, p. 771-783, 1973.

TASK FORCE of the European Society of Cardiology and the North American Society of Pacing and Electrophysiology. Heart rate variability standards of measurement, physiological interpretation, and clinical use. Circulation, v. 93 p. 1043-1065. 1996.

TULLPO, M. P., MÄKIKALLIO, T. M., SEPPÄNEN, T., LAUKKANEN, R. T.\& HUIKURI, H. V. Vagal modulation of heart rate during exercise: effects of age and physical fitness. Am. J. Physiol., v. 274 (Heart Circ. Physiol. 43), pp. H424-H429, 1998.

VITASSALO, J. T.; LUHTANEN, P.; RAHKILA, P.; RUSKO, H. Electromyographic activity related to aerobic and anaerobic threshold in ergometer bicycling. Acta Physiol Scand, 124, p.287-293, 1985.

WASSERMAN, K.; HANSEN, J.E.; SUE, D.; WHIP, B.J.; CASABURI, R. Principles of exercise testing and interpretation. Editora LEA \& FEBIGER, $3^{\text {a }}$ edição, 1999.

ZACHAROGIANNIS, E.; FARRALY, M. Ventilatory threshold, heart rate deflection point and middle distance running performance. The Journal of Sports Medicine and Physical Fitness. V. 33, n.4, p.337-347, 1993 


\title{
8 APÊNDICES
}

\subsection{Apêndice 1}

Parecer de aprovação do Comitê de Ética e Pesquisa (CEP) da Universidade Federal de São Carlos (UFSCar).

\author{
UNIVERSIDADE FEDERAL DE SÃO CARLOS \\ PRÓ - REITORIA DE PÓS - GRADUAÇÃO E PESQUISA \\ COORDENAÇĀO DE PESQUISA \\ COMITÊ DE ETICA EM PESQUISA
}

O Comitê de Ética em Pesquisa (CEP) da UFSCar, registrado no CONEP/Conselho Nacional de Saúde, pelo ato de 18 de março de 1997, DELIBEROU aprovação sem restriçōes o projeto com protocolo $n^{\circ} 086$ e título: "DETERMINAÇĀo DO LIMIAR DE ANAEROBIOSE A PARTIR DA VARIABILIDADE DA FREQUÊNCIA CARDIACA, DA ELETROMIOGRAFIA E DE VARIÁVEIS VENTILATÓRIAS E METABÓLICAS DE HOMENS DURANTE TESTE DE ESFORÇO FÍSICO DINÅMICO" de autoria de Profa. Dra. Ester da Silva.

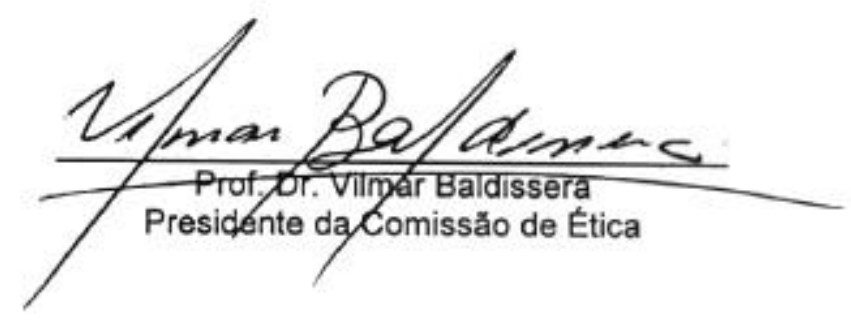




\subsection{Apêndice 2}

Análise da modulação autonômica do coração em repouso e atividade eletromiográfica relacionada a variabilidade da freqüência cardíaca durante exercício dinâmico em cicloergômetro.

\section{Responsáveis:}

Orientadora: Profa. Dra. Ester da Silva

Pesquisador: Cristiano Sales da Silva

$\mathrm{Eu}$,

portador do RG n..: residente a Rua:

n.. :

Bairro:

Cidade:

Estado:

concordo em participar do projeto de pesquisa proposto pelo Fisioterapeuta e pesquisador Cristiano Sales da Silva.

A pesquisa tem por finalidade observar a modulação das atividades simpática e parassimpática do coração, através da resposta da freqüência cardíaca ( $\mathrm{FC}$ ), bem como a atividade mioelétrica do músculo vasto lateral, durante exercício físico dinâmico submáximo em cicloergômetro eletromagnético.

Antes do início do teste em questão, serei submetido a uma avaliação constando de anamnese, exame físico e postural e eletrocardiograma (ECG) de repouso deitado e sentado com verificação da FC e da pressão arterial, e exames laboratoriais, com o objetivo de detectar possíveis alterações cardiovasculares, musculares ou articulares que contra-indique minha participação na pesquisa.

A sua continuidade dar-se-á com um teste de esforço físico dinâmico contínuo em degraus (TEFDC-D) máximo, realizado com a presença de um médico cardiologista especializado neste procedimento, para a avaliação de minha condição física e cardiovascular. Durante o TEFDC-D, a FC será registrada a 
partir do ECG durante todo o teste. A pressão arterial será mensurada no repouso, ao final de cada potência de exercício e durante a recuperação.

Antes de iniciar os testes, serei instruído sobre os sinais e sintomas que devem me alertar a parar a seqüência do teste; ainda serei observado por uma equipe treinada que estará alerta a qualquer alteração que possa sugerir a interrupção do exercício exigido.

Os benefícios que terei com tais procedimentos incluem a verificação de possíveis alterações eletrocardiográficas associadas com a análise dos exames físico e postural, observando assim, minha situação física. Os testes me possibilitarão reconhecer meus limites fisiológicos durante o exercício dinâmico submáximo, servindo também como parâmetro para treinamento físico que evitem sobrecarga cardiorrespiratória, muscular e articular.

As informações obtidas durante as avaliações e os exames laboratoriais serão mantidos em sigilo e não poderão ser consultados por pessoas leigas sem minha expressa autorização por escrito. As informações assim obtidas, no entanto, poderão ser usadas para fins estatísticos ou científicos, sempre resguardando minha privacidade.

Eu li e entendi as informações precedentes. Além disso, todas as dúvidas que me ocorreram já foram sanadas completamente.

Durante o período de observação científica, estarei ciente da minha condição de inatividade física, não realizando exercícios físicos para, assim, não alterar os resultados do programa proposto.

Comprometo-me, por meio deste, seguir com o programa até sua finalização, visando reconhecer os meus limites orgânicos, além de me desempenhar para a continuidade do estudo proposto, salvo algum problema que possa surgir que me impossibilite de participar.

São Carlos, de de $200 \ldots$. 


\subsection{Apêndice 3}

\section{LABORATÓRIO DE FISIOTERAPIA CARDIOVASCULAR FICHA DE AVALIAÇÃO}

Fisioterapeuta:

Data: ................

Temperatura:

\author{
ThA
}

Umidade ar: $\pi . . \%$
Avaliação número:

Horário: $\mathrm{h}$

\section{I - DADOS PESSOAIS:}

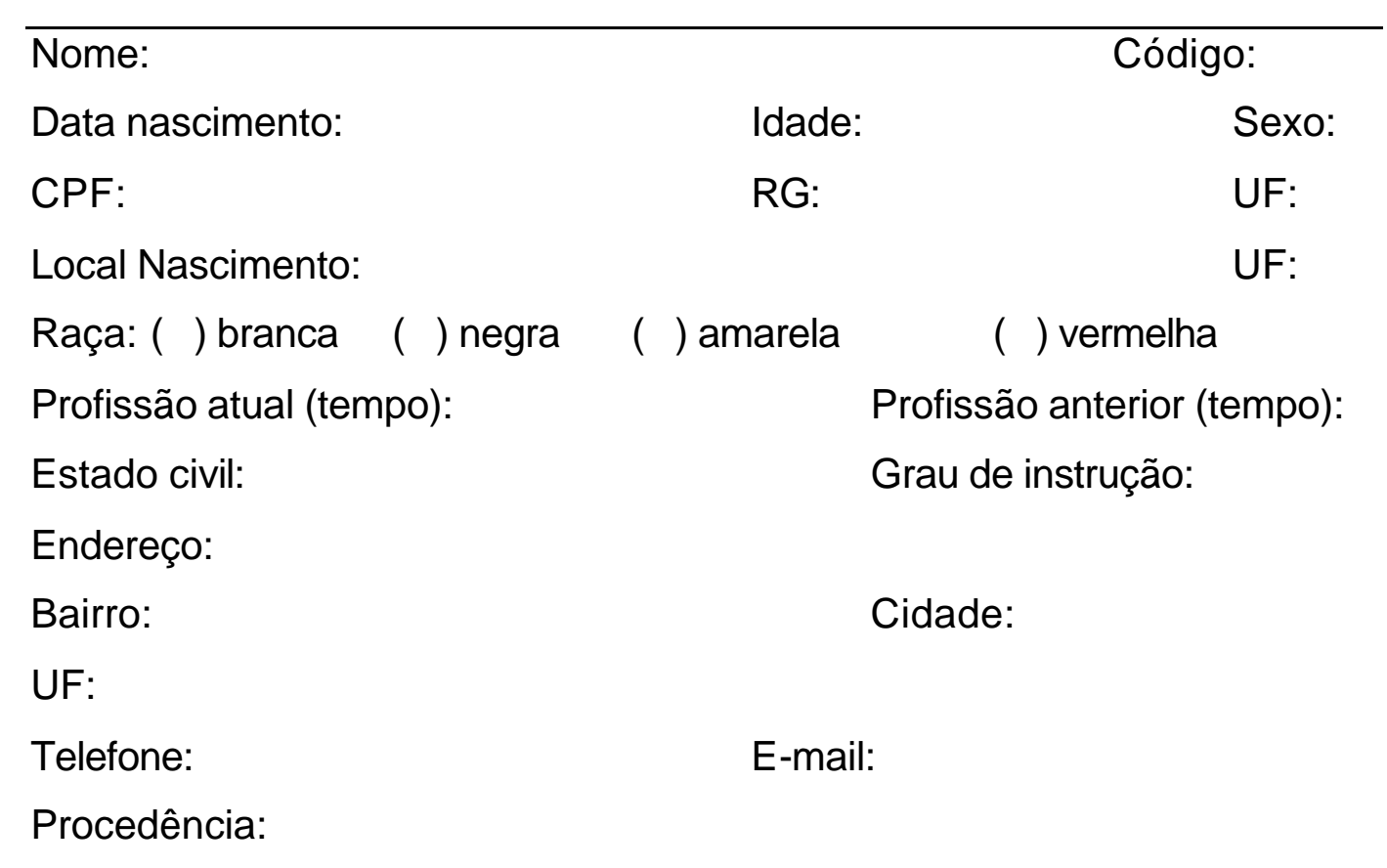

\section{II - ANAMNESE:}

\section{Possui convênio médico?}
( ) $\operatorname{sim}$ Qual?:
( ) não

2. Hábitos de vida:

a) É fumante atualmente?
( ) Sim
Cigarros/dia:
Há quanto tempo?:
( ) Não 
b) Já fumou antes (se a resposta anterior for não)?

( ) Sim Cigarros/dia: Período fumante:

Quando parou?:

( ) Não

c) Ingere bebida alcoólica atualmente?

( ) Sim Que tipo?: ( ) destilados ( ) fermentados

( ) ambos

Quantidade: Freqüência/semana:

Há quanto tempo?:

( ) Não

d) Já ingeriu bebida alcoólica antes (se resposta anterior for não)?

( ) Sim Que tipo?: ( ) destilados ( ) fermentados

( ) ambos

Quantidade: Freqüência/semana:

Há quanto tempo?:

( ) Não

e) Faz algum tipo de dieta alimentar?

( ) $\operatorname{Sim}$ Qual? Há quanto tempo?:

( ) Não

f) Pratica alguma atividade física?

( ) Sim Qual?:

Tem orientação?: Nível: ( ) leve ( ) moderada

( ) intensa ( ) muito intensa

Freqüência semanal:

( ) Não

g) Já praticou alguma atividade física?

( ) Sim Qual?: Por quanto tempo?:

Freqüência semanal: Há quantos anos parou?:

( ) Não

h) Qual nível de stress na profissão? (ou ficha específica)

( ) trabalho normal em ambiente tranqüilo 
( ) trabalho com estresse e preocupações moderadas

( ) trabalho estafante em ambiente estressante

i) Nível de estresse apresentado pelo estilo de vida e tipo de personalidade

( ) Vida normal sem queixas

( ) Sono normal/fisiológico

( ) Problemas conjungais e/ou familiares

( ) sono perturbado com menos de 8 horas por dia

( ) comportamento do tipo "A"

\section{Dados Clínicos:}

a) Tem DCV diagnosticada?

( ) Sim Qual?: Há quanto tempo?: Médico:

( ) Não

b) É hipertenso?

( ) Sim Grau: ( ) limítrofe-140x90 a 160×95

( ) hipertenso - 161×96 a 180x120

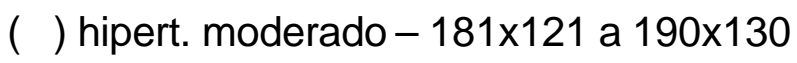

( ) hipertenso grave-maior 191x131

( ) Não

c) Apresenta algum problema musculo-esquelético?

(Obs: quando a resposta for "sim" mencionar local e a data da lesão.)

Fraturas: ( ) não ( ) $\operatorname{sim}$

Luxações: ( ) não ( ) sim

rupturas musculares ( ) não ( ) sim

Instabilidade: ( ) não ( ) sim

Lesões nervosas: ( ) não ( ) sim

Tendinites: ( ) não ( ) sim

Problema de coluna: ( ) não ( ) sim

Dificuldade de movimento: ( ) não ( ) sim

Outros: 
d) Apresenta outras doenças?

\begin{tabular}{|l|l|l|l|}
\hline & \multicolumn{1}{|c|}{ Tipo } & $\begin{array}{c}\text { Há quanto } \\
\text { tempo }\end{array}$ & Tratamento \\
\hline Tireóide & & & \\
\hline Diabetes & & & \\
\hline Dislipidemia & & & \\
\hline Obesidade & & & \\
\hline Renais & & & \\
\hline Pulmonares & & & \\
\hline
\end{tabular}

e) Medicamentos em uso:

\begin{tabular}{|c|c|c|}
\hline Medicamento & Dosagem & Tempo que toma \\
\hline & & \\
\hline & & \\
\hline & & \\
\hline
\end{tabular}

f) Cirurgia
( ) não
( ) sim (quais e data?)

g) Qual o membro dominante?
- Superior:
( ) destro
( ) sinistro
- Inferior:
( ) direito
( ) esquerdo

h) Outras observações a respeito de sua saúde que não foram apresentadas acima:

\section{Antecedentes Familiares}
a) Idade do Pai:
Idade da Mãe:
b) Apresenta antecedentes das seguintes doenças?

\begin{tabular}{|l|l|l|}
\hline & Grau Parentesco & Tipo e/ou Tempo \\
\hline DCV & & \\
\hline Alteração Tireóide & & \\
\hline Diabetes & & \\
\hline Dislipemia & & \\
\hline Obesidade & & \\
\hline Renais & & \\
\hline Pulmonares & & \\
\hline
\end{tabular}




\section{III - EXAME FÍSICO:}

\section{Sinais vitais}

Padrão Respiratório:

( ) apical ( ) costal ( ) diafragmático ( ) paradoxal

PA:.................mmHg FC:........bpm FR:.......jpm TEMP........ ${ }^{\circ} \mathrm{C}$

\section{Exame antropométrico}

Peso corporal $(\mathrm{em} \mathrm{kg})$ : $\quad$ Estatura $(\mathrm{em} \mathrm{cm})$ :

\begin{tabular}{|l|l|l|l|l|l|l|l|l|}
\cline { 2 - 8 } \multicolumn{1}{c|}{} & \multicolumn{3}{c|}{ Diâmetros (ósseos) } & \multicolumn{5}{c}{ PERÍMETROS } \\
\cline { 2 - 9 } \multicolumn{1}{c|}{} & punho & úmero & fêmur & Coxa & Perna & Braço & Antebraço & Tórax \\
\hline Direito & & & & & & & & \\
\hline Esquerdo & & & & & & & & \\
\hline
\end{tabular}

\begin{tabular}{|l|c|c|c|c|}
\hline \multicolumn{5}{|c|}{ MENSURAÇÃO (Membro Inferior) } \\
\hline & Real & Aparente & Schoelmaner & Ângulo Q \\
\hline Direita & & & & \\
\hline Esquerda & & & & \\
\hline
\end{tabular}

\section{Exame fisioterápico}

3.1 - Músculo-esquelético

a) Inspeção e palpação

b) Testes especiais

c) Testes de força muscular (biodex)

\begin{tabular}{|l|c|c|c|c|}
\hline & $\begin{array}{c}\text { Flexão } \\
\text { Joelho }\end{array}$ & $\begin{array}{c}\text { Extensão } \\
\text { Joelho }\end{array}$ & $\begin{array}{c}\text { Flexão } \\
\text { Cotovelo }\end{array}$ & $\begin{array}{c}\text { Extensão } \\
\text { Cotovelo }\end{array}$ \\
\hline Direito & & & & \\
\hline Esquerdo & & & & \\
\hline
\end{tabular}


d) Testes retrações musculares

\begin{tabular}{|c|c|c|}
\hline Direito & Músculos & Esquerdo \\
\hline \multicolumn{3}{|c|}{ Decúbito Dorsal } \\
\hline & Ísquiostibiais & \\
\hline & Peitoral Maior & \\
\hline & Peitoral Menor & \\
\hline & Grande dorsal & \\
\hline & Rotadores Internos & \\
\hline & $\begin{array}{c}\text { Rotadores } \\
\text { Externos }\end{array}$ & \\
\hline & Reto Femoral & \\
\hline & Iliopsoas & \\
\hline \multicolumn{3}{|c|}{ Decúbito Lateral } \\
\hline & Tensor fáscia lata & \\
\hline \multicolumn{3}{|c|}{ Decúbito Ventral } \\
\hline & Quadríceps & \\
\hline \multicolumn{3}{|c|}{ Sentado } \\
\hline & $\begin{array}{l}\text { Paravertebral } \\
\text { lombar }\end{array}$ & \\
\hline \multicolumn{3}{|c|}{ Em pé } \\
\hline & Tríceps sural & \\
\hline & $\begin{array}{c}\text { Trapézio (fibras } \\
\text { superiores) }\end{array}$ & \\
\hline & Angular escapula & \\
\hline & escalenos & \\
\hline
\end{tabular}

e) Relatório Avaliação postural:

\section{2 - Avaliação Cardiológica}

a) ECG repouso

b) Relatório do ECG: 


\begin{tabular}{|l|l|l|}
\hline & PA (mmHg) & FC (bpm) \\
\hline Deitado & & \\
\hline Sentado & & \\
\hline
\end{tabular}

4. Exame Médico:

5. Exames laboratoriais

\begin{tabular}{|c|c|c|c|c|}
\hline \multicolumn{2}{|c|}{ EXAME } & DATA & $\begin{array}{l}\text { VALORES } \\
\text { OBTIDOS }\end{array}$ & $\begin{array}{c}\text { VALORES } \\
\text { REFERÊNCIAS }\end{array}$ \\
\hline \multicolumn{2}{|l|}{ Triglicérides } & & & \\
\hline \multicolumn{2}{|l|}{ Glicemia } & & & \\
\hline \multirow{3}{*}{ Colesterol } & total & & & \\
\hline & LDL & & & \\
\hline & HDL & & & \\
\hline \multicolumn{2}{|l|}{ Urina (tipo I) } & & & \\
\hline \multicolumn{2}{|l|}{ Ácido Úrico } & & & \\
\hline \multicolumn{2}{|l|}{ Creatina } & & & \\
\hline Uréia & & & & \\
\hline
\end{tabular}

6. Exames complementares: 


\subsection{Apêndice 4}

TABELA 1 - Dados da umidade relativa do ar em porcentagem (\%) e temperatura em graus Celsius do laboratório durante a realização do protocolo II (TEFDC-R) dos voluntários estudados $(n=10)$.

\begin{tabular}{ccc}
\hline Voluntário & $\begin{array}{c}\text { Umidade relativa do ar } \\
(\%)\end{array}$ & Temperatura ( Celsius) \\
\hline CHS & 63 & 23,8 \\
CJr & 54 & 23,4 \\
FP & 46 & 24 \\
GHS & 55 & 23,2 \\
IDM & 68 & 23,5 \\
JC & 56 & 23,6 \\
KGG & 68 & 21,6 \\
LBC & 50 & 23,4 \\
RAJ & 52 & 24,5 \\
RSR & 48 & 23,8 \\
\hline Média & 56 & 23,4 \\
Desvio Padrão & 7,8 & 0,7 \\
Mínimo & 46 & 21,6 \\
1ㅇQuartil & 50 & 23,4 \\
Mediana & 54,5 & 23,5 \\
3o Quartil & 63 & 23,8 \\
Máximo & 68 & 24,5 \\
\hline
\end{tabular}




\subsection{Apêndice 5}

TABELA 3 - Dados referentes aos exames laboratoriais: colesterol total, HDL colesterol, LDL colesterol, VLDL colesterol, triglicérides, ácido úrico, creatinina, uréia e glicemia em jejum dos voluntários estudados $(n=10)$

\begin{tabular}{|c|c|c|c|c|c|c|c|c|c|}
\hline Voluntários & \multicolumn{9}{|c|}{ Exames laboratoriais } \\
\hline & C. T. & HDL & LDL & VLDL & Triglicérides & $\begin{array}{l}\text { Ácido } \\
\text { úrico }\end{array}$ & Creatinina & Uréia & $\begin{array}{l}\text { Glicemia } \\
\text { de jejum }\end{array}$ \\
\hline $\mathrm{CHS}$ & 173,0 & 60,0 & 96,0 & 18.4 & 94,0 & 4,9 & 1,02 & 32,0 & 96,0 \\
\hline $\mathrm{FP}$ & 153,0 & 46,0 & 83,0 & 23,0 & 101,0 & 5,6 & 0,88 & 35,0 & 89,0 \\
\hline $\mathrm{GHS}$ & 130,0 & 65,0 & 92,0 & 28,0 & 96,0 & 4,7 & 0,92 & 32,0 & 76,0 \\
\hline IDM & 125,0 & 52,0 & 103,0 & 22,0 & 89,0 & 3,4 & 0,88 & 42,0 & 86,0 \\
\hline LBC & 155,0 & 58,0 & 78,4 & 18,6 & 93 & 6,6 & 1,4 & 31,0 & 78,0 \\
\hline RAJ & 158,0 & 58,0 & 86,2 & 13,8 & 69 & 4,2 & 0,87 & 34,5 & 89,0 \\
\hline RSR & 161,0 & 62,0 & 92,0 & 19,2 & 87,0 & 5,0 & 1,16 & 33,0 & 91,0 \\
\hline $\begin{array}{l}\text { Valores de } \\
\text { referência }\end{array}$ & $\begin{array}{c}\text { Até } \\
200 \mathrm{mg} / \mathrm{dl}\end{array}$ & $\begin{array}{l}\text { Acima de } \\
35 \mathrm{mg} / \mathrm{dl}\end{array}$ & $\begin{array}{c}\text { Inferior a } \\
150 \mathrm{mg} / \mathrm{dl}\end{array}$ & $\begin{array}{l}\text { Inferior a } \\
32 \mathrm{mg} / \mathrm{dl}\end{array}$ & $\begin{array}{c}\text { Até } \\
200 \mathrm{mg} / \mathrm{dl}\end{array}$ & $\begin{array}{c}\text { Entre } \\
2,5 \text { e } 7,0 \\
\text { mg/dl }\end{array}$ & $\begin{array}{c}\text { Entre } \\
0,4 \text { e } 1,4 \\
\text { mg/dl }\end{array}$ & $\begin{array}{c}\text { Entre } \\
10 \text { e } 50 \\
\text { mg/dl }\end{array}$ & $\begin{array}{c}\text { Entre } \\
70 \text { e } 110 \\
\mathrm{mg} / \mathrm{dl}\end{array}$ \\
\hline
\end{tabular}

C. T.: colesterol total; HDL: Lipoproteína de alta densidade; LDL: Lipoproteína de baixa densidade; VLDL: lipoproteína de muito baixa densidade; mg: miligramas; dl:decilitros. 